Portland State University

PDXScholar

Fall 1-3-2020

\title{
Glacial Meltwater Modeling to Simulate Lake Water Budget (1996-2013) in Taylor Valley, Antarctica
}

Julian Michael Cross

Portland State University

Follow this and additional works at: https://pdxscholar.library.pdx.edu/open_access_etds

Part of the Geography Commons, and the Hydrology Commons

Let us know how access to this document benefits you.

Recommended Citation

Cross, Julian Michael, "Glacial Meltwater Modeling to Simulate Lake Water Budget (1996-2013) in Taylor Valley, Antarctica" (2020). Dissertations and Theses. Paper 5364.

https://doi.org/10.15760/etd.7237

This Thesis is brought to you for free and open access. It has been accepted for inclusion in Dissertations and Theses by an authorized administrator of PDXScholar. Please contact us if we can make this document more accessible: pdxscholar@pdx.edu. 
Glacial Meltwater Modeling to Simulate Lake Water Budget

(1996-2013) in Taylor Valley, Antarctica

by

Julian Michael Cross

A thesis submitted in partial fulfillment of the requirements for the degree of

Master of Science

in

Geography

Thesis Committee:

Andrew G. Fountain, chair

Kelly E. Gleason

Paul C. Loikith

Portland State University

2019 


\begin{abstract}
The McMurdo Dry Valleys (MDV), the largest ice-free region $\left(4,500 \mathrm{~km}^{2}\right)$ in Antarctica, are a polar desert with an average annual temperature of $-18^{\circ} \mathrm{C}$. In Taylor Valley, one of the MDV, closed-basin, perennially ice-covered lakes occupy the valley floor. Their water balance is controlled by inflow from glacial meltwater runoff and loss due to sublimation, making them sensitive indicators of climate. In this study, a physically-based model of glacier meltwater and lake ice sublimation is adapted to explain modern (1996 to 2013) lake-level variations. Meltwater model results were improved by the inclusion of MODIS remotely-sensed albedo measurements $(E=0.47$; nRMSE $=0.73)$. After 2008 the meltwater model significantly under-predicted streamflow and only through decreasing albedo by $-30 \%$ (equivalent to a decrease of -0.18 on average) did the results match observations $(E=0.79 ; n R M S E=0.45)$. This study provides the first estimate of direct (unmeasured) glacier inflow to the lakes, 69\%, $73 \%$ and $28 \%$, and sublimation loss rates, $0.37 \mathrm{~m} \mathrm{yr}^{-1}, 0.24 \mathrm{~m} \mathrm{yr}^{-1}$ and $0.16 \mathrm{~m} \mathrm{yr}^{-1}$, for Lakes Bonney, Hoare and Fryxell, respectively. Despite similar meltwater volumes entering Lakes Bonney and Fryxell, the difference in basin hypsometry results in a much faster lake rise at Bonney from 2002-13. If future climate conditions match current (1996-2013) conditions, all lakes will rise through the end of the century.
\end{abstract}




\section{Acknowledgements}

I owe a sincere thanks to my advisor, Andrew G. Fountain, who has readily offered guidance, direction, and good humor throughout this project. Thank you for giving me this opportunity to explore, from both behind a desk and in the field, the amazing landscape of the McMurdo Dry Valleys. I am indebted to Matt Hoffman for all his help implementing the ICEMELT model and to Maciej Obryk for providing the beginnings of the lake-level model, and to both Matt and Maciej for their helpful insight and discussion about this topic. Thank you to my committee members, Kelly Gleason and Paul Loikith, for their time and feedback. I have appreciated the time spent in and out of the office with fellow grad students and coworkers Felix Zamora, Luna Brett, Christina Gray, and Allison Trcka of the Glaciers Research group. Particularly to Bryce Glenn for your friendship and for our many helpful conversations over the last two years. I am grateful to my parents for encouraging life-long learning and academic curiosity. Finally, I am extraordinarily thankful for the support and patience of my partner Isabelle and our

dog Agave. Funding for this research came from the National Science Foundation (OPP ANT - 1643573). 


\section{Table of Contents}

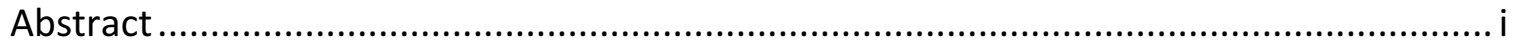

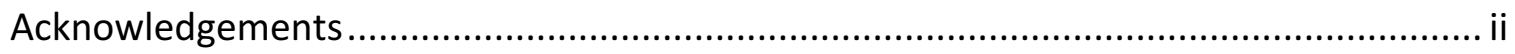

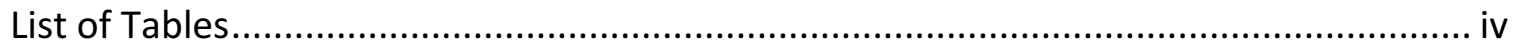

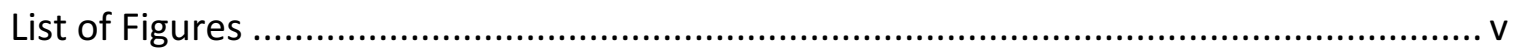

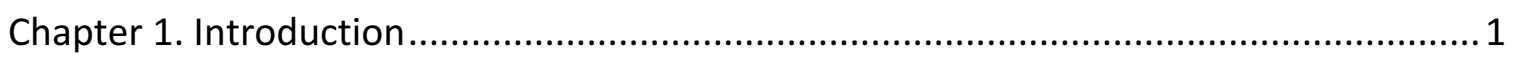

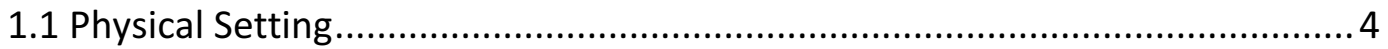

1.2 Climate and Hydrology Summary ......................................................... 5

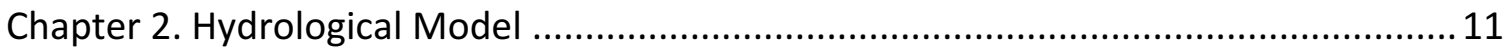

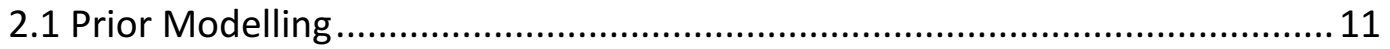

2.2 Glacier Meltwater Model ..................................................................... 14

2.3 Modifying the Meltwater Model ......................................................... 22

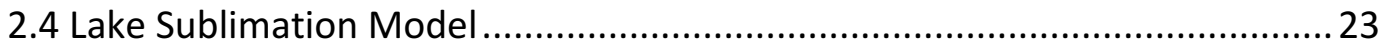

2.5 Lake Water Balance Model...................................................................... 24

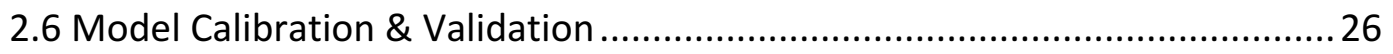

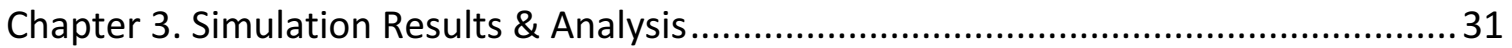

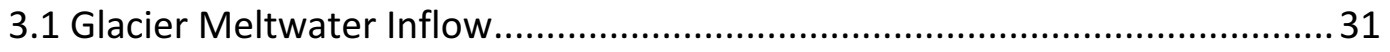

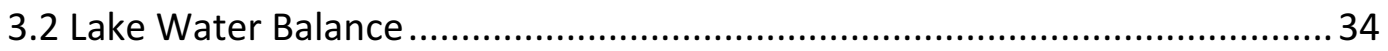

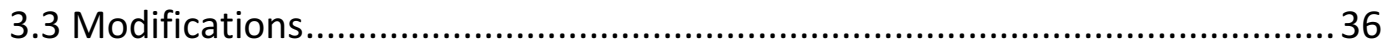

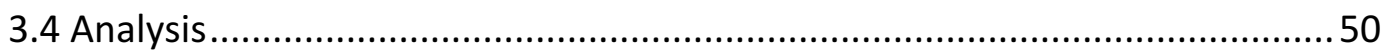

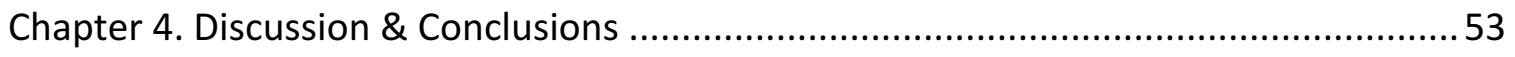

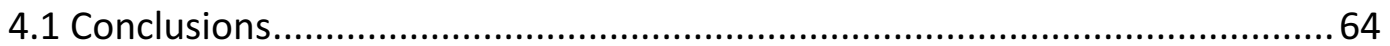

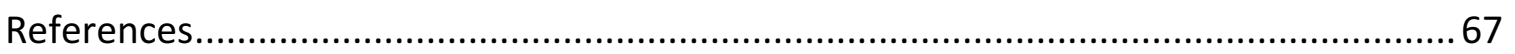

Appendix A: Incorporating Remotely-sensed MODIS Albedo ..................................... 73

Appendix B: Meltwater Model Supplemental Information......................................... 87

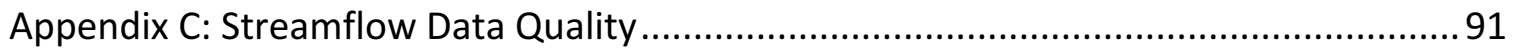

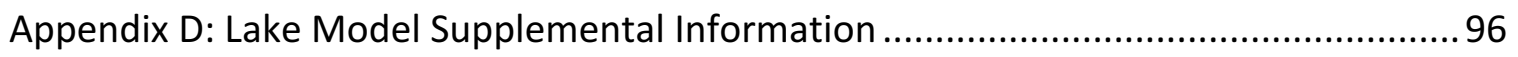

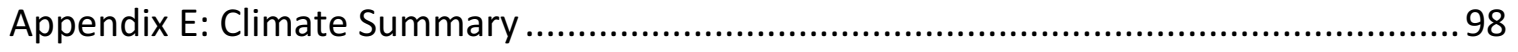




\section{List of Tables}

Table 2.1 Sub-domain adjusted parameters and micro-climate meteorological adjustments.

Table 2.2 Taylor Valley meteorological station locations. 20

Table 2.3 Summary of Taylor Valley streams with gauged discharge. 27

Table 3.1 Sublimation model results for 1996 to 2013 showing optimized $z_{0}$ and corresponding root-mean-square error (RMSE) and cumulative error (CE, simulated observed) in winter (Feb-Nov) sublimation estimates. 34

Table 3.2 Summary of modifications made to ICEMELT (M4). 38

Table 3.3 Model efficiency results for model runs M1-M4. 39

Table 3.4 Estimated magnitude of sub-aqueous melt flux into Lakes Bonney and Hoare.

Table 3.5 Summary of estimated mean annual and seasonal sublimation rates for Taylor Valley lakes. Summer defined as per Dugan et al. (2013) as December and January. 'W' for mean winter, ' $\mathrm{S}$ ' for mean summer, ' $\mathrm{S}$ ' for mean summer required to balance the lake water budget at Lake Fryxell $\left(z_{0}=0.4 \mathrm{~mm}\right)$, ' $A_{s}^{\prime}$ ' for mean annual (with modified summer rate at Fryxell), and ' $A_{A}$ ' for annual measured ablation.

Table 3.6 Estimated evaporation loss from lake moats. The estimated evaporation rate $(E)$ is applied to moat surface area $\left(A_{M}\right.$, based on the lake perimeter $\left.P_{L}\right)$. The ratio of moat area versus lake area $\left(A_{L}\right)$ and the ratio of the estimated annual losses due to evaporation $\left(L_{E}\right)$ versus sublimation $\left(L_{S}\right)$ are shown.

Table 3.7 Mean (1996-2013) annual inflow from various sources based on the simulated water budget for Taylor Valley lakes. 50

Table 3.8 Lake-level sensitivity to basin hypsometry. Inflow (I), losses (L) and net volume change $\left(\Delta V_{N E T}\right)$ are pre- and post-2002 total values. Lake area $\left(A_{L}\right)$ is from 2001 , the smallest lake area in the record. The mean annual inflow (I divided by the number of years) divided by the glacier contributing area to each lake $\left(A_{C}\right)$ gives the mean annual specific melt (M) for each lake catchment. The theoretical height change $\Delta \mathrm{h}$ of the lakes, ignoring basin hypsometry is $\Delta \mathrm{V}_{\mathrm{NET}}$ divided by the area. The ratio of the theoretical height change and the observed height change $\Delta z$ is the hypsometric effect (last column). 


\section{List of Figures}

Figure 1.1 Map of the McMurdo Dry Valleys (MDV) in the Ross Sea region of Antarctica (A \& B). The MDV are transverse valleys of the Transantarctic Mountains. Map of Taylor Valley study site (C) showing Lakes Bonney (LB), Hoare (LH), and Fryxell (LF).

Approximate lake surface elevations (based on 1995 survey) are shown. 3

Figure 1.2 Hydrographs from Taylor Valley, Antarctica. (A) 15-minute discharge hydrographs on December $12^{\text {th }}, 1998$ for Andersen Creek and Canada stream; note discharge in liters per second. The cliffs along Andersen Stream are west facing and along Canada are east facing. (B) Daily discharge hydrograph for Crescent Stream for the 2003-04 season plotted with air temperature at the Howard Glacier meteorological station. Note the smaller peak in November, compared to January, despite warmer temperatures in November.

Figure 1.3 The 2006 water year at Lake Hoare. (A) Lake stage drops from April to December, rises rapidly until mid-January, and then begins to fall again. (B) Daily and cumulative discharge for Andersen Creek. (C) Daily and cumulative sublimation of Lake Hoare ice-cover. Dotted box indicates summer season used by Dugan et al. (2013) while gray shading indicates the full melt season. 10

Figure 2.1 Map showing the modelling domain, glacier ablation zones, meteorological stations, streams, and stream gauges. A hillshade of 2015 LiDAR (Fountain et al. 2015) is displayed as the background. Numbered labels correspond to streams listed in Table 2.3.

Figure 2.2 Canada Glacier meteorological station with relevant instrumentation labelled, including: anemometer measuring wind speed at 3m, Campbell Scientific 207T RH probe measuring relative humidity at $3 \mathrm{~m}$, Campbell Scientific $107 \mathrm{~T}$ probe measuring air temperature at $3 \mathrm{~m}$ and two LI-COR LI200S pyranometers measuring incoming and outgoing shortwave radiation.

Figure 2.3 Lake-level changes in Taylor Valley over the measurement period. (A) Surveyed (dotted) lake-level change relative to 1995 smoothed with a running mean (solid line). (B) Annual lake volume change inferred from basin hypsometry. Colors indicate Lakes Bonney (black), Hoare (red) and Fryxell (blue).

Figure 2.4 Measured lake ice ablation for the lakes in Taylor Valley from Dugan et al. (2013). Winter sublimation (black) and summer ablation (gray). 
Figure 3.1 M1 and M2 meltwater model results. (A) Daily discharge hydrograph for Canada Stream for the 2002 water year. (B) Annual discharge from all measured streams in Taylor Valley from water years 1996 to 2013. The $x$-axis label indicates the water year (e.g. melt season from November 2001 through February 2002 would be water year 2002). The solid line is observed stream discharge with $\pm 20 \%$ measurement uncertainty (shading). Preliminary meltwater model results ( $M 1$, dashed) and with MODIS remotely-sensed albedo (M2, dotted). The legend in (B) also applies to (A)..... 32

Figure 3.2 Annual discharge for each measured stream (labels above each plot) from 1996 to 2013. Streams are ordered generally by valley position west to east. Streams in the top row (B) flow to Lake Bonney, streams in the dashed box $(\mathrm{H})$ flow to Lake Hoare, streams from Green to Lost Seal (F) flow to Lake Fryxell, while Commonwealth Stream in the dotted box flows to McMurdo Sound (M). Grey boxes indicate eastern Kukri Hills Glaciers. The solid line shows observed stream discharge with $20 \%$ measurement uncertainty displayed as grey area. Meltwater model results with (dashed) and without (dotted) MODIS remotely-sensed albedo. The $\mathrm{x}$-axis label indicates the water year......33

Figure 3.3 Sublimation model results. (A) Modeled winter (February to November) sublimation compared to measured values of winter ablation from Dugan et al. (2013). Winter ablation measurements are measurements of sublimation, as melt does not occur during the winter. (B) Modeled annual sublimation, split into winter and summer, plotted with annual measured ablation, split into winter sublimation and summer ablation, both melt and sublimation. All measured values are based on based on Dugan et al. (2013). The year label on the $x$-axis of the lower three panels indicates the starting year of the austral water year.

Figure 3.4 Simulated (dashed, with symbols) versus observed (dotted) annual lake-level change, relative to the January 1995 datum. Observed data were smoothed with a running mean (solid). Simulated lake-levels are plotted on March 31 of each year (close to peak lake-level and the end of the water year).

Figure 3.5 M1 and M2 meltwater model results. (A) Daily discharge hydrograph for Canada Stream for the 2009 water year. (B) Annual discharge from all measured streams in Taylor Valley from water years 1996 to 2013. The solid line shows observed stream discharge with $\pm 20 \%$ measurement uncertainty displayed as grey area. Preliminary ICEMELT results (M1, dotted) and (M2, dashed) MODIS remotely-sensed albedo and subsequent modifications to ICEMELT (M3 and M4, black and red chain-dot lines, respectively).

Figure 3.6 Taylor diagram (Taylor, 2001) summarizing model (M1-M4) model performance, showing centered RMS difference, correlation coefficient and standard deviations compared with measurements. The statistics have been normalized and nondimensionalized to be plotted on a single plot. The location of the blue point indicates perfect agreement with observations. 
Figure 3.7 Annual discharge for each measured stream (labels above each plot) from 1996 to 2013. Streams are ordered generally by valley position west to east: (B) to Lake Bonney, (H) to Lake Hoare, (F) to Lake Fryxell, (M) to McMurdo Sound. Grey boxes indicate eastern Kukri Hills Glaciers. The solid line shows observed stream discharge with $20 \%$ measurement uncertainty displayed as grey area. Preliminary ICEMELT results (M1, dashed) and (M2, dotted) MODIS remotely-sensed albedo and subsequent modifications to ICEMELT (M3 and M4, black and red chain-dot lines, respectively). ....41

Figure 3.8 Lake-level simulated with the addition of sub-aqueous melt and the modified meltwater inflow (dashed line with symbols). Level was also simulated with measured stream inflows where available and modeled meltwater inflows otherwise (dashed line with no symbols). An upper and lower bound, based on the $\pm 20 \%$ streamflow measurement uncertainty, was applied to the stream inflow (chain-dot line bounded by grey shading).

Figure 3.9 Simulated (sim.) seasonal and annual sublimation after summer surface roughness was adjusted. Values at lake Fryxell are based on $z_{0}=5 \mathrm{~mm}$. Also shown is observed (obs.) annual ablation; measured summer ablation includes both melt and sublimation. All observed values are based on based on Dugan et al. (2013). The year label on the $\mathrm{x}$-axis indicates the austral water year (e.g. 2002 for water year from April 2001 to March 2002).

Figure 3.10 Lake-level simulated with modified inflows (MM4) and losses (dashed line with symbols). See Figure 3.8 caption.

Figure 3.11 Cumulative daily inflow and sublimation loss (outflow) for Lake Hoare....... 49

Figure 4.1 Example of a $0.5 \mathrm{~m}$ deep ablation hollow on the ice cover of Lake Hoare (photo courtesy of A.G. Fountain). 


\section{Chapter 1. Introduction}

The McMurdo Dry Valleys (MDV), located in the Ross Sea region of Antarctica (Figure 1.1), are the largest ice-free $\left(4,500 \mathrm{~km}^{2}\right)$ area on the continent (Levy, 2012). The MDV are a polar desert with extreme cold and dry conditions. The Transantarctic Mountains restrict the East Antarctic Ice Sheet from flowing eastward into the MDV and reduce precipitation via a rain shadow effect on their lee side. This combination of an arid climate and topography limits local glaciation to small alpine glaciers (Fountain et al. 1998). Perennially ice-covered lakes, fed by ephemeral meltwater streams flowing from the glaciers, populate the valley floor (Chinn, 1993). MDV lakes occupy closedbasins and lake-levels are therefore not controlled by the elevation of an outflow point. Because of this they can be considered amplifier lakes (Street-Perrott, 1985) due to the sensitivity of lake-levels to climate (Chinn, 1981). The water balance of these lakes is controlled by inflow from glacial meltwater runoff and loss due to sublimation of the frozen lake surface (Chinn, 1993). Inter-annual variability of lake ice sublimation is small (Dugan et al. 2013) compared to year-to-year variability of glacier runoff (Chinn, 1981; Fountain et al. 1999). Thus, the amplification of climate by lake-levels is mediated by the surface energy balance of MDV glaciers (Fountain et al. 1999).

The ice-free expanse of the MDV provides one of few regions in Antarctica with exposed geologic evidence of past ice sheet change. Paleo-lacustrine features along valley walls suggest that proglacial lakes, much larger than modern lakes, occupied Taylor, Wright and Victoria valleys during the Last Glacial Maximum (LGM; Hall et al. 
2000; Toner et al. 2013). The environmental conditions required to produce enough meltwater to fill these paleo-lakes are unknown.

The goal of this thesis is to adapt an energy balance model of the MDV glaciers to estimate meltwater inflow to and sublimation loss from the lakes to explain modern (1996 to 2013) level variations. This is a first step towards understanding the lake-level response to present changes in climate as well as the formation of large paleo-lakes in the region at the end of the LGM. The value of a physically-based water balance model is that the physical principles behind hydrological processes in Taylor Valley now were the same in the past, or will be in the future. Therefore, this model can ultimately be used to explore the water budget of paleo-lakes or make projections into the future.

The model has a couple of key implications if applied to future conditions in Taylor Valley. The microbially-dominated ecosystem in Taylor Valley relies on the hydrological connectivity between glaciers, streams and lakes for the distribution of water, energy and nutrients (Gooseff et al. 2011). This 'cold desert ecosystem' is highly sensitive to changes in meltwater flux (Doran et al. 2008; Gooseff et al. 2017). A full lake water balance model could be applied to simulate the effects of climate change on water flux to the lakes. Furthermore, estimates of future lake-level change are also of importance to the McMurdo Long-term Ecological Research project (MCM-LTER) and United States Antarctic Program (USAP) as key infrastructure to support USAP science operations are located close to lake margins. Modeled future lake-levels could inform the relocation of this infrastructure out of reach of rising lake-levels. 


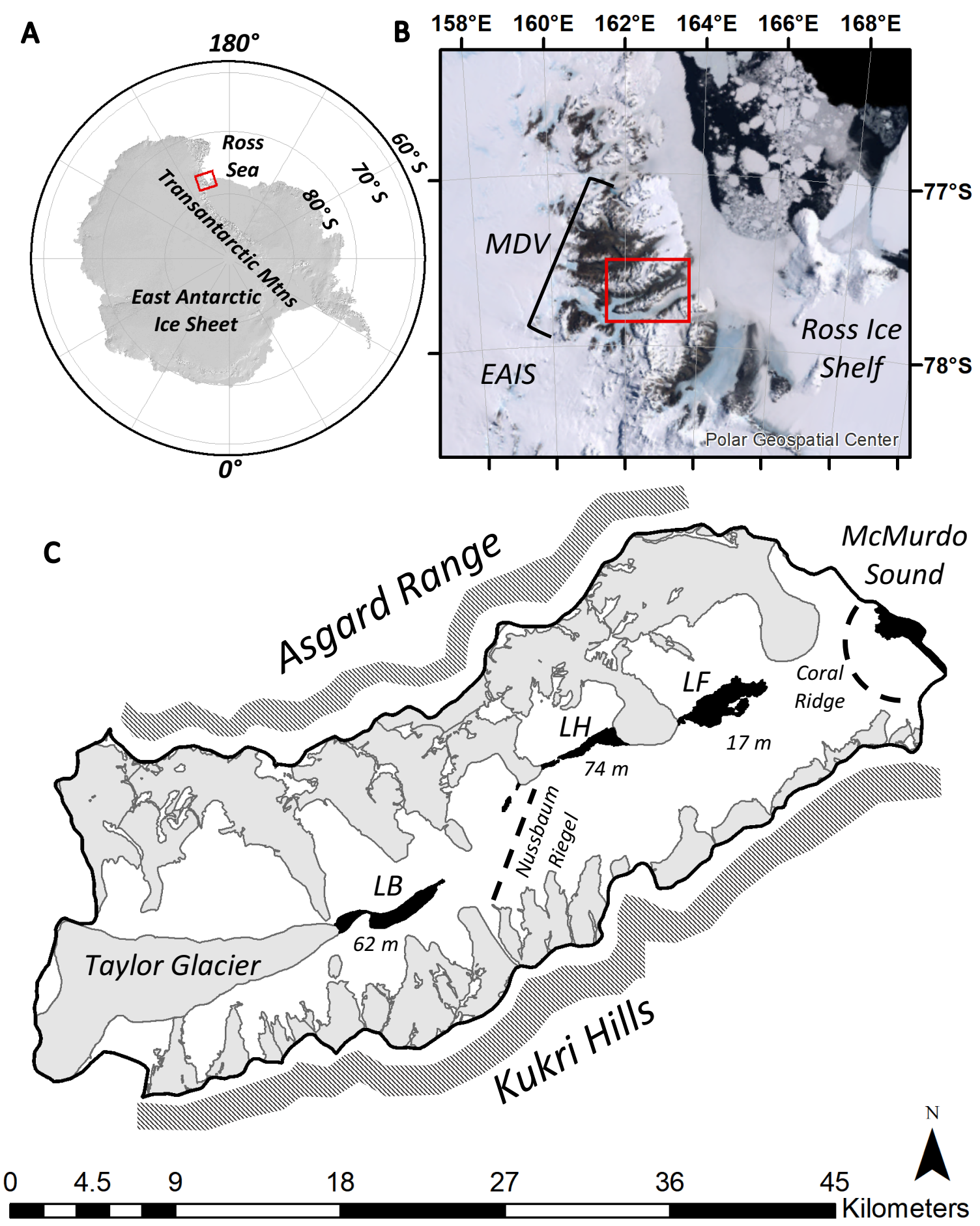

Figure 1.1 Map of the McMurdo Dry Valleys (MDV) in the Ross Sea region of Antarctica (A \& B). The MDV are transverse valleys of the Transantarctic Mountains. Map of Taylor Valley study site (C) showing Lakes Bonney (LB), Hoare (LH), and Fryxell (LF). Approximate lake surface elevations (based on 1995 survey) are shown. 


\subsection{Physical Setting}

My study is focused on Taylor Valley $\left(77^{\circ} 40^{\prime} \mathrm{S}, 162^{\circ} 30^{\prime} \mathrm{E}\right)$, one of the MDV, which has a rich dataset of meteorological and hydrological measurements. The valley was first visited in 1903 by Robert Falcon Scott's Discovery Expedition (Scott, 1907). Modern scientific studies of the biology, hydrology and geology in the MDV followed the International Geophysical Year 1957-58 (Bull, 2009). Since 1992 Taylor Valley has been extensively monitored by the MCM-LTER to understand the physical controls on a microbially dominated ecosystem (Conovitz et al. 1998; Dana et al. 1998; Fountain et al. 1998, 1999; Lewis et al. 1998; McKnight et al. 1999). This program maintains eight yearround automated weather stations, mass balance measurements on four glaciers, 15 summer stream gauges, and seasonal lake-level measurements in Taylor Valley. The availability of physical measurements in Taylor Valley make it an ideal natural laboratory for studying interactions between climate and hydrology, both in the past and present.

Taylor Valley is about $40 \mathrm{~km}$ long and oriented roughly southwest to northeast from Taylor Glacier, an outlet glacier of the East Antarctic Ice Sheet (EAIS), to McMurdo Sound (Figure 1.1). The north side of Taylor Valley rises to $\sim 1,600 \mathrm{~m}$ in the Asgard Range while the south side is bounded by the Kukri Hills ( 1,300 m). Elevation of the valley floor ranges from $18 \mathrm{~m}$ along Lake Fryxell to $156 \mathrm{~m}$ at the Nussbaum Riegel, a crossvalley ridge that divides Taylor Valley. Three closed-basins contain large $\left(>2 \mathrm{~km}^{2}\right)$ lakes. The Bonney basin lies west of the Nussbaum; Lake Bonney $\left(4.3 \mathrm{~km}^{2}\right)$ abuts Taylor Glacier to the west and has two lobes divided by a narrow channel. East of the Nussbaum the 
greater Fryxell basin contains Lakes Hoare $\left(2.2 \mathrm{~km}^{2}\right)$ and Fryxell $\left(6.7 \mathrm{~km}^{2}\right)$. The Lake Hoare basin is divided from the main Fryxell basin by the piedmont lobe of Canada Glacier. We consider the Hoare basin to be separate from Fryxell as no water drains from one to the other. At the mouth of Taylor Valley the 74-m high Coral Ridge separates the Fryxell basin from McMurdo Sound.

\subsection{Climate and Hydrology Summary}

Mean annual temperatures in Taylor Valley are around $-18^{\circ} \mathrm{C}$ while mean summer temperatures hover below $0^{\circ} \mathrm{C}$ (Doran et al. 2002; Figure E.1). Mean annual relative humidity is around 70\% for Taylor Valley locations (Doran et al. 2002; Figure 1.3). Summer temperatures commonly reach $+1^{\circ} \mathrm{C}$ to $+5^{\circ} \mathrm{C}$, typically near the summer solstice, but tend to be short-lived, lasting only a few hours to a few days. Summer air temperatures increase away from the coast resulting from the soil warming of the sea breeze from the coast (Doran et al. 2002; Fountain et al. 2016). Additionally, drier conditions are found in the western portion of the valley (Figure E.1).

Sunlight is continuous during the austral summer from November to February and completely absent during the winter months May to July. The typical diurnal fluctuation of incoming solar radiation in December is from $100 \mathrm{~W} \mathrm{~m}^{-2}$ at midnight to $600 \mathrm{~W} \mathrm{~m}^{-2}$ at noon (Dana et al. 1998). Mean summer incoming solar radiation is around $250 \mathrm{~W} \mathrm{~m}^{-2}$ (Dana et al. 1998). 
The rain shadow formed by the Transantarctic Mountains reduces precipitation on the valley floors (Monaghan et al. 2005). An up-valley precipitation gradient exists, with the greatest at Explorers Cove (50 mm w.e.) and decreases to $<18 \mathrm{~mm}$ w.e. at Lake Bonney (Fountain et al. 2010). Snow is redistributed by strong foehn winds, and this effect can double snow accumulation in places (Fountain et al. 2010). Accumulated snowfall typically sublimates before making any significant contribution to the water balance (Chinn, 1981; Eveland et al. 2013; Fountain et al. 1999; Gooseff et al. 2003).

Topographic modification of regional wind patterns produces foehn winds that descend from the EAIS and the adjacent ranges into Taylor Valley, warming adiabatically as they descend. Gusts during these drainage wind events can reach $35 \mathrm{~m} \mathrm{~s}^{-1}$ (Doran et al. 2002, 2008; Nylen et al. 2004; Speirs et al. 2010). The foehn winds have been shown to have a strong influence of on air temperatures, particularly in wintertime where they can cause extreme warming (up to $+20^{\circ} \mathrm{C}$, Nylen et al. 2004). Foehn winds can increase summer average temperatures by $0.1^{\circ}$ to $0.4^{\circ} \mathrm{C}\left(+1^{\circ}\right.$ to $+4^{\circ} \mathrm{C}$ for winter average temperature) and decrease relative humidity $-0.9 \%$ to $-4.1 \%$ (Nylen et al. 2004), this has a notable effect on glacier melt and Taylor Valley hydrology (Doran et al. 2008).

Permafrost distribution in the MDV is a continuous cover of either ice-cemented or dry-frozen permafrost (Bockheim et al, 2007). With a shallow active layer, e.g. depths of about 20 to $45 \mathrm{~cm}$ (Bockheim et al, 2007), no significant groundwater interaction occurs below the active layer (Gooseff et al, 2011). 
Alpine glaciers, up to $50 \mathrm{~km}^{2}$, descend from the surrounding mountains, some of which reach the valley floor. Steep $\left(70^{\circ}-90^{\circ}\right)$ cliffs, approximately $20 \mathrm{~m}$ high, form at the glacier terminus (Fountain et al. 1998; Chinn, 1998). Taylor Valley glaciers appear to be in equilibrium with climate (Fountain et al. 2006, 2016). Net annual mass loss on is on the order of $0.1 \mathrm{~m}$ w.e. (Fountain, 1998). The glaciers are polar such that they are frozen to the bed, with the possible exception of Taylor Glacier, and internal and basal temperatures are well below freezing (Fountain et al. 1998). Flow velocities are low, about $5 \mathrm{~m} \mathrm{yr}^{-1}$ (Fountain et al. 1998), and their frontal positions have seen no significant change over the last century (Fountain et al. 2004). Melt accounts for only $15-30 \%$ of total ablation while sublimation accounts for $60-90 \%$ and calving from terminal cliffs another 1-3\% (Fountain et al. 1998; Hoffman et al. 2016; Lewis et al. 1995; Lewis et al. 1998). Meltwater runoff is sourced from the glacier ablation zones (up to $1500 \mathrm{~m}$ ); in the snow-covered accumulation zones, what little snowmelt occurs refreezes within the snowpack (Fountain et al. 1998). Below-freezing internal temperatures prevent the formation of internal drainage systems like those found in temperate glaciers and meltwater routing occurs only at or near the surface (Fountain et al. 1998).

Ephemeral streams drain meltwater runoff to the lakes during the austral summer, which lasts up to 10 weeks from November to February (McKnight et al. 1999). Daily peak runoff is sourced from the glacier cliff faces, melting here controlled by cliff face orientation and solar position (Figure 1.2; Conovitz et al. 1998; Dana et al. 1998; Fountain et al. 1999; Lewis et al. 1998; Hoffman et al. 2016), while baseflow is sourced 
from glacier surface melt (Conovitz et al. 1998; Hoffman 2011). Lag time between direct sun and peakflow is a function of stream length due to storage in the hyporheic zone (Conovitz et al. 1998), which is limited in size to the active layer (Gooseff et al, 2003). Instream losses via evaporation from the channel and adjacent hyporheic zone have been estimated at $6.17 \mathrm{~mm}$ w.e. day ${ }^{-1}$ (Gooseff et al, 2003). Hyporheic zone storage is recharged by the first melt events early in the season (Figure 1.2; Hoffman, 2011).
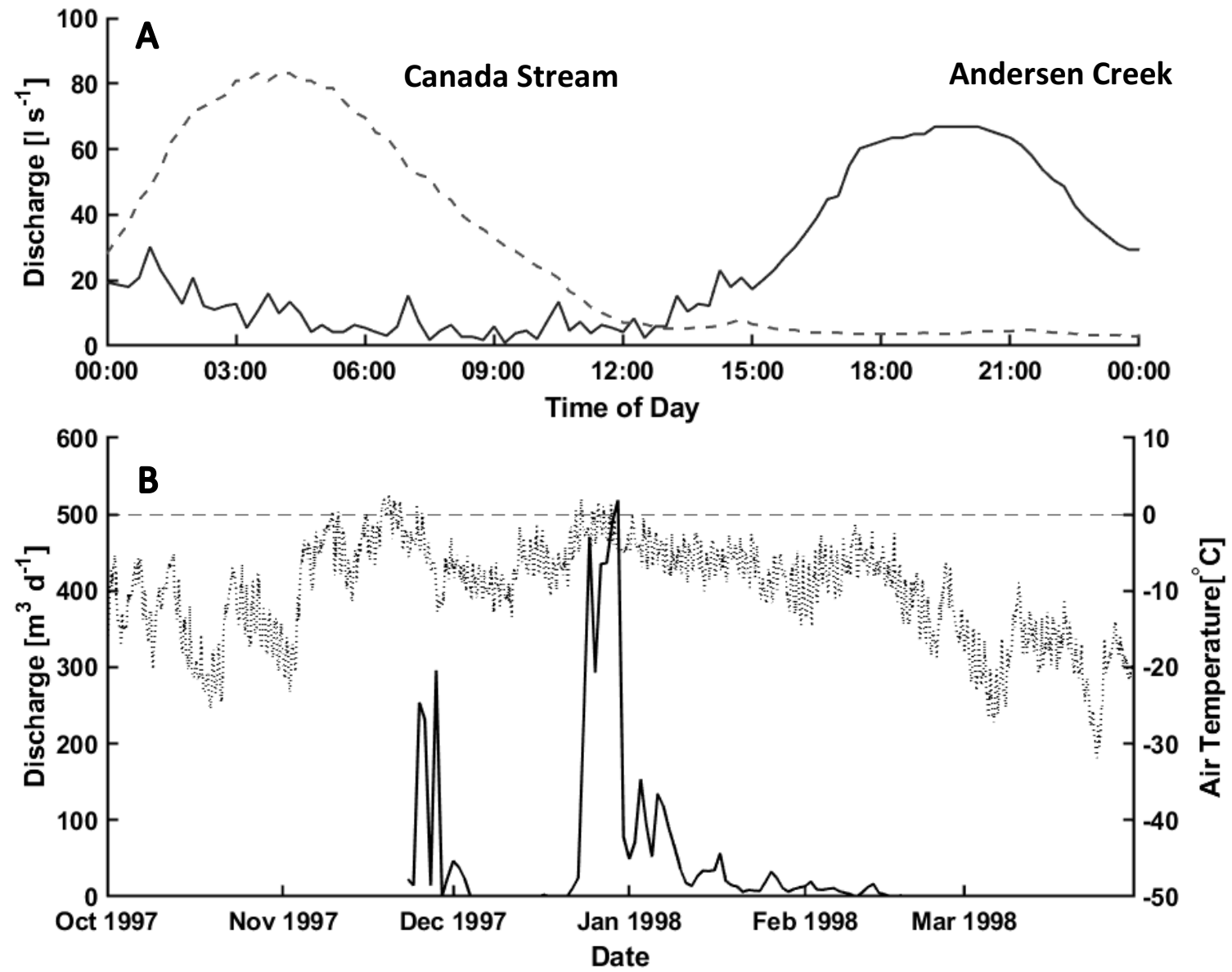

Figure 1.2 Hydrographs from Taylor Valley, Antarctica. (A) 15-minute discharge hydrographs on December $12^{\text {th }}, 1998$ for Andersen Creek and Canada stream; note discharge in liters per second. The cliffs along Andersen Stream are west facing and along Canada are east facing. (B) Daily discharge hydrograph for Crescent Stream for the 2003-04 season plotted with air temperature at the Howard Glacier meteorological station. Note the smaller peak in November, compared to January, despite warmer temperatures in November. 
Lake-levels exhibit an annual pattern of summer rise and winter fall, with peak lakelevel occurring January or February (Figure 1.3). Narrow ice-free moats surround form along the edges of Taylor Valley lakes allowing for direct evaporation, however, this is a minor component of the lake water budget (Chinn, 1993). During the winter months glacier runoff ceases and ablation occurs entirely through sublimation (0.07-0.21 m w.e.), lake-levels drop due to a negative water balance (Chinn, 1993, Dugan et al. 2013). Melt and sublimation from the ice-covered lakes sum to 0.75 to $1 \mathrm{~m}$ w.e. $\mathrm{yr}^{-1}$ of annual ablation, only sublimation is lost in the water balance as melt returns to the lake (Dugan et al, 2013). Using a physical model of sublimation and detailed meteorological measurements made over two season at Lake Hoare (some of the first data collected with an automated weather station in Taylor Valley), Clow et al. (1988) estimated an annual ablation rate of 0.35 w.e. $\mathrm{yr}^{-1}$.

Lake-levels also show high inter-annual variability. From 1903 to 1994 the level at Lake Bonney has risen 15 m (Scott, 1907; Chinn, 1993). From 1974 until 1990 lake Hoare and Fryxell levels rose steadily at an average rate of $\sim 0.6 \mathrm{~cm} \mathrm{yr}{ }^{-1}$ (Chinn, 1993), followed by a decade of gradual lowering $\left(-0.45\right.$ to $\left.0.76 \mathrm{~cm} \mathrm{yr}^{-1}\right)$, due to a decade long regional climate cooling trend (Doran et al. 2002). Anomalously warm and sunny conditions during a two-week period of the 2001-02 summer, referred to as the 'floodyear', resulted in a hydrological regime shift (Doran et al. 2008; Gooseff et al. 2017). An increase in positive degree-days (Appendix E Figure E.1) drove elevated glacier melt and significantly increased streamflow, in some streams one to two orders of magnitude 
higher discharge was recorded than the year prior (Doran et al. 2008). Lake-levels rose between 0.58 to $1.13 \mathrm{~m}$ during the flood year and have continued to rise since (Doran et al. 2008).

For clarity in describing hydrological processes and for modelling purposes, a water year in Taylor Valley runs from April to March of the following year. This can be divided into winter, from April to October, and the summer melt season, from November to March (Figure 1.3). For ease in comparison to measured ablation values, estimates of sublimation are partitioned into summer (December and January) and winter (February to November) to correspond with the seasons used by Dugan et al. (2013).

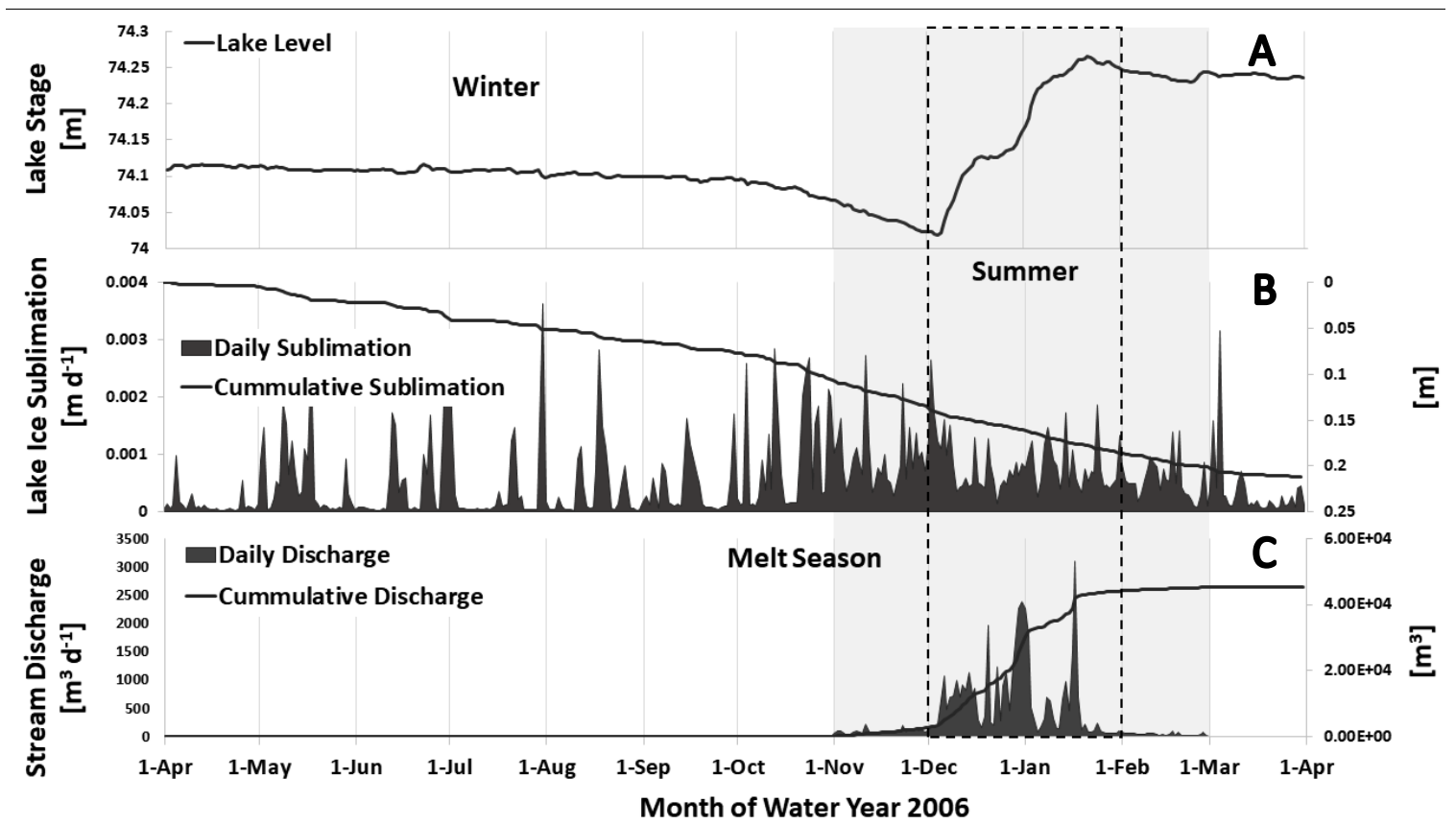

Figure 1.3 The 2006 water year at Lake Hoare. (A) Lake stage drops from April to December, rises rapidly until mid-January, and then begins to fall again. (B) Daily and cumulative discharge for Andersen Creek. (C) Daily and cumulative sublimation of Lake Hoare ice-cover. Dotted box indicates summer season used by Dugan et al. (2013) while gray shading indicates the full melt season. 


\section{Chapter 2. Hydrological Model}

The hydrology of Taylor Valley is treated as a relatively simple system, in which glacier meltwater runoff is conveyed to closed-basin lakes with minimal in-stream losses and insignificant inflow due to precipitation or groundwater. Lake water budgets are controlled by the balance of inflow from glacier melt and loss due to sublimation from the ice-cover. The hydrological model used in this study applies a physically-based energy balance model (ICEMELT) to estimate meltwater inflows and lake ice sublimation losses from the lakes. Both models are forced using spatially-distributed, micrometeorological data from 1996-2013. The meltwater inflow and sublimation loss estimates are calibrated to available observations independently. Ultimately, simulated lake-levels are compared to measured lake-levels to validate estimated components of the lake water budget.

\subsection{Prior Modelling}

Temperature-index and temperature-radiation-index melt models have been used to model meltwater in Taylor Valley (Dana et al. 2002; Ebnet et al. 2005). Dana et al. (2002) used satellite thermal emissivity images to model stream discharge using a mean surface temperature index. Scale limitations of this model both spatially $(1.1 \mathrm{~km}$ resolution pixels) and temporally, as imagery represents an instantaneous point in time, while streamflow represents daily averages constrained its applicability. Ebnet et al. (2005) employed a spatially distributed temperature-index melt model in Taylor Valley to model streamflow. Average summer air temperatures, measured at eight 
meteorological stations in Taylor Valley, were interpolated and applied to a distributed point based model of melt. Model skill in predicting runoff was improved by the addition of a solar radiation index, particularly for north-facing glaciers. The statisticallybased model relies on empirical relationships derived from the historical record, which are undoubtedly non-stationary, lessening their utility for modelling efforts exploring the past or future.

Several studies have employed energy balance models to characterize ablative processes and quantify meltwater runoff in Taylor Valley (Lewis et al. 1998; Hoffman et al. 2008, 2014, 2016; Hoffman 2011). Lewis et al. (1998) use a 1-D surface-energy balance model, driven by meteorological measurements and calibrated to ablation measurements, to model meltwater runoff on Canada Glacier. The meteorological data used were from a single permanent station in the ablation zone; these measurements were compared to measurements made by a roving station to map spatial changes in the micro-meteorology of the ablation zone. Modelled meltwater runoff was within $\pm 20 \%$ of measured discharge on Andersen Creek and underestimated by $\sim 50 \%$ on Canada Stream. Modelling results highlighted that sublimation dominated over melt, accounting for $\sim 80 \%$ of summer ablation on Canada Glacier (Lewis et al. 1998).

Hoffman et al. $(2008,2014)$ adapted a one-dimensional energy balance model (ICEMELT), created by Liston et al. (1999) for regions of Antarctica with exposed ice, for conditions in Taylor Valley. The advantage of this model was the inclusion of subsurface solar heating, an important process for polar glaciers. The modelled contribution of 
subsurface melt to total runoff was notable ( $55 \%)$ and these results are consistent with field observations of a lack of surface melt, a near surface weathering crust, and subsurface drainage networks.

The spatially-distributed version of the model used MICROMET (Liston and Elder, 2006), a meteorological interpolation code that distributed measurements from the eight meteorological stations to a $250-\mathrm{m}$ grid. The model showed better performance on glaciers in the Bonney basin (e.g. Taylor Glacier) where snowfall and cloud cover are less frequent and ice albedo measurements were more reliable. Model bias was removed over the first 11 years (1995-2006) with adjustments to global albedo values of -0.04 , within the instrumental uncertainty. After 2006 , offsets to albedo of -0.09 on average were required to remove model bias, the authors hypothesize that an influx of sediment to the glaciers from 2006 to 2007 increased the spatial variability of albedo and increased sub-surface solar heating where the dust was incorporated into the weathering crust.

To my knowledge only two previous studies attempted to model the water budget of Taylor Valley. Bomblies et al. (2001) used Monte Carlo simulation to retrospectively model inflow and volume change for Lake Bonney, but do not explicitly model sublimation loss. Obryk et al. (2017) develop a numerical water balance model for Taylor Valley to simulate lake-level change of Glacial Lake Washburn (GLW), a large proglacial lake that filled Taylor Valley, over a 12,000 year period. The annual inflow rate was simulated using Monte Carlo methods to draw from a distribution with a minimum 
of $1 \times 10^{4} \mathrm{~m}^{3} \mathrm{yr}^{-1}$ and maximum of $1.82 \times 10^{7} \mathrm{~m}^{3} \mathrm{yr}^{-1}$, this maximum value is the measured inflow during the 2001-02 flood-year. Loss rates, ranging from 0.46 and $0.70 \mathrm{~m} \mathrm{yr}^{-1}$, were applied in order to explore what was required to reach GLW high-stands. Lakelevel was inferred from volume changes through the volume-area relationship. The 2001-02 flood-year is assumed to be an analog for LGM conditions. This hypothesis is tested through probabilistic modelling of the frequency of positive air temperatures per year. This study is limited in that meltwater inflows are not explicitly modeled under the simulated climate.

\subsection{Glacier Meltwater Model}

To quantify glacier meltwater production, I employ the spatially-distributed, hourly ICEMELT version of Hoffman et al. (2016). The model is a physically-based model that evaluates the energy balance of the glacier surface. Its prior application at a high spatiotemporal resolution, and its treatment of absorbed solar radiation in the sub-surface, make it ideal for modelling meltwater runoff in Taylor Valley.

To estimate the surface and subsurface mass balance, ICEMELT solves the surface energy balance in the form of

$$
\chi(1-\alpha) Q_{s i}+Q_{l i}+Q_{l e}+Q_{h}+Q_{e}+Q_{c}=Q_{M}
$$

where $\chi$ accounts for a fraction of absorbed solar radiation at the surface, $\alpha$ is the albedo of the ice surface, $Q_{s i}$ the incoming solar radiation flux, $Q_{l i}$ the incoming longwave radiation flux, $Q_{l e}$ the emitted longwave energy flux, $Q_{h}$ the turbulent flux of 
sensible heat, $Q_{e}$ the turbulent flux of latent heat, $Q_{c}$ the conduction of heat into the ice, $Q_{M}$ the energy available for melt (all fluxes in $W m^{-2}$ ).

All energy flux terms in (1) are positive towards the glacier surface. Incoming shortand longwave radiation $\left(Q_{s i}\right.$ and $\left.Q_{l i}\right)$ are directly measured while albedo $(\alpha)$ is calculated based on measured outgoing shortwave radiation. The other terms cannot be measured directly, but relate to meteorological conditions at the surface and thus can be cast in form that leaves ice surface temperature $\left(T_{0}\right)$ as the only unknown (Liston et al. 1999; Hoffman et al. 2014).

The cold, dry and windy conditions in Taylor Valley favor sublimation over surface melt despite the eightfold increase in energy required for sublimation over melt (Lewis et al. 1998; Hoffman et al. 2014). The low relative humidity and frequent wind increase the turbulent exchange of latent heat through sublimation and surface melt can only occur once this and all other heat sinks have been satisfied. However, at air temperatures below $0^{\circ} \mathrm{C}$ in conditions favoring sublimation, subsurface melt can occur within the upper 20-50 cm (Fountain et al. 2004; Hoffman et al. 2008). This melt occurs through a solid-state greenhouse effect where a portion of the incoming near-infrared radiation is transmitted to lower ice layers (Brandt and Warren, 1993). Subsurface heating through this effect has been shown to be an important component of the energy balance in other ice-exposed regions of Antarctica (Bintanja and van den Broeke, 1995; Liston et al. 1999). 
Heat conduction, $Q_{c}$, into and out of the ice is evaluated as,

$$
\rho_{i} c_{p} \frac{\partial T_{i}}{\partial t}=\frac{\partial}{\partial z}\left[k \frac{\partial T_{i}}{\partial z}\right]-\frac{\partial q}{\partial z}
$$

where $\rho_{i}$ is the density of glacier ice $\left(\mathrm{kg} \mathrm{m}^{-3}\right), c_{p}\left(\mathrm{~J} \mathrm{~kg}^{-1} \mathrm{~K}^{-1}\right)$ is the specific heat of the ice, $T_{i}(\mathrm{~K})$ is the ice temperature, subscript $i$ specifies initial ice conditions, $t(\mathrm{~s})$ is time, $z(\mathrm{~m})$ is the vertical coordinate, $k\left(\mathrm{~W} \mathrm{~m}^{-1} \mathrm{~K}^{-1}\right)$ is the thermal conductivity of the ice, and $q$ (W $\mathrm{m}^{-2}$ ) is the net solar radiative flux.

The first term on the right-hand side, $k \frac{\partial T_{i}}{\partial z}$, accounts for the change in density and thermal conductivity in the ice column due to the water fraction present in each cell. The second term is the subsurface heating source term, $\partial q / \partial z$, from the penetration of solar radiation using a two-stream approximation. Equation (2) is solved from the surface to a depth of $15 \mathrm{~m}$, approximately the depth at which the ice temperature is equal to the mean annual temperature. The vertical grid is composed of 70 layers with the upper $30 \mathrm{~cm}$ at $1 \mathrm{~cm}$ intervals and the remaining cells increasing in size exponentially with the lowest cell at $15 \mathrm{~m}$ having a thickness of $1.8 \mathrm{~m}$ (Liston et al. 1999; Hoffman et al. 2016). 
Equations (1) and (2) are solved hourly to calculate ice surface temperature $\left(T_{0}\right)$. For each grid cell, if temperature exceeds $0^{\circ} \mathrm{C}$, the temperature is reset to $0^{\circ} \mathrm{C}$ and the residual temperature is used to calculate melt energy, $Q_{M}$. By solving for the energy available for melt, a meltwater volume $M$ can be calculated as

$$
M=\frac{Q_{M}}{\rho_{w} L_{f}},
$$

where $\rho_{w}$ the density of water, and $L_{f}$ is the latent heat of fusion $\left(334,000 \mathrm{~J} \mathrm{~kg}^{-1}\right.$; Cuffey and Patterson 2010). If the water fraction in a given cell exceeds $10 \%$, all subsurface melt is assumed to drain (Hoffman et al. 2016).

The initial ice temperature profile was calculated with a 14-year spin-up run starting with all cells equal to the mean annual air temperature, (Hoffman 2011). The model includes three adjustable parameters, which were calibrated to reduce average rootmean-square-error (RMSE) in estimated ablation at three sites, two on Taylor Glacier and one on Canada Glacier (Hoffman et al. 2014). The solar radiation surface fraction $\chi$, which is adjusted through changing the thickness of the uppermost layer $\delta z$, was adjusted to $22 \%$ of the solar radiation absorbed at the surface $(\delta z$ of $0.25 \mathrm{~cm})$. The effective grain radius $r_{\text {eff }}$ accounts for the ice grain size, bubbles, and impurities in the ice, and is a proxy for scattering of transmitted solar radiation, is set to $0.065 \mathrm{~mm}$. The surface roughness $z_{0}$, which relates to the turbulent exchange of heat between the surface and the atmosphere, is was calibrated separately for three different surface subdomains in the ICEMELT model. 


\section{Spatially-distributed meltwater model}

The modelling domain is Taylor Valley, which includes the ablation zones of all glaciers (an area of approximately $75 \mathrm{~km}^{2}$; Figure 2.1). ICEMELT is distributed across a 250-m grid and forced using meteorological data distributed to a matching grid.

Hoffman (2011) describes the generation of this grid and the delineation of glacier ablation zones. The snow zone above the equilibrium line is not included in the domain because melt in the high albedo region is uncommon and typically refreezes in the cold snow beneath, preventing runoff.

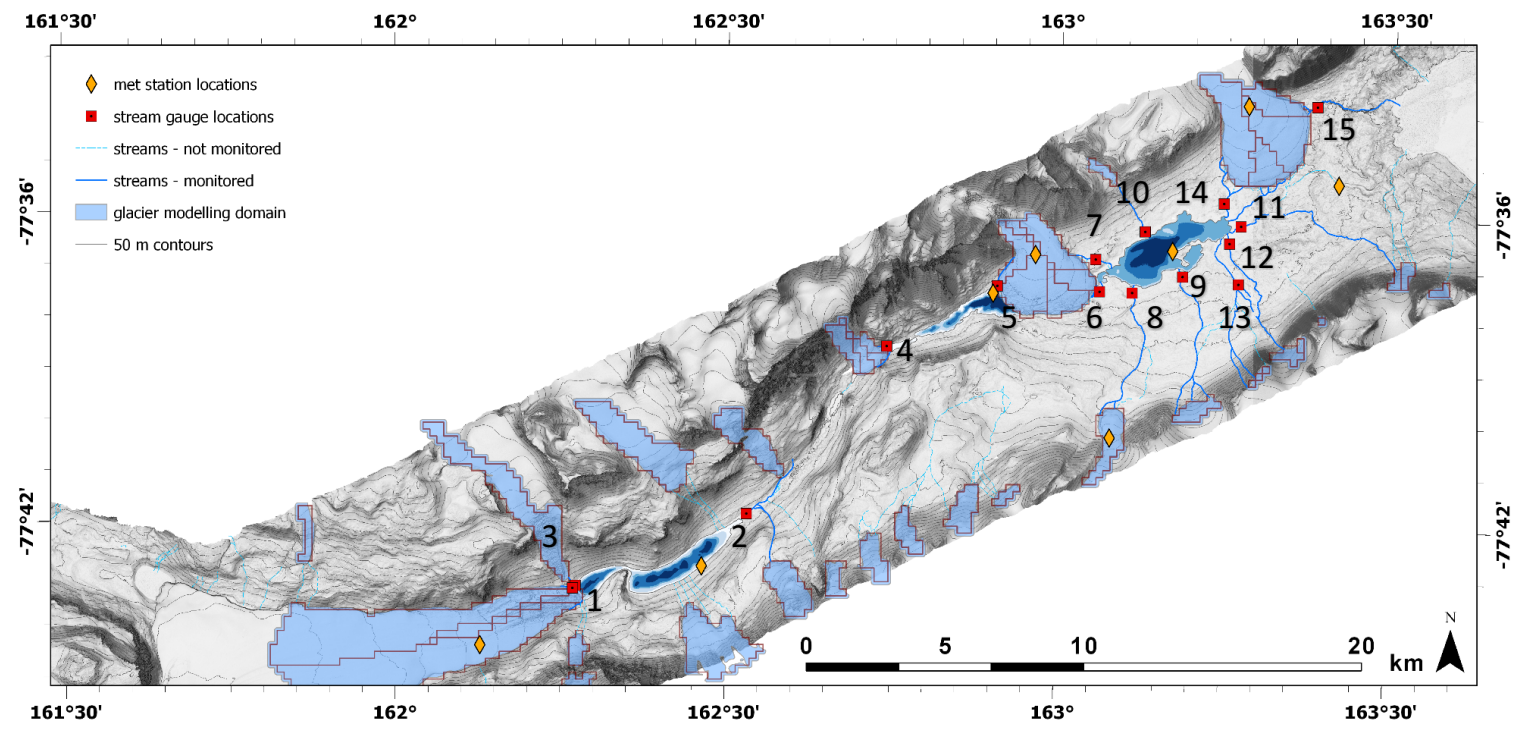

Figure 2.1 Map showing the modelling domain, glacier ablation zones, meteorological stations, streams, and stream gauges. A hillshade of 2015 LiDAR (Fountain et al. 2015) is displayed as the background. Numbered labels correspond to streams listed in Table 2.3.

Glacier topography generates microclimates by creating wind shadows, altering solar geometry and lowering albedo, greatly affecting the energy balance (Dana et al. 1998; Lewis et al. 1999; Fountain et al. 1999; Hoffman et al. 2016). These microclimates are generated at cliffs along the glacier margins and in 2-5 $\mathrm{m}$ deep basins in the lower 
ablation zones. The glaciers were divided into four sub-domains based on surface morphology: basin floors, basin walls, relatively low relief surfaces (including the tops of ridges between basins), and marginal cliffs. These features were originally extracted using 2 m LIDAR (US Geological Survey, 2002) and the methodology used to classify each is described by Hoffman (2011). For steep basin walls, which are not resolved by the DEM, the planimetric surface area of cells mapped as glacier basins is increased by $20 \%$ (Table 2.1). Cliff face area was estimated based on the length of the cliff and uniform height of 25 meters (Hoffman 2011). Air temperature, wind speed and ice albedo offsets are parameterized for each sub-domain microclimate based on measured differences in these variables and surface roughness is adjusted (Table 2.1; Hoffman et al. 2016).

Table 2.1 Sub-domain adjusted parameters and micro-climate meteorological adjustments. Surface area increase is applied only to basin wall cells to account for their true area. Ice albedo for cliffs is set to a constant 0.56 , the average albedo of snow-free ice in the study area.

\begin{tabular}{lccccc}
\hline & $\begin{array}{c}\text { Air Temperature } \\
{\left[{ }^{\circ} \mathbf{C}\right]}\end{array}$ & $\begin{array}{c}\text { Wind Speed } \\
{[\%]}\end{array}$ & $\boldsymbol{\alpha}$ & $\begin{array}{c}\mathbf{z}_{\mathbf{0}} \\
{[\mathbf{m m}]}\end{array}$ & $\begin{array}{c}\text { Surface Area } \\
{[\%]}\end{array}$ \\
\hline Smooth surfaces & -- & -- & -- & 0.05 & -- \\
Basin floors & +1.5 & -67 & -0.170 & 1 & -- \\
Basin walls & +0.5 & -33 & -0.065 & 1 & +20 \\
Cliffs & +0.5 & -32 & $(0.560)$ & 0.1 & -- \\
\hline
\end{tabular}

ICEMELT predicts melt, from both the surface and subsurface, for each glacier cell as a water equivalent depth and runoff volume is depth multiplied by the cell area. For glaciers that drain to multiple streams, surface catchments are defined using the DEM. Total runoff volume for each catchment is the sum of the melt volume of each cell within the catchment. No explicit meltwater routing scheme is used to model meltwater 
travel times; glacier runoff is assumed to drain directly from the glacier the same day that it is generated (Hoffman 2011).

\section{Distributed meteorological data}

The model was run from July $1^{\text {st }}, 1995$ to February $1^{\text {st }}, 2013$ capturing 16 full melt seasons (water years 1996-2013), defined as November 1st to February 28th. ICEMELT is forced using measured meteorological data from eight meteorological stations (Table 2.2). To interpolate and extrapolate the meteorological measurements MICROMET was used (Liston and Elder, 2006; Hoffman 2011). MICROMET assimilates 15-minute measurements from each station, fills short gaps using an autoregressive integrated moving average (ARIMA) and interpolates values to the grid between them based on known relationships between meteorological variables and topography (Liston and Elder, 2006). The results are averaged to hourly intervals for the model. A 40-m DEM was resampled to a 250-m model grid to provide topography for MICROMET (Hoffman et al. 2011). Meteorological input grids generated by Hoffman (2011) are used for this thesis, with no subsequent modifications.

Table 2.2 Taylor Valley meteorological station locations.

\begin{tabular}{lccccccc}
\hline Location & ID & $\begin{array}{c}\text { Lake } \\
\text { Basin }\end{array}$ & $\begin{array}{c}\text { Latitude } \\
{\left[{ }^{\circ}\right]}\end{array}$ & $\begin{array}{c}\text { Longitude } \\
{\left[{ }^{\circ}\right]}\end{array}$ & $\begin{array}{c}\text { Elevation } \\
{[\mathbf{m}]}\end{array}$ & Surface & $\begin{array}{c}\text { Season } \\
\text { Installed }\end{array}$ \\
\hline Taylor Glacier & TAR & LB & -77.740 & 162.128 & 334 & ice & $1994-95$ \\
Lake Bonney & BOY & LB & -77.714 & 162.464 & 60 & soil & $1993-94$ \\
Lake Hoare & HOE & LH & -77.625 & 162.900 & 72 & soil & $1985-86$ \\
Canada Glacier & CAA & LH/LF & -77.613 & 162.963 & 264 & ice & $1994-95$ \\
Howard Glacier & HOD & LF & -77.671 & 163.079 & 472 & ice & $1993-94$ \\
Lake Fryxell & FRL & LF & -77.611 & 163.170 & 20 & soil & $1993-94$ \\
Commonwealth Glacier & COH & LF & -77.564 & 163.280 & 290 & ice & $1993-94$ \\
Explorer's Cove & EXE & LF & -77.589 & 162.418 & 26 & soil & $1997-98$ \\
\hline
\end{tabular}


The MCM-LTER operates a network of automated weather stations in Taylor Valley

(Figure 2.2; Doran et al. 1996). These stations record air temperature, relative humidity, wind speed, and incoming solar radiation. Measurements are collected by Campbell Scientific data loggers (CR10X) at 30-second sampling intervals with mean values stored at 15-minute intervals. Incoming solar radiation is measured at all eight meteorological stations. Daily average albedo is calculated from 15-minute measurements of incoming and outgoing solar radiation for the four glacier meteorological stations where reflected solar radiation is measured (TAR, CAA, HOD, COH; see Table 2.2 for abbreviations).

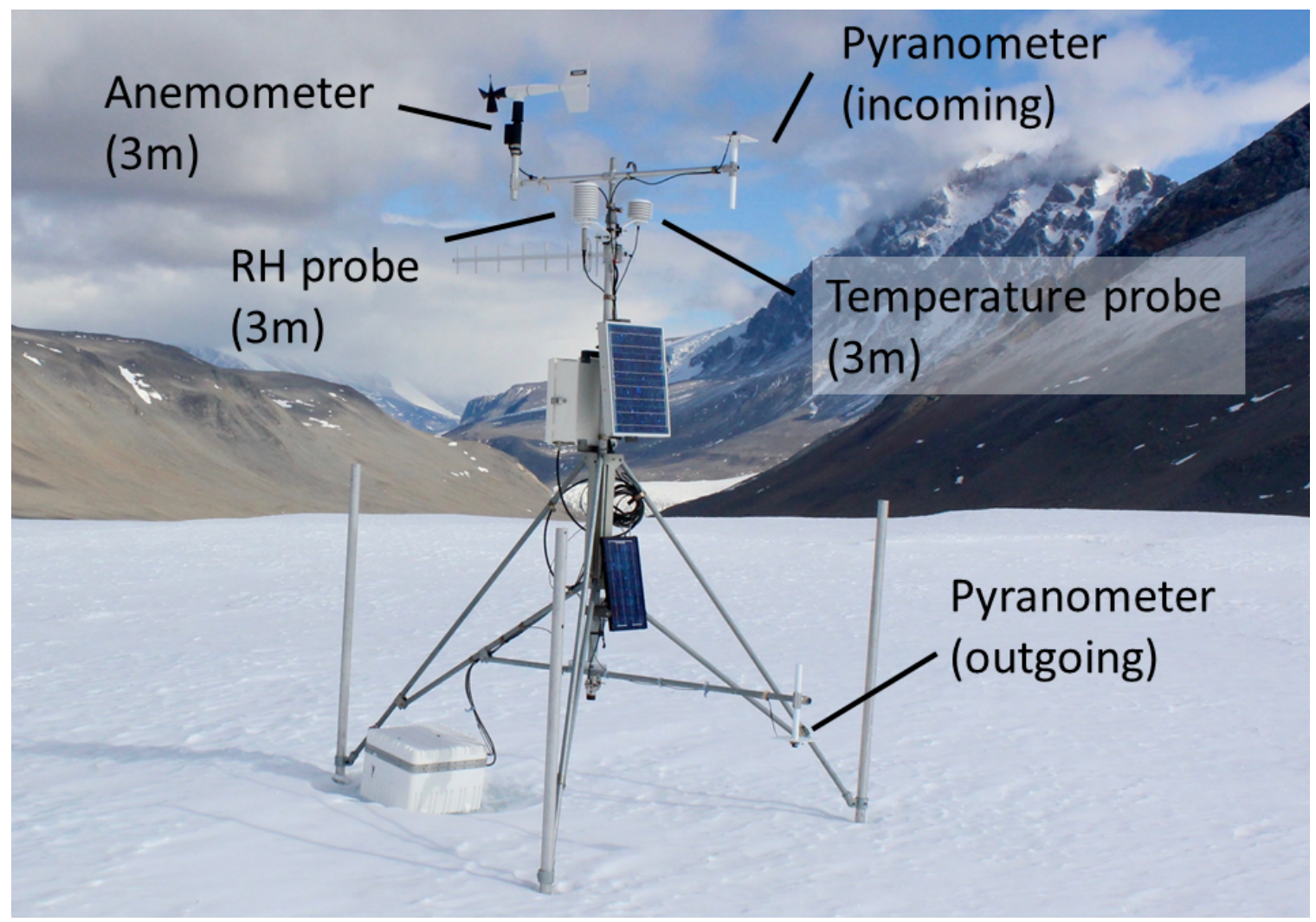

Figure 2.2 Canada Glacier meteorological station with relevant instrumentation labelled, including: anemometer measuring wind speed at 3m, Campbell Scientific 207T RH probe measuring relative humidity at $3 \mathrm{~m}$, Campbell Scientific $107 T$ probe measuring air temperature at $3 \mathrm{~m}$ and two LI-COR LI200S pyranometers measuring incoming and outgoing shortwave radiation. 
Hoffman (2011) found that the LI-COR LI-200 pyranometer used at CAA station overestimates ice albedo by $8 \%$ ( +0.04 for ice and +0.07 for snow) when compared to measurements made with an Eppley PSP pyranometer. The spectral response of the LICOR device is limited to the visible wavelengths where snow and ice have the highest spectral albedo. To correct for this bias, an adjustment of $-8 \%$ was made to the LI-COR albedo measured at CAA (Hoffman 2011). ICEMELT averaged the albedo measured at Canada and Taylor stations for glaciers in the Bonney and Hoare basin. For glaciers in the Fryxell Basin (except Canada Glacier) albedo was lowered by -0.05 from the adjusted Canada Station measurements.

\subsection{Modifying the Meltwater Model}

The albedo of glacier surfaces is highly variable spatially (dust and debris) and temporally (snowfall events) and cannot be distributed in a similar manner to the other meteorological measurements. I supplemented the station measurements of albedo with remotely-sensed daily albedo measurements. Daily MODIS-derived albedo images (Schaaf and Wang, 2015) were compiled in Google Earth Engine to develop daily, spatially-averaged albedo of each glacier (Appendix A describes the methods). When MODIS albedo measurements are not available, typically due to cloud cover, the Taylor station albedo is used for glaciers in the Bonney basin, and Canada station albedo is used for glaciers in the Hoare basin. For the Fryxell basin, the Canada station albedo is lowered by 0.05 . The comparison of the spatially-averaged MODIS albedo compared to the nearest meteorological station is shown in Figures A.5-7 in Appendix A. At all sites, 
meteorological station measurements were higher than the MODIS-derived spatiallyaveraged albedo, by as much as 0.18 on average.

\subsection{Lake Sublimation Model}

Sublimation from the lake ice was modeled using ICEMELT's sub-routines for the turbulent heat fluxes. By estimating temperature and vapor pressure gradients between the ice surface and a reference height $(3 \mathrm{~m})$, ICEMELT uses a bulk aerodynamic method to determine the turbulent flux of latent heat $\left(Q_{e}\right)$, which are defined as:

$$
Q_{e}=\rho_{a} L_{v} D_{e} \zeta\left(0.622 \frac{e_{a}-e_{s}}{p_{a}}\right)
$$

where $\rho_{a}\left(\mathrm{~kg} \mathrm{~m}^{-3}\right)$ is the density of air, $L_{v}\left(\mathrm{~J} \mathrm{~kg}^{-1}\right)$ is the latent heat of vaporization, $D_{e}$ is the turbulent exchange coefficient, $\zeta$ is a unit-less stability function, $e$ is vapor pressure $(\mathrm{Pa})$ and $p$ is air pressure $(\mathrm{Pa})$, measured at the Lake Hoare meteorological station, while subscripts $s$ and $a$ denote conditions at the surface and at the reference height above the ice, respectively (Hoffman et al. 2014). The model uses MICROMET input data of air temperature, relative humidity and wind speed for the MICROMET cell corresponding to each lake meteorological station.

The turbulent exchange coefficient, $D_{e}$, takes the form:

$$
D_{e}=\frac{\kappa^{2} u_{a}}{\left[\ln \left(z_{a} / z_{0}\right)\right]^{2}}
$$

where $\kappa$ is von Kármán's constant and $u_{a}$ is the wind speed at the reference height $z_{a}$. The surface roughness length, $z_{0}$, is the only adjustable parameter and is calibrated independently for each lake to minimize bias in the estimates of winter sublimation. 
The surface temperature of the lake ice is neither measured nor modeled. Instead, I assume that the lake ice skin temperature is equal to the air temperature when air temperatures are $<0^{\circ} \mathrm{C}$; and equal to $0^{\circ} \mathrm{C}$ when air temperatures are $>0^{\circ} \mathrm{C}$. To define whether the saturated vapor pressure is based on ice or water, air temperature is used such that for temperatures $>0{ }^{\circ} \mathrm{C}$ the ice is assumed to be covered by a film of water and the vapor pressure is that of water, otherwise the surface is ice. Additionally, the appropriate atmospheric stability case is also determined from air temperature; if $>0{ }^{\circ} \mathrm{C}$, the boundary layer is assumed to be stable, and $<0^{\circ} \mathrm{C}$ the boundary layer are assumed to be unstable, if equal to $0^{\circ} \mathrm{C}$, a neutral case is assumed.

\subsection{Lake Water Balance Model}

The annual hydrologic budget of Lakes Bonney, Hoare and Fryxell are modelled using a simple conservation of mass (Obryk et al. 2017):

$$
\frac{d V}{d t}=\mathrm{Q}_{\text {direct }}+\mathrm{Q}_{\text {stream }}+\mathrm{Q}_{\text {ground }}+[P-S-E] A(h),
$$

where $V$ is lake volume $\left(\mathrm{m}^{3}\right)$ and $t$ is the time interval (year); inflows are from $\mathrm{Q}_{\text {direct }}$, sub-aerial glacial melt directly to the lake, $\mathrm{Q}_{\text {stream, }}$ glacier-fed stream discharge, $\mathrm{Q}_{\text {ground }}$, shallow ground-water recharge (all in $\left.\mathrm{m}^{3} \mathrm{yr}^{-1}\right)$, and precipitation $P\left(\mathrm{~m}\right.$ w.e. $\left.\mathrm{yr}^{-1}\right)$,

and losses ( $\mathrm{m}$ w.e. $\mathrm{yr}^{-1}$ ) due to sublimation $S$ and moat evaporation $E$, and $A(\mathrm{~m})$ lake surface area at a given lake-level $h(\mathrm{~m})$. Any lake ice melt is returned to the lake and is not a mass loss. 
To evaluate (6), $Q_{\text {direct }}$ and $Q_{\text {stream }}$ are lumped together as total glacier runoff inflow. Ground-water recharge is a very small portion of the water budget and is ignored (Chinn, 1993; Levy et al. 2017). Additionally, precipitation onto the lake surface is small and is also ignored (Fountain et al. 2010). The area lake moats is considered to be less than 3\% of the total lake area (Spigel and Priscu, 1998), so evaporation from the moats is ignored; this assumption is explored in Section 3.2.

By treating glacier melt as the sole inflow and ignoring evaporation from the moats, (6) can be simplified to:

$$
\frac{d V}{d t}=Q_{\text {glacier }}-S * A(h),
$$

where $Q_{\text {glacier }}\left(\mathrm{m}^{3} \mathrm{yr}^{-1}\right)$ is the modeled meltwater inflow, both direct and through stream discharge.

The lake model is used to estimate lake-level change using the 1995 level as datum. A change in lake volume $d V$ for a given change in level can be calculated based on the height-area relation $A(h)$,

$$
d V=A(h) d h,
$$

where $A(h)$ is described by the hypsographic function of the lake basin, $A(\mathrm{~m})$ is the lake area at a given height $(\mathrm{h})$ and $d h(\mathrm{~m})$ is the change in height. Lake bathymetry has been mapped (Priscu 1995), so the full hypsometry of each lake basin is well known (Appendix D). 
Rewriting Equation (8) as a function of time,

$$
\frac{d V}{d t}=A(h) \frac{d h}{d t}
$$

allows Equation (7) to be rewritten as:

$$
\frac{d h}{d t}=\frac{Q_{\text {glacier }}}{A(h)}-S
$$

to solve for $d h / d t\left(\mathrm{~m} \mathrm{yr}^{-1}\right)$, the lake-level change through time.

Finally, hourly ICEMELT runoff and sublimation totals are summed annually for each lake. These are applied to equation (10) in a MATLAB code that solves for lake-level change using an analytical solver (Obryk et al. 2017).

\subsection{Model Calibration \& Validation}

The meltwater model was calibrated against ablation stake networks on Taylor and Canada glaciers. Modelled glacier runoff is compared to measured stream discharges in Taylor Valley (Table 2.3). Finally, measured lake-level changes are used to validate the modeled inflow, loss due to sublimation, and total water budget of the lakes. 


\section{Streamflow record}

The MCM-LTER project measures streamflow at fifteen streams in Taylor Valley (Table 2.3; McKnight and Gooseff 2016). In the Lake Bonney basin three of the five streams draining to the lake were gauged. One gauge on the Santa Fe Stream was taken offline in 2000 because rising lake-levels flooded the gauging site. Lake Bonney receives additional inflow from several ungauged streams and water tracks. Lake Hoare receives meltwater inflows from four streams, two of which are gauged. In the Fryxell basin, thirteen streams flow into the lake, and nine of these are gauged. Finally, Commonwealth Stream drains the east side of the Commonwealth Glacier into New Harbor.

Table 2.3 Summary of Taylor Valley streams with gauged discharge. Left column corresponds to labels on the map in Figure 2.1. Notes: $A$ - decommissioned after 2000; $B$ - Bohner Stream is tributary, decommissioned in 2011; C - flows through a pond; D - has a tributary; E - Relict channel is tributary or distributary. NH for New Harbor.

\begin{tabular}{|c|c|c|c|c|c|}
\hline & & Lake Basin & Source & Period of Record & Notes \\
\hline 1 & Santa Fe Stream & LB & Taylor Glacier & $1993-2000$ & A \\
\hline 2 & Priscu Stream & LB & Lacroix and Sollas Glaciers & $1993-2013$ & $\mathrm{~B}$ \\
\hline 3 & Lawson Creek & LB & Rhone Glacier & $1994-2015$ & \\
\hline 4 & House Stream & $\mathrm{LH}$ & Seuss Glacier & 1993-2012 & \\
\hline 5 & Andersen Creek & $\mathrm{LH}$ & Canada Glacier & 1993-2014 & \\
\hline 6 & Green Creek & LF & Canada Glacier & $1990-2015$ & $\mathrm{C}$ \\
\hline 7 & Canada Stream & LF & Canada Glacier & $1990-2015$ & $\mathrm{C}$ \\
\hline 8 & Delta Stream & LF & Howard Glacier & $1990-2015$ & $C, D$ \\
\hline 9 & Crescent Stream & LF & Crescent Glacier & 1990-2016 & $E$ \\
\hline 10 & Huey Creek & LF & Asgard Range glacier & 1993-2014 & \\
\hline 11 & Aiken Creek & LF & Kukri Hills glacier & $1991-2015$ & $C, D, E$ \\
\hline 12 & Von Guerard Stream & LF & Kukri Hills glacier & $1990-2015$ & $E$ \\
\hline 13 & Harnish Creek & LF & Kukri Hills glacier & 1997-2015 & $C, D, E$ \\
\hline 14 & Lost Seal Stream & LF & Commonwealth Glacier & $1990-2015$ & \\
\hline 15 & Commonwealth Str. & $\mathrm{NH}$ & Commonwealth Glacier & $1993-2015$ & \\
\hline
\end{tabular}




\section{Lake-level record}

Lake-level measurements that span the modelled time-period area available for Lakes Bonney, Hoare and Fryxell (Doran and Gooseff 2018). Level measurements were made by optical surveys whenever possible, typically at least two measurements were made per season, one at the beginning of the season and one at the end. Continuous level measurements are available after 2000, but due to the shorter measurement period and problems co-registering with the optical measurements (Maciej Obryk, personal communication, May 2019) they were not used. The optical measurements are smoothed with a running mean and compared to modelled lake-level.
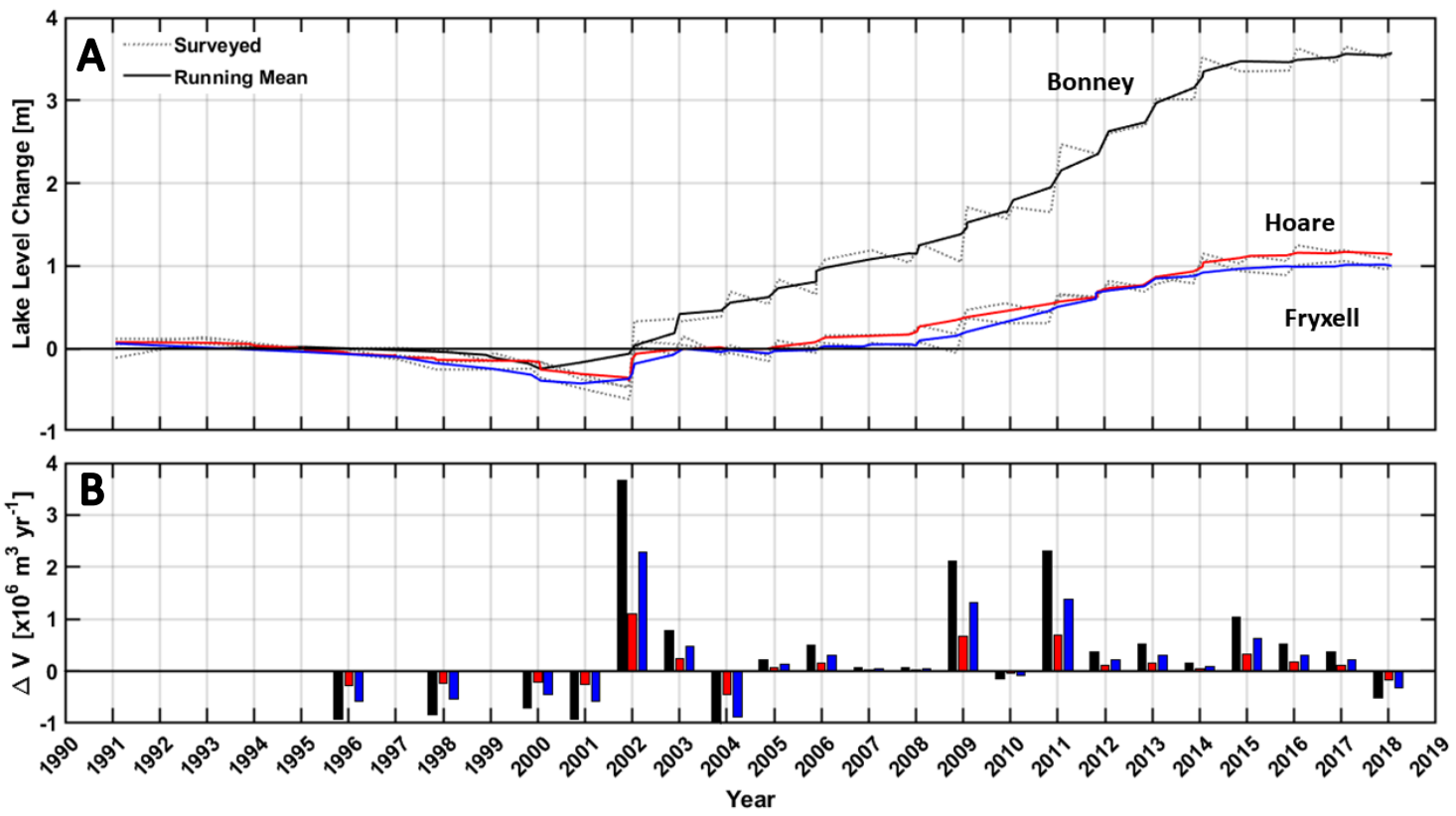

Figure 2.3 Lake-level changes in Taylor Valley over the measurement period.

(A) Surveyed (dotted) lake-level change relative to 1995 smoothed with a running mean (solid line). (B) Annual lake volume change inferred from basin hypsometry. Colors indicate Lakes Bonney (black), Hoare (red) and Fryxell (blue). 


\section{$\underline{\text { Lake sublimation record }}$}

Estimating lake ice sublimation is critical to calculating the basin's water budget, however this topic has received little attention (Henderson et al. 1966; Clow et al. 1988; Chinn 1993). More recently, however, a long-term record of ablation (melt and sublimation, 2001 to 2011) has been compiled using both manual and automated measurements (Dugan et al. 2013). Lake Hoare shows the highest annual ablation rates, while Lake Bonney shows the highest winter sublimation rates (Figure 2.3). Annual ablation totals are highly variable and the 2002 and 2008 high-melt years can be resolved at all lakes. Dugan et al. (2013) infer winter sublimation from the drop in stage between February and November, with sublimation calculated as the inverse of drop in stage. Winter sublimation is relatively constant year to year.

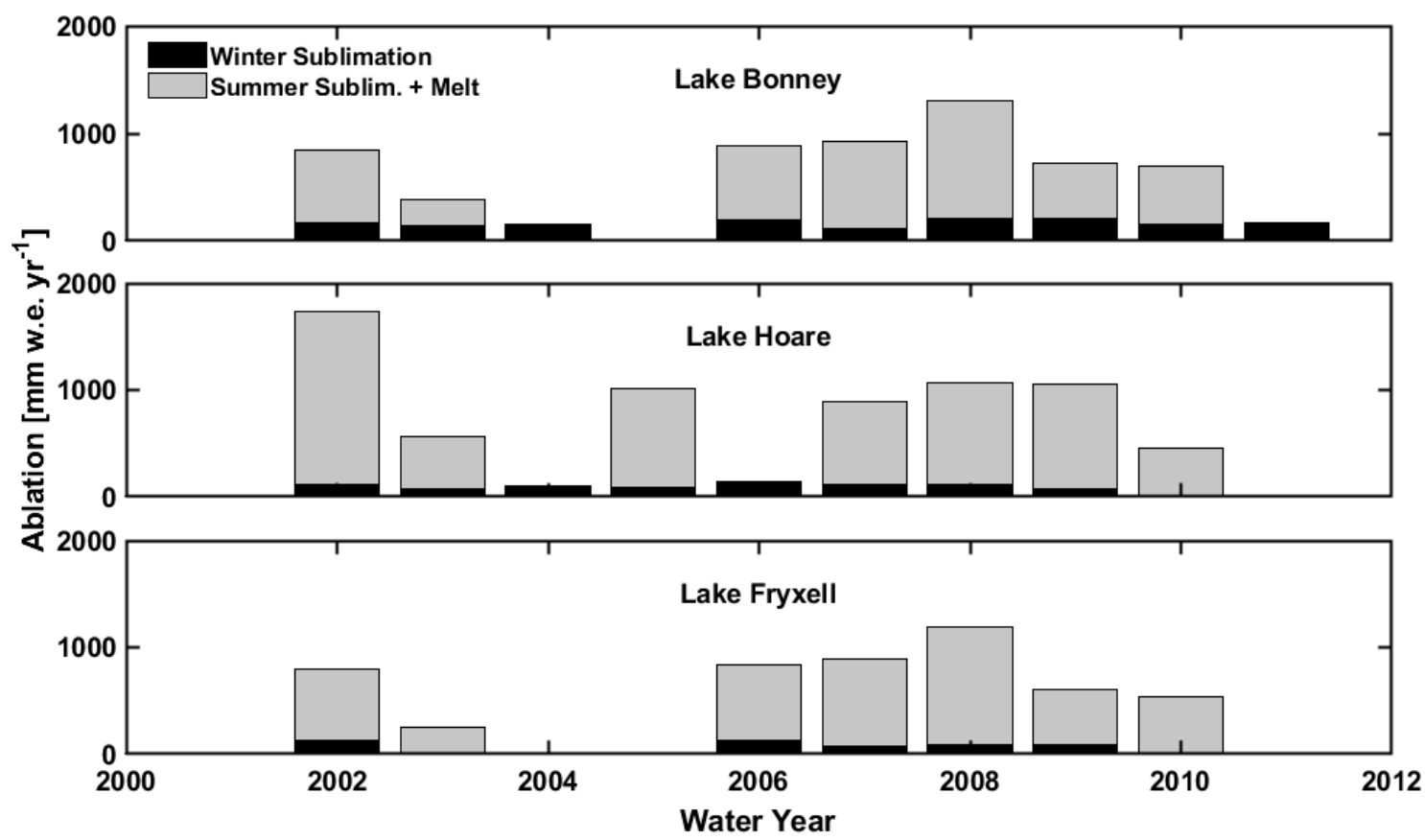

Figure 2.4 Measured lake ice ablation for the lakes in Taylor Valley from Dugan et al. (2013). Winter sublimation (black) and summer ablation (gray). 


\section{Uncertainties in available data}

The hydrological measurements available in Taylor Valley have varying degrees of associated uncertainty. Stake measurements, used to calibrate glacier ablation and energy balance parameters (e.g. surface roughness length and effective ice grain radius) have a low degree of uncertainty ( 2-10\%; Fountain et al. 2006). They are not, however, representative of the micro-topographic basins on the lower glacier, so ablation in these areas is unconstrained.

Measured stream discharge, on the other hand, provides a good constraint on distributed glacier melt by integrating mass loss across the entire contributing area. However, stream discharge measurements have a high degree of uncertainty. Discharge measurements are tagged with a daily quality flag ("good" for most data accurate within $10 \%$, "fair" for within $25 \%$, "poor" for significant amounts of data may be $>25 \%$ off) based on the gauge condition that day or over the course of the season (McKnight and Gooseff 2016). The streamflow data quality is highly variable year-to-year and between gauges; data quality and the completeness of stream records are detailed in Appendix C.

Lake-level measurement methods have a low degree of uncertainty $( \pm 1 \%)$, however, some surveys were not as carefully made (Maciej Obryk, personal communication, May 2019). Winter lake ice ablation provide some constraint on estimated winter sublimation rates (Dugan et al. 2013). To test my model of sublimation, winter ablation values are used, but this leaves uncertainty in constraining the full lake water balance due to the unknown summer rate. 


\section{Chapter 3. Simulation Results \& Analysis}

The initial application of ICEMELT was run with Hoffman et al. (2016) parameters and meteorological station albedo as version M1. The model was run again but incorporated a spatially-distributed albedo, derived from a gridded MODIS product, as version $\mathrm{M} 2$. The lake water balance model used inflows from $\mathrm{M} 2$.

\subsection{Glacier Meltwater Inflow}

The skill of ICEMELT (M1 and M2) in predicting stream discharge is evaluated by comparing observed and simulated stream discharge at a daily and annual resolution. The model shows reasonable skill in predicting daily variations of stream discharge (Figure 3.1A). The daily discharge hydrographs and efficiency metrics show that the meltwater model adequately captures the timing of most melt events (melt dynamics), while not necessarily capturing the full magnitude of events. Model efficiency metrics, including Nash-Sutcliffe efficiency E (Nash \& Sutcliffe 1970), indicate adequate dynamical efficiency, $M 2: E=0.47, r^{2}=0.71$ for all days with observed streamflow at all gauges (Appendix B Table B.1).

In both versions the model generally under-predicts annual discharge (Figure 3.1B); the $M 1$ and $M 2$ runs had a cumulative error (CE) of $28.8 \times 10^{6} \mathrm{~m}^{3}$ and $23.6 \times 10^{6} \mathrm{~m}^{3}$, respectively (Appendix B Table B.1). The assimilation of MODIS albedo (M2) after 2000 improved ICEMELT skill, particularly during the 2002 flood-year. Furthermore, following the 2001 water year, the model results more closely follow trends in annual discharge totals, compared to 1996 to 2000 . Most notably, in both runs the meltwater model 
significantly under-predicts two significant melt seasons of 2009 and 2011, the MODIS albedo used in M2 did not make as significant of an improvement as seen for the 2002 flood-year. These patterns are generally consistent for all gauged streams, except for streams flowing from the Kukri Hills into Lake Fryxell, which show generally poor model results, particularly Aiken, Von Guerard and Harnish streams. Meltwater discharge in Green Creek is over-predicted for both $\mathrm{M} 1$ and $\mathrm{M} 2$ in nearly every year.
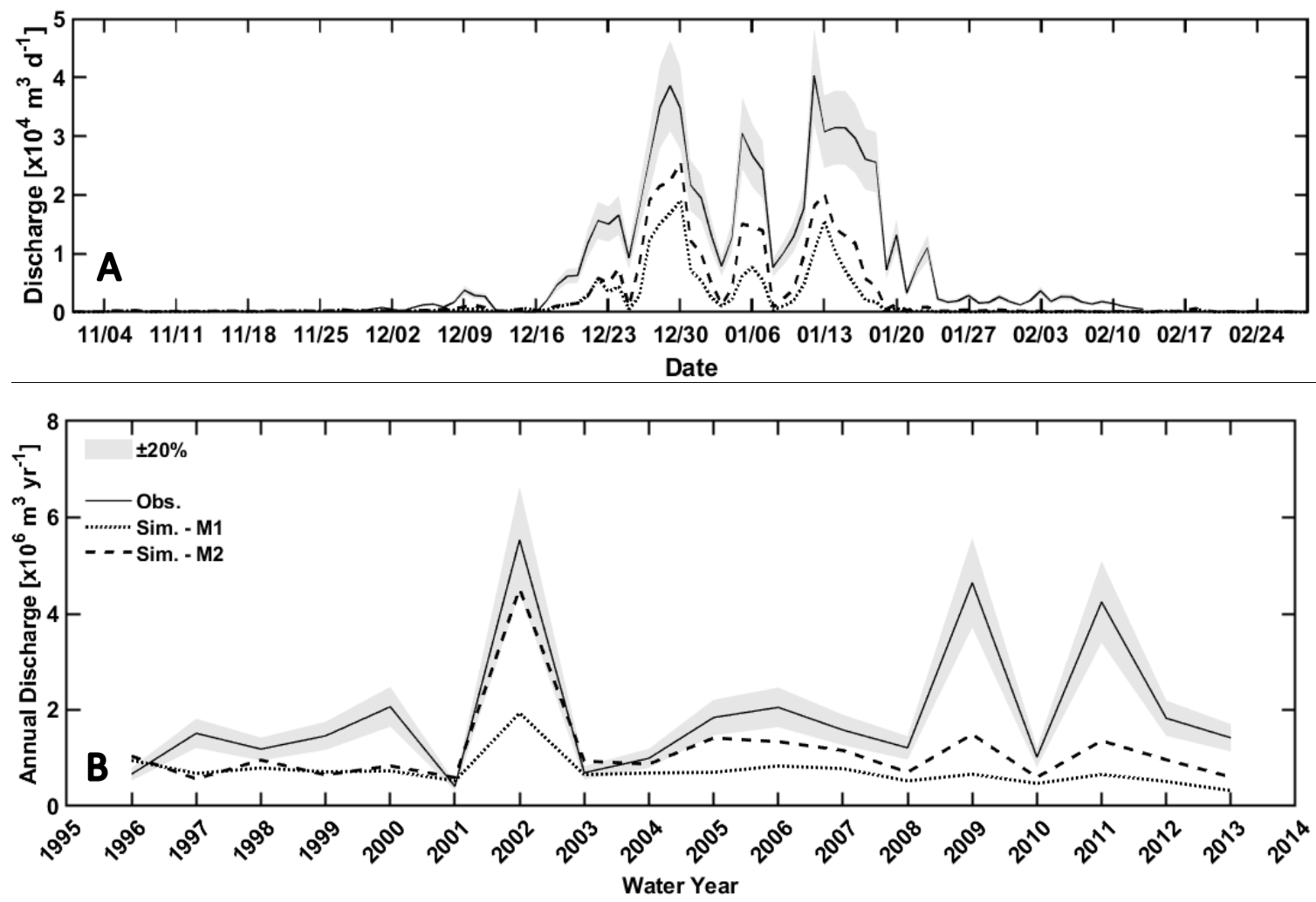

Figure 3.1 M1 and M2 meltwater model results. (A) Daily discharge hydrograph for Canada Stream for the 2002 water year. (B) Annual discharge from all measured streams in Taylor Valley from water years 1996 to 2013. The $x$-axis label indicates the water year (e.g. melt season from November 2001 through February 2002 would be water year 2002). The solid line is observed stream discharge with $\pm 20 \%$ measurement uncertainty (shading). Preliminary meltwater model results (M1, dashed) and with MODIS remotely-sensed albedo (M2, dotted). The legend in (B) also applies to (A). 

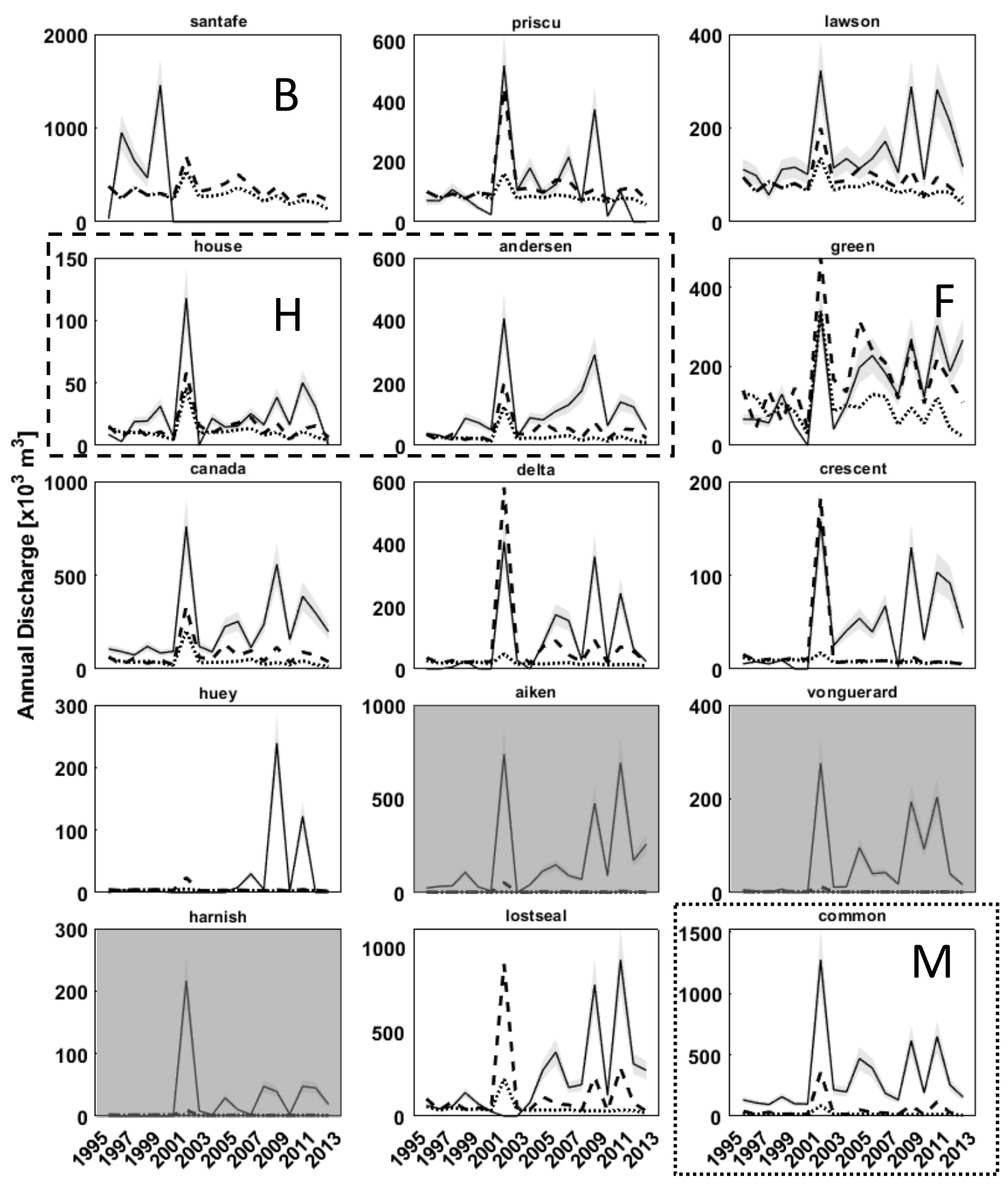

Figure 3.2 Annual discharge for each measured stream (labels above each plot) from 1996 to 2013. Streams are ordered generally by valley position west to east. Streams in the top row (B) flow to Lake Bonney, streams in the dashed box $(H)$ flow to Lake Hoare, streams from Green to Lost Seal (F) flow to Lake Fryxell, while Commonwealth Stream in the dotted box flows to McMurdo Sound (M). Grey boxes indicate eastern Kukri Hills Glaciers. The solid line shows observed stream discharge with 20\% measurement uncertainty displayed as grey area. Meltwater model results with (dashed) and without (dotted) MODIS remotely-sensed albedo. The x-axis label indicates the water year. 


\subsection{Lake Water Balance}

Modeled sublimation shows good results (Table 3.1 and Figure 3.3) when compared to measured winter (February - November) ablation values of Dugan et al. (2013). The surface roughness length $\left(z_{0}\right)$ was adjusted to reduce error of estimated winter ablation. Similar to the observed record, modeled winter sublimation was not highly variable between years. Total annual modelled sublimation was significantly less than total annual measured ablation, accounting for $16 \%$ at Lake Bonney and $5 \%$ at both Lakes Hoare and Fryxell.

Table 3.1 Sublimation model results for 1996 to 2013 showing optimized $z_{0}$ and corresponding root-mean-square error (RMSE) and cumulative error (CE, simulatedobserved) in winter (Feb-Nov) sublimation estimates. For reference, $z_{0}$ in glacier meltwater model is $0.05 \mathrm{~mm}$ on smooth surfaces and $1 \mathrm{~mm}$ for basins.

\begin{tabular}{cccc}
\hline Lake & $\begin{array}{c}\mathbf{z}_{0} \\
{[\mathrm{~mm}]}\end{array}$ & $\begin{array}{c}\text { RMSE } \\
{[\mathrm{mm}]}\end{array}$ & $\begin{array}{c}\text { CE } \\
{[\mathrm{mm}]}\end{array}$ \\
\hline Bonney & 0.086 & 12.0 & -0.48 \\
Hoare & 0.121 & 13.3 & 0.12 \\
Fryxell & 0.291 & 10.6 & 0.40 \\
\hline
\end{tabular}

Modeled lake-levels exhibit varying degrees of correspondence to observations. For Lakes Bonney and Hoare modeled lake-levels match observed levels fairly well through 2007. Over the same period variations in the modeled level of Fryxell matched the observations, but with an increasing underestimate over time. After 2007 none of the modeled lake-levels capture the observed increase. 

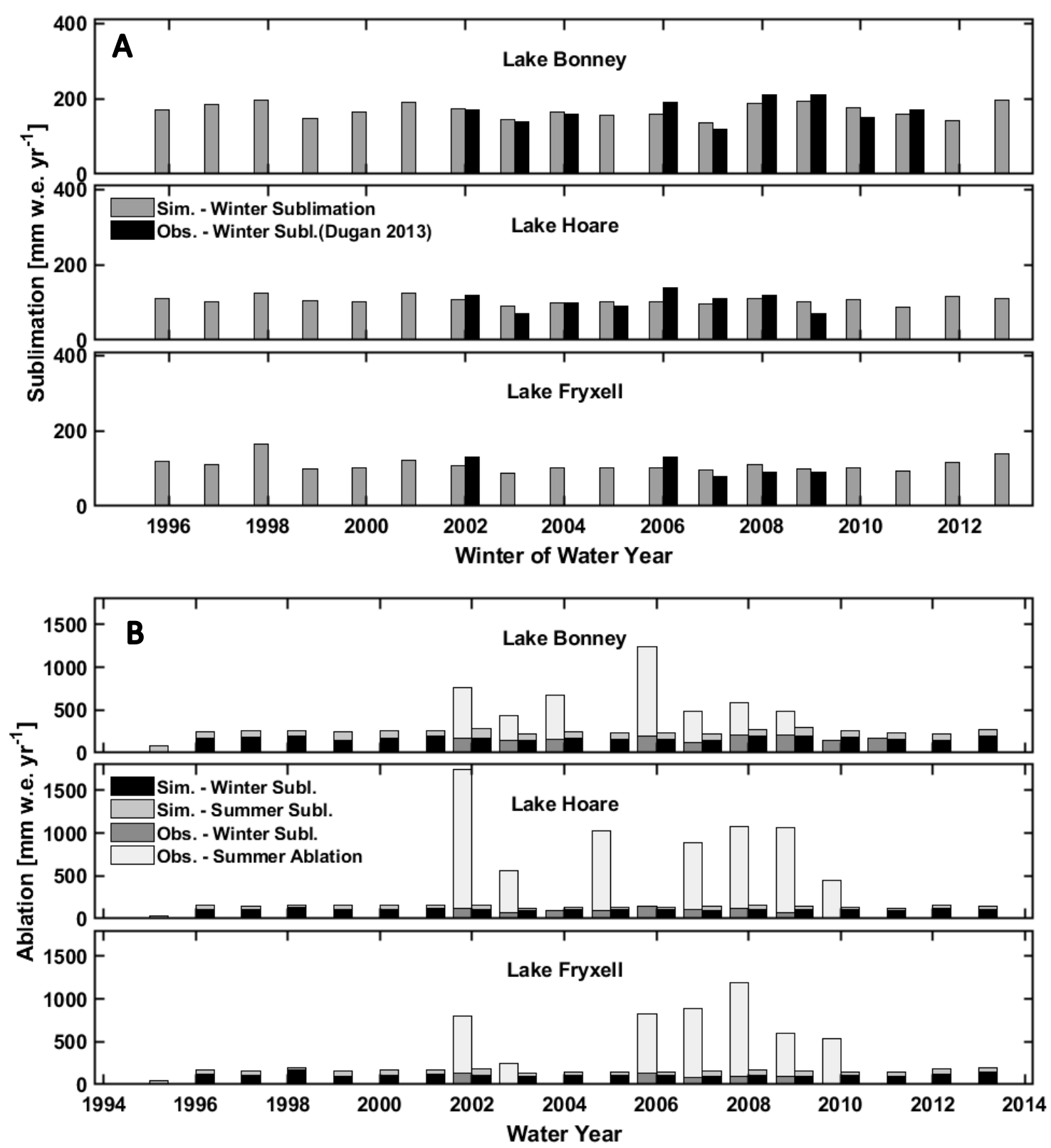

Figure 3.3 Sublimation model results. (A) Modeled winter (February to November) sublimation compared to measured values of winter ablation from Dugan et al. (2013). Winter ablation measurements are measurements of sublimation, as melt does not occur during the winter. (B) Modeled annual sublimation, split into winter and summer, plotted with annual measured ablation, split into winter sublimation and summer ablation, both melt and sublimation. All measured values are based on based on Dugan et al. (2013). The year label on the $x$-axis of the lower three panels indicates the starting year of the austral water year. 

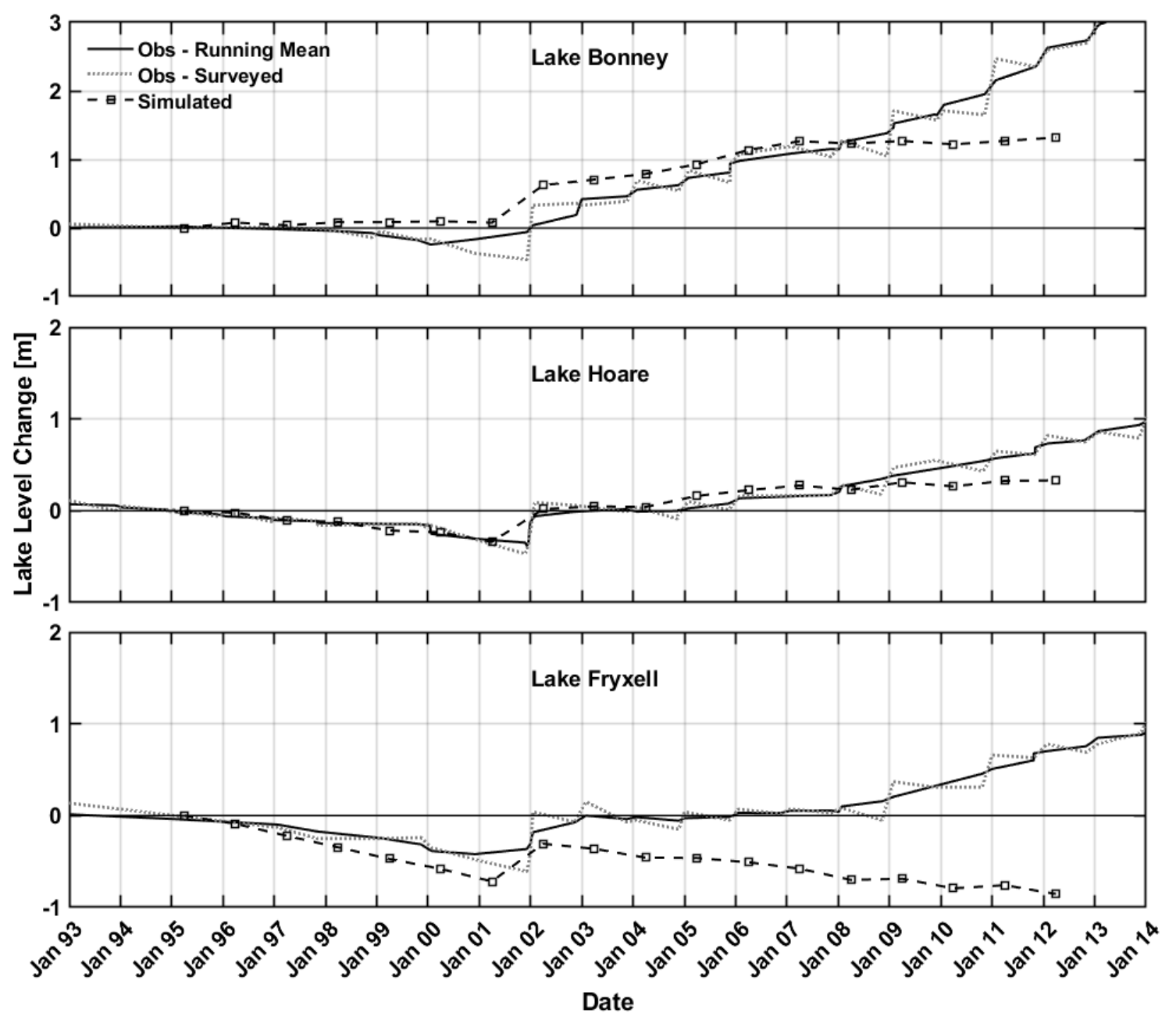

Figure 3.4 Simulated (dashed, with symbols) versus observed (dotted) annual lake-level change, relative to the January 1995 datum. Observed data were smoothed with a running mean (solid). Simulated lake-levels are plotted on March 31 of each year (close to peak lake-level and the end of the water year).

\subsection{Modifications}

To improve model results, several modifications were made to ICEMELT, including a global adjustment to albedo and surface roughness. Uncertainty exists in the albedo measurements of in-situ pyranometers and those remotely-sensed by MODIS. The Eppley pyranometers, used at three of the four glacier meteorological sites, have a reported uncertainty of $\pm 5 \%$; propagating this instrumental uncertainty through the 
calculation of albedo (ratio of reflected and direct) yields an uncertainty of $\pm 7 \%$.

Uncertainty in the MODIS measurements (reported in Appendix A Figure A.2) was calculated to be $\pm 7 \%$ as well. ICEMELT, configured to run with MODIS albedo (M2), was run with albedo lowered by $-7 \%$, the maximum value within the instrumental uncertainty, to address the over-all deficit in estimated in melt (M3, Figure 3.5).
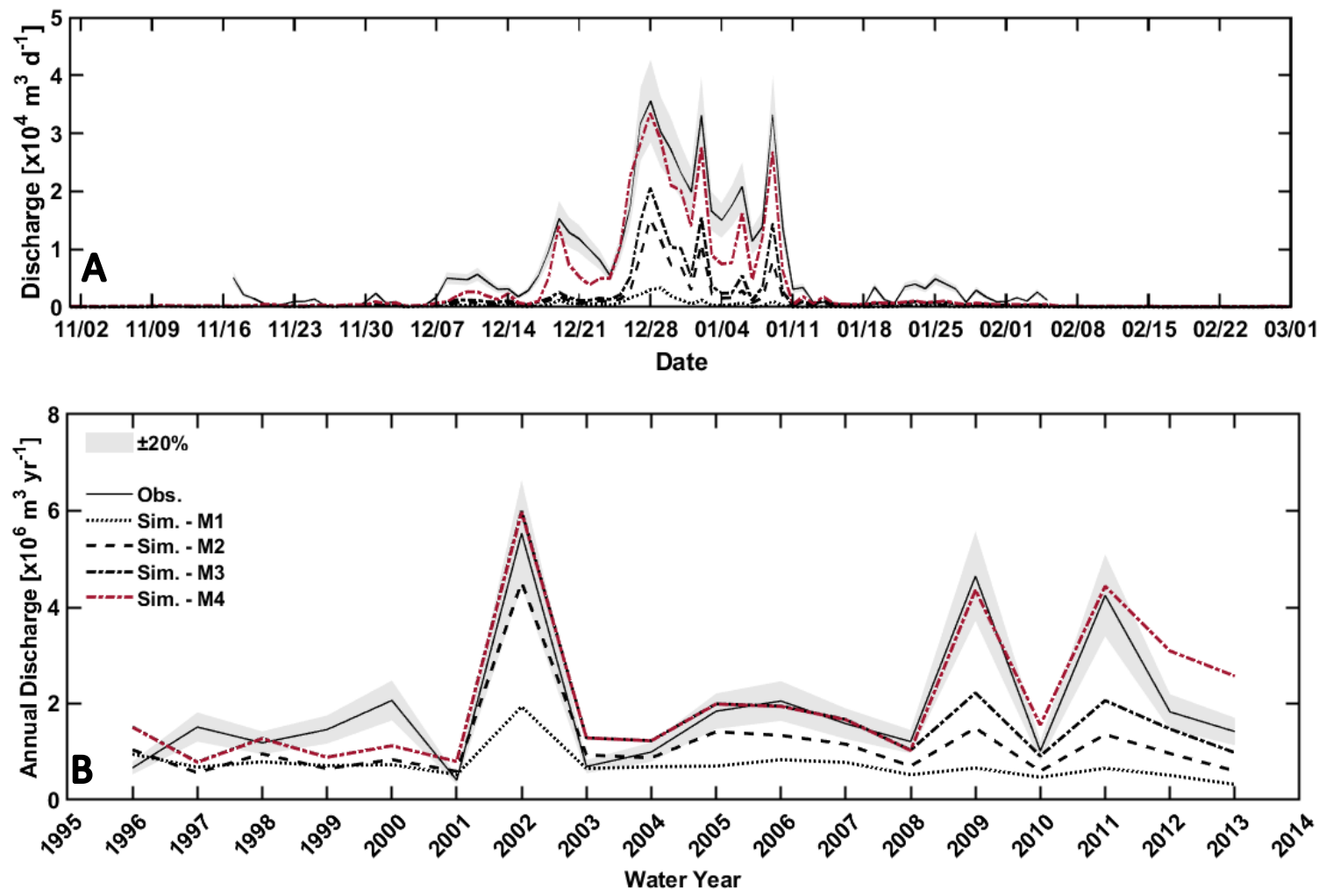

Figure 3.5 M1 and M2 meltwater model results. (A) Daily discharge hydrograph for Canada Stream for the 2009 water year. (B) Annual discharge from all measured streams in Taylor Valley from water years 1996 to 2013. The solid line shows observed stream discharge with $\pm 20 \%$ measurement uncertainty displayed as grey area. Preliminary ICEMELT results (M1, dotted) and (M2, dashed) MODIS remotely-sensed albedo and subsequent modifications to ICEMELT (M3 and M4, black and red chain-dot lines, respectively).

Lowering albedo by $-7 \%$ (M3) improved valley wide discharge total results, particularly from 2000 to 2008, while the large melt years of 2009 and 2011 remained lower than observed annual discharge (Figure 3.5). This pattern is mirrored for most 
streams, particularly in the Fryxell basin. M3 yielded satisfactory results prior to 2009 at most streams (Figure 3.5), however, the large melt years of 2009 and 2011 are poorly captured. The decrease in albedo was only applied to the smooth ice of the glaciers and not basins. The basins are pools of semi-frozen water in summer about $1 \mathrm{~m}$ deep. The addition of small amounts of aeolian sediment would not change the albedo significantly as these are already areas of low albedo and the sediment would collect in the deepest points. If the basins were also to be decreased, then runoff from basindominated catchments would be over predicted significantly (Appendix B.1).

To improve ICEMELT results after 2008, the surface roughness and albedo were adjusted for the smooth ice sub-domain (M4; Table 3.2). This alteration is based on the hypothesized influx of sediment after 2007 by Hoffman et al. (2016). Lowering albedo by $-30 \%$ (total, not in addition to $-7 \%$ for $M 3$ ), equivalent to lowering mean summer (DJF) albedo by -0.18 (Appendix B Table B.3), was required to improve model skill.

Table 3.2 Summary of modifications made to ICEMELT (M4).

\begin{tabular}{lccc}
\hline Glacier & Years & $\begin{array}{c}\boldsymbol{\alpha} \\
{[\%]}\end{array}$ & $\begin{array}{c}\mathbf{z}_{\mathbf{0}} \\
{[\mathbf{m m}]}\end{array}$ \\
\hline All glaciers & All years & -7 & -- \\
All glaciers (except lower Canada Glacier) & After 2008 & -30 & -- \\
Lower Canada Glacier (e.g. Green Creek Catchment) & -- & -7 & -- \\
Fryxell basin glaciers (except Canada) & -- & -- & 1.00 \\
\hline
\end{tabular}

Adjustments of $-20 \%$ and $-25 \%$ to albedo were also examined. These adjustments were compared using several model efficiency metrics (Table 3.3), e.g. the Nash-Sutcliffe Efficiency (Nash and Sutcliffe 1970). The relative improvement over M3 after 2008 was evaluated (Figure 3.6) and the adjustment of $-30 \%$ was determined to have the best result. Ice roughness of glaciers in the Fryxell Basin was increased from 
$0.05 \mathrm{~mm}$ to $1 \mathrm{~mm}$ after 2008. Also, it became apparent that the flow divide between two catchments on Commonwealth Glacier was misplaced and this was readjusted (Appendix B.2).

Table 3.3 Model efficiency results for model runs M1-M4. The Nash-Sutcliffe Efficiency (E), coefficient of determination $\left(r^{2}\right)$, root-mean-squared error (RMSE in $\left.10^{3} \mathrm{~m}^{3}\right)$, normalized root-mean-squared error (nRMSE) and cumulative error (CE in $\left.10^{6} \mathrm{~m}^{3}\right)$ are shown for all Taylor Valley. Error was calculated as the difference between observed and simulated discharge (obs. - sim.) on days with observed discharge.

\begin{tabular}{rccccc}
\hline & E & $\mathbf{r}^{2}$ & $\begin{array}{c}\text { RMSE } \\
{\left[\mathbf{x} \mathbf{0}^{3} \mathrm{~m}^{3}\right]}\end{array}$ & nRMSE & $\begin{array}{c}\text { CE } \\
{\left[\mathbf{1 0} \mathbf{0}^{\mathbf{3}}\right]}\end{array}$ \\
\hline M1 & 0.177 & 0.578 & 20.46 & 0.907 & 28.80 \\
M2 & 0.473 & 0.714 & 16.36 & 0.726 & 23.57 \\
M3 & 0.634 & 0.766 & 13.64 & 0.605 & 17.62 \\
M3.1 & 0.763 & 0.845 & 10.97 & 0.487 & 14.44 \\
M3.2 & 0.769 & 0.846 & 10.83 & 0.480 & 14.13 \\
M4 & 0.794 & 0.843 & 10.24 & 0.454 & 12.71 \\
\hline
\end{tabular}

The final model (M4) successfully captures the magnitude of melt during the 2009 and 2011 seasons (Figure 3.5). This adjustment to albedo succeeds in increasing total annual discharge to within $20 \%$ of the measured streamflow. M4 does not overestimate melt during the low-melt year of 2008, but it does over estimate melt in 2010, 2012 and 2013. For streams flowing to Lake Bonney, M4 improves predictions during 2009 and 2011, but does not capture the full magnitude (Figure 3.7). In the Lake Hoare basin, modeled total annual discharge is close to observations for both House $(E=0.74$, $\mathrm{nRMSE}=0.51)$ and Andersen streams $(\mathrm{E}=0.82, \mathrm{nRMSE}=0.42)$. In the Fryxell Basin most streams (e.g. Canada and Delta streams) show good correspondence between predicted streamflow and observations. Crescent Stream shows improvements in 2009 and 2011. Green Creek discharge is over-predicted by the model all years. Finally, the streams 
draining the eastern part of the Kukri Hills, Aiken, Von Guerard and Harnish streams, show no improvement.

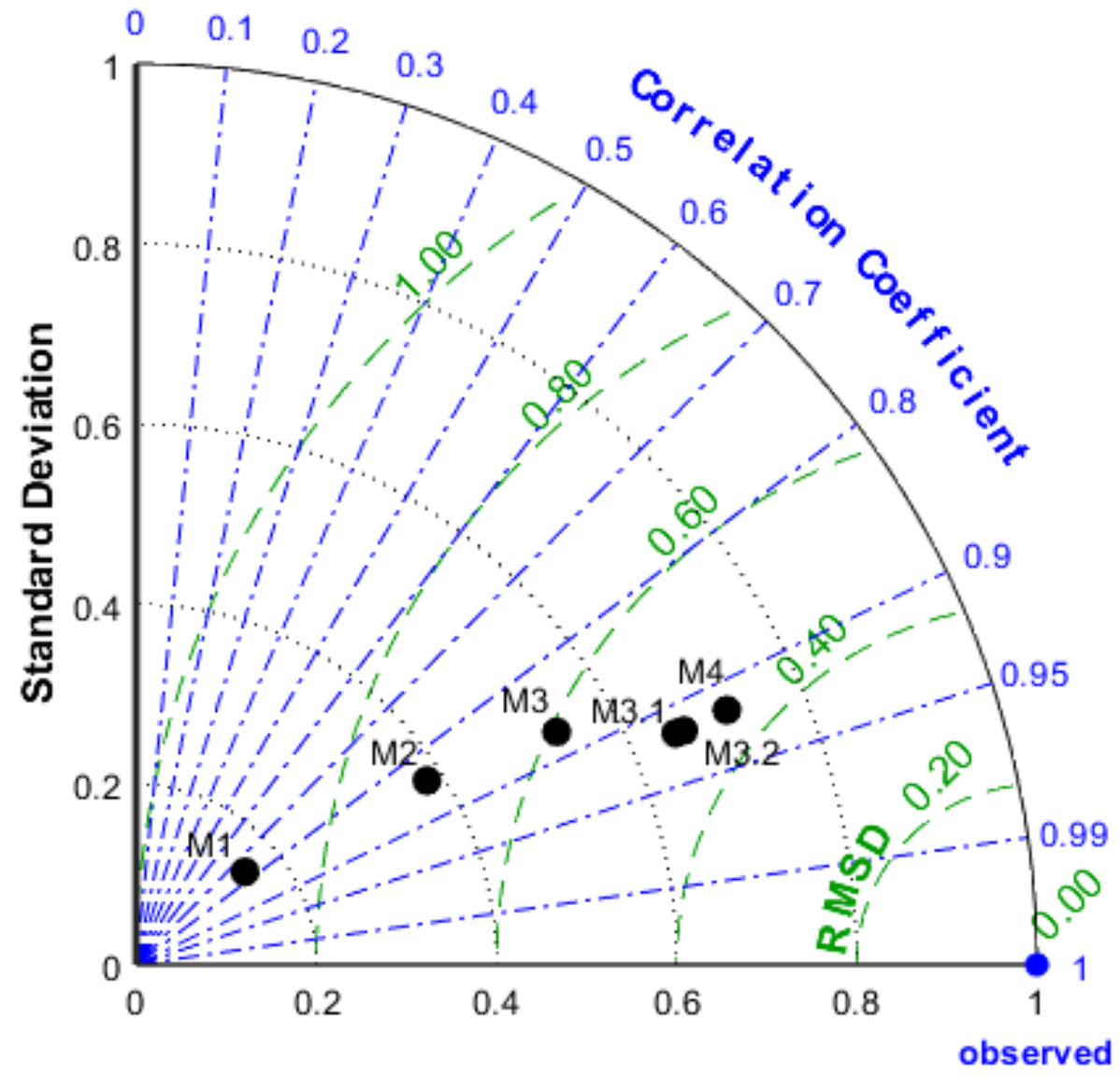

Figure 3.6 Taylor diagram (Taylor, 2001) summarizing model (M1-M4) model performance, showing centered RMS difference, correlation coefficient and standard deviations compared with measurements. The statistics have been normalized and nondimensionalized to be plotted on a single plot. The location of the blue point indicates perfect agreement with observations. 

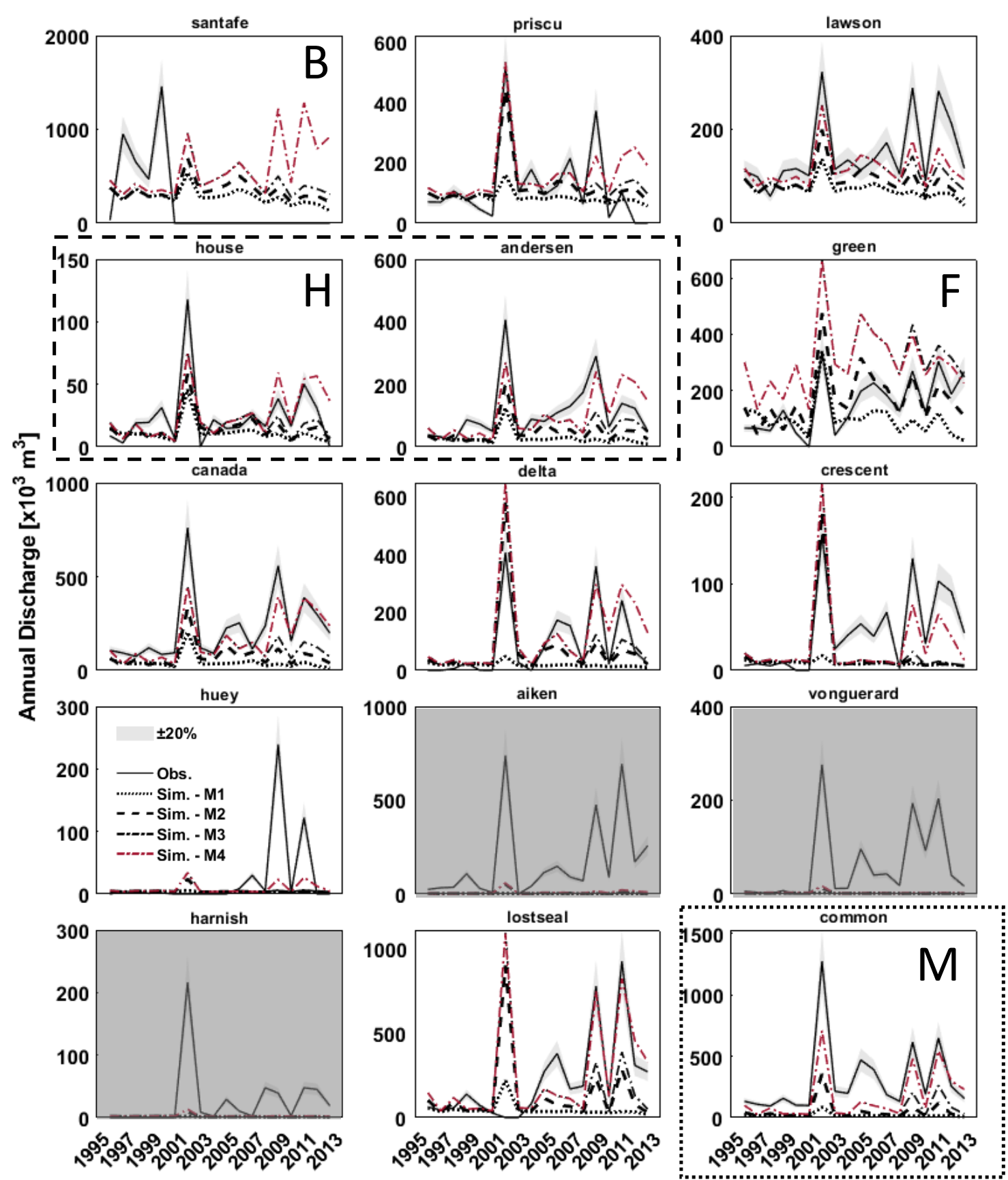

Figure 3.7 Annual discharge for each measured stream (labels above each plot) from 1996 to 2013. Streams are ordered generally by valley position west to east: (B) to Lake Bonney, (H) to Lake Hoare, (F) to Lake Fryxell, (M) to McMurdo Sound. Grey boxes indicate eastern Kukri Hills Glaciers. The solid line shows observed stream discharge with $20 \%$ measurement uncertainty displayed as grey area. Preliminary ICEMELT results (M1, dashed) and (M2, dotted) MODIS remotely-sensed albedo and subsequent modifications to ICEMELT (M3 and M4, black and red chain-dot lines, respectively). 


\section{Direct subaqueous melt}

Another possible source of meltwater to the lakes is sub-aqueous, where the glacier is in direct contact with the lake. Sub-aqueous melt occurs mostly from heat stored in the water column and to a lesser degree solar radiation that penetrates the ice cover and water column (Spigel et al. 2018). Flux estimates at Lake Bonney (Spigel et al. 2018) and Lake Untersee (Queen Maud Land, Antarctica; Faucher et al. 2019) show that sub-aqueous melt, $Q_{s a}\left(\mathrm{~m}^{3} \mathrm{yr}^{-1}\right)$, can be approximated based on the flux of ice through the area at the lake-glacier contact, assuming that the glacier terminus is stable. This can be calculated as:

$$
Q_{s a}=A_{c} * \bar{u} *\left(\frac{\rho_{i}}{\rho_{w}}\right)
$$

where $A_{c}\left(\mathrm{~m}^{2}\right)$ is the area of the lake-glacier contact, $\bar{u}\left(\mathrm{~m} \mathrm{yr}{ }^{-1}\right)$ is the mean annual horizontal ice velocity, and $\rho_{w}$ and $\rho_{i}$ are the density of water and ice $\left(870 \mathrm{~kg} \mathrm{~m}^{-3}\right.$ for Taylor Valley glaciers; Hoffman, 2011), respectively.

Sub-aqueous melt occurs where Taylor Glacier enters Lake Bonney and where Canada Glacier enters Lake Hoare. The contact between Lake Fryxell and Canada Glacier is minimal and is ignored. The terminus positions for both Canada and Taylor glaciers are assumed to be stable (Fountain et al. 2016), making Equation 11 applicable. Because both lake basins have linearly sloping sides, the lake-glacier contact area at both locations can be approximated using a trapezoid. At Taylor Glacier I use the trapezoidal geometry defined by Spigel et al. (2018) and at Canada Glacier the area was defined by a 
surface length of $1750 \mathrm{~m}$, bottom length of $400 \mathrm{~m}$ and depth of $25 \mathrm{~m}$. The geometry of Canada Glacier's contact with Lake Hoare was extracted from gridded lake bathymetric data (Obryk, personal communication, June 2019). Horizontal flow velocities at the termini of Taylor and Canada glaciers have been estimated at about $5.3 \mathrm{~m} \mathrm{yr}^{-1}$ (Pettit et al. 2014) $1.5 \mathrm{~m} \mathrm{yr}^{-1}$ (Telling et al. 2017), respectively. The results show (Table 3.5) that sub-aqueous melt rates are equivalent to $75 \%$ of the mean annual inflow from House Stream into lake Hoare $\left(24.2 \times 10^{3} \mathrm{~m}^{3}\right)$ and $25 \%$ of the mean annual inflow from Priscu Stream into Lake Bonney $\left(149.1 \times 10^{3} \mathrm{~m}^{3}\right)$.

Table 3.4 Estimated magnitude of sub-aqueous melt flux into Lakes Bonney and Hoare.

\begin{tabular}{cccllcc}
\hline Lake & $\begin{array}{c}\boldsymbol{A}_{c} \\
{\left[\mathrm{~m}^{2}\right]}\end{array}$ & $\begin{array}{c}\overline{\boldsymbol{u}} \\
{\left[\mathrm{m} \mathrm{vr}^{-1}\right]}\end{array}$ & Source & $\boldsymbol{\rho}_{\boldsymbol{i}} / \boldsymbol{\rho}_{\boldsymbol{w}}$ & $\begin{array}{c}\boldsymbol{Q}_{\boldsymbol{s a}} \\
{\left[\mathbf{1 0}^{\mathbf{3}} \mathbf{~ m}^{\mathbf{3}} \mathbf{y r}^{-\mathbf{1}}\right]}\end{array}$ \\
\hline Bonney & 6,840 & 5.00 & Fountain et al. 2004 & 0.870 & 29.8 \\
& -- & 5.30 & Pettit et al. 2014 & -- & $\mathbf{3 1 . 5}$ \\
Hoare & 24,355 & 0.97 & Telling et al. 2017 -manual & -- & 20.6 \\
& -- & 1.50 & Telling et al. 2017 - automated & -- & $\mathbf{3 1 . 8}$ \\
\hline
\end{tabular}

\section{Simulated lake-level with measured streamflow}

To minimize the various uncertainties of the hydrologic model, the lake-level model is simulated using inflows based on measured streamflow and modeled streamflow where it is not measured or where data are missing to test whether the sublimation model results are reasonable. A $\pm 20 \%$ uncertainty bound, derived from the moderate data quality rating (McKnight and Gooseff, 2016), was placed on the measured streamflow. Results showed that modeled lake-levels did not match well at Lake Bonney and Hoare, but were reasonable at Lake Fryxell up to 2008 (Figure 3.8). However, the trend in modeled lake-level change at Lakes Bonney and Hoare parallel the measured 
levels. In these results, it is most likely that the lake-level misfit is due to sublimation the sublimation rates used and I suspect that the surface roughness values used in the winter are not representative of summer conditions and as a result estimates of summer sublimation are too low.
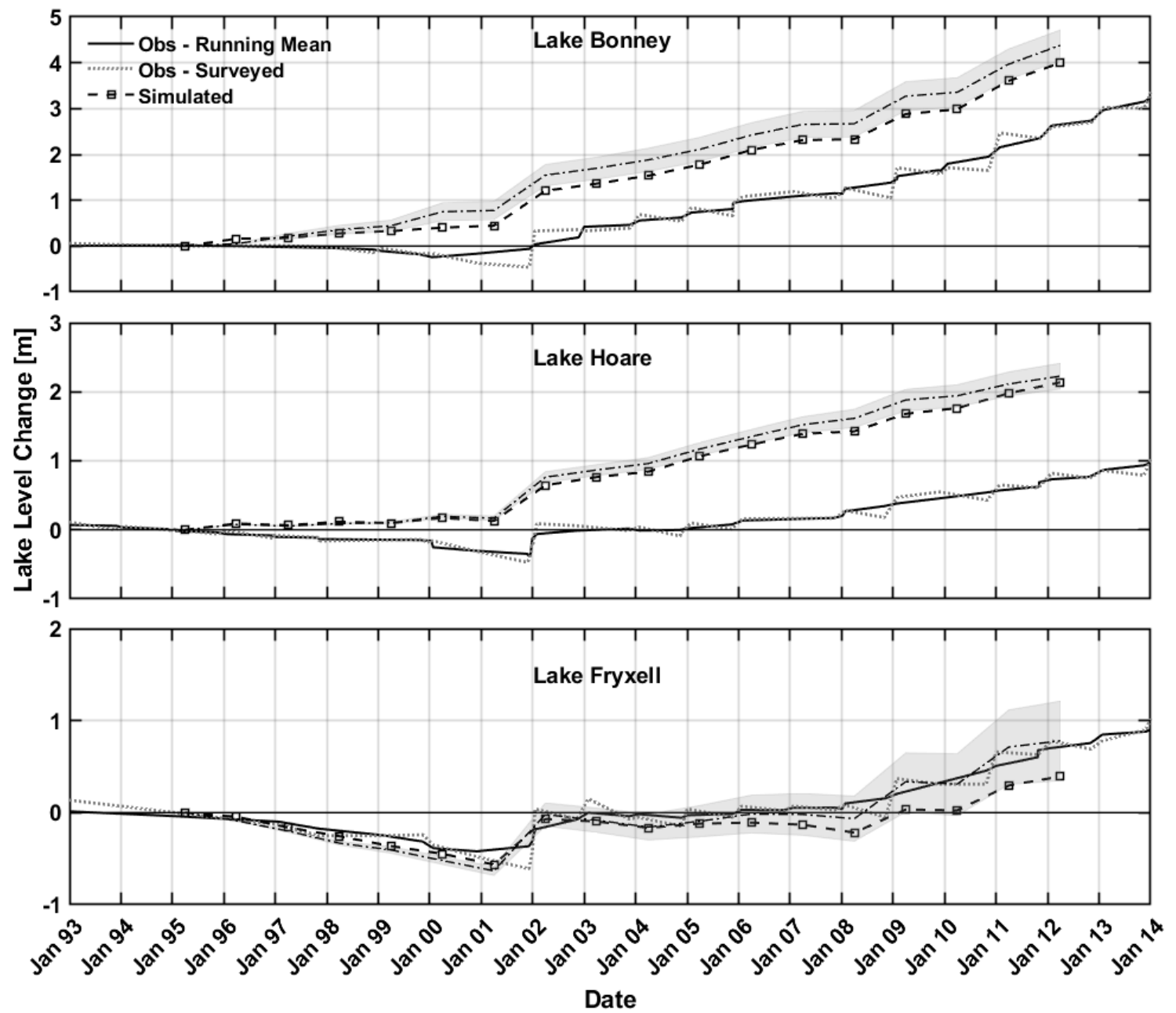

Figure 3.8 Lake-level simulated with the addition of sub-aqueous melt and the modified meltwater inflow (dashed line with symbols). Level was also simulated with measured stream inflows where available and modeled meltwater inflows otherwise (dashed line with no symbols). An upper and lower bound, based on the $\pm 20 \%$ streamflow measurement uncertainty, was applied to the stream inflow (chain-dot line bounded by grey shading). 


\section{Adjustments to summer sublimation rate}

Lake roughness length $\left(z_{0}\right)$ was increased for the summer months of December and January to account for increased roughness caused by melting in of patches of sediment and solar penetration of the ice creating a crust (Jepsen et al. 2010; Dugan et al. 2013). A seasonal cycle of surface roughness whereby ablation hollows melted into the lake ice during the summer are 'smoothed out' through preferential sublimation of the highest roughness features during the winter has been observed in the field (A.G. Fountain, personal communication, August 2019), thus it is reasonable to assume a seasonally variation in surface roughness.

The value of summer $z_{0}$ was adjusted to until the water balance at each lake was closed, resulting in values of $4 \mathrm{~mm}$ for Bonney, $12 \mathrm{~mm}$ for Lake Hoare, and $0.4 \mathrm{~mm}$ for Fryxell. The estimates of total annual sublimation, including this adjusted summer rate, were remained less than the total annual ablation measured at each lake (Figure 3.9). At Lake Fryxell this first pass adjustment to surface roughness resulted in a value very close to the winter value $(0.3 \mathrm{~mm})$. The ratio of the newly adjusted summer to original the winter (February to November) sublimation at the other two lakes was close to one (Table 3.5). By increasing the surface roughness at Fryxell to obtain a similar ratio, the result was a value of $5 \mathrm{~mm}$. Sublimation losses from Fryxell resulting from this $z_{0}$ value, however, were too high, requiring the annual sublimation rate used in the lake model to be lowered by $-0.06 \mathrm{~m} \mathrm{yr}^{-1}$ to close the water budget and match observed lake-level. Clow et al. (1988) found a similar sensitivity of estimated sublimation to surface 
roughness at Lake Hoare; an order of magnitude adjustment of $z_{0}$ in their model

corresponded to a difference in estimated annual sublimation on the order of

centimeters.

Table 3.5 Summary of estimated mean annual and seasonal sublimation rates for Taylor Valley lakes. Summer defined as per Dugan et al. (2013) as December and January. 'W' for mean winter, 'S' for mean summer, ' $S$ *' for mean summer required to balance the lake water budget at Lake Fryxell $\left(z_{0}=0.4 \mathrm{~mm}\right)$, ' $A_{S}$ ' for mean annual (with modified summer rate at Fryxell), and ' $A_{A}$ ' for annual measured ablation.

\begin{tabular}{cccccccc}
\hline Lake & & \multicolumn{2}{c}{$\begin{array}{c}\text { Sublimation } \\
{\left[\mathrm{m} \mathrm{yr}^{-1}\right]}\end{array}$} & & \multicolumn{2}{c}{$\begin{array}{c}\text { Annual } \\
\text { Ablation } \\
{\left[\mathrm{m} \mathrm{yr}^{-1}\right]}\end{array}$} & \multicolumn{2}{c}{$\begin{array}{c}\text { Ratios } \\
{[\%]}\end{array}$} \\
& $\mathbf{W}$ & $\mathbf{S}$ & $\mathbf{S}^{*}$ & $\mathbf{A}_{\mathbf{S}}$ & $\mathbf{A}_{\mathbf{A}}$ & $\mathbf{S : A}_{\mathbf{S}}$ & $\mathbf{A}_{\mathbf{S}}: \mathbf{A}_{\mathbf{A}}$ \\
\hline Bonney & 0.170 & 0.198 & -- & 0.368 & 0.494 & 54 & 74 \\
Hoare & 0.106 & 0.139 & -- & 0.244 & 0.887 & 57 & 28 \\
Fryxell & 0.110 & 0.109 & 0.049 & 0.159 & 0.654 & 24 & 24 \\
\hline
\end{tabular}

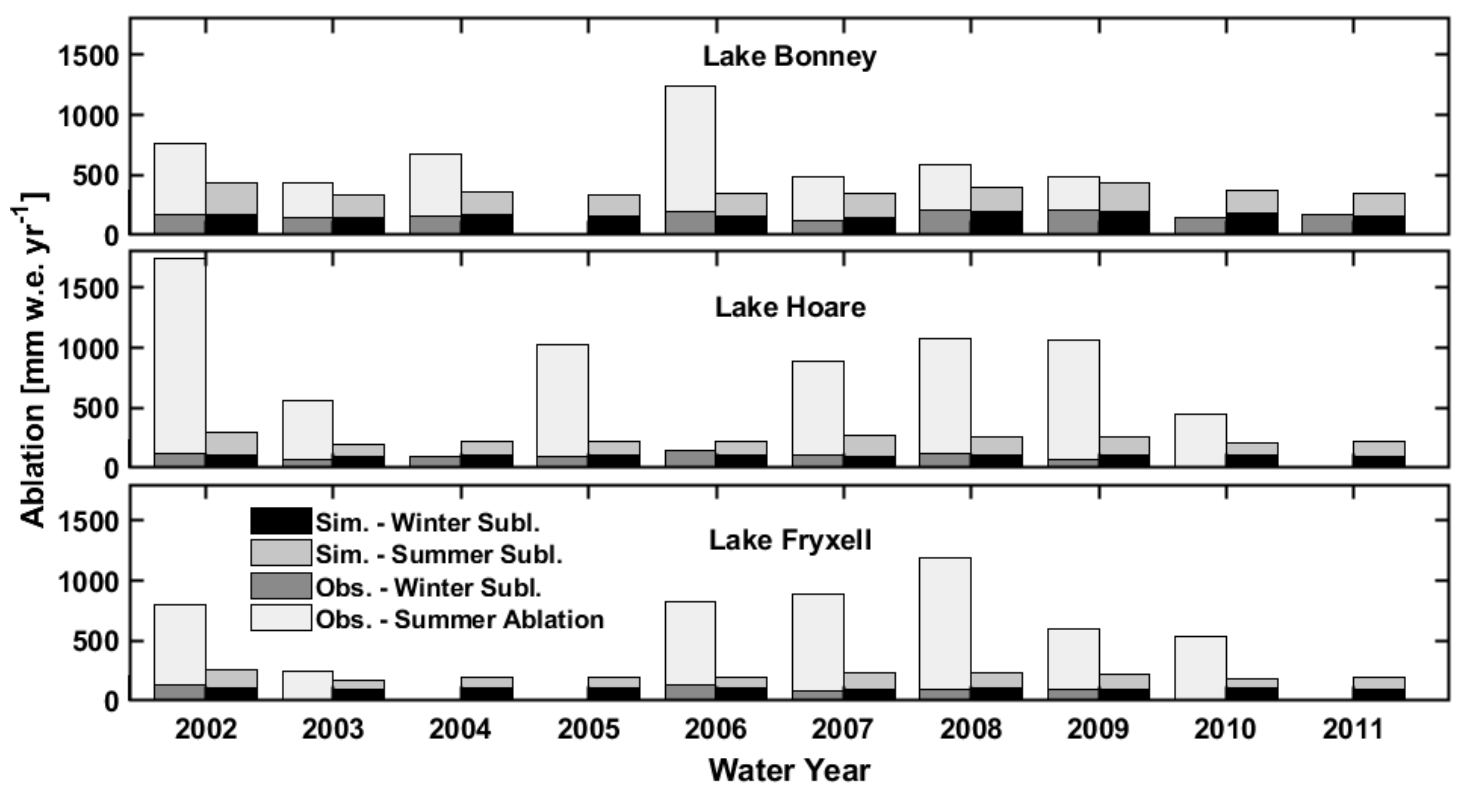

Figure 3.9 Simulated (sim.) seasonal and annual sublimation after summer surface roughness was adjusted. Values at lake Fryxell are based on $z_{0}=5 \mathrm{~mm}$. Also shown is observed (obs.) annual ablation; measured summer ablation includes both melt and sublimation. All observed values are based on based on Dugan et al. (2013). The year label on the $x$-axis indicates the austral water year (e.g. 2002 for water year from April 2001 to March 2002). 


\section{Moat evaporation loss}

To estimate the loss due to moat evaporation, I adapted the ICEMELT latent heat subroutine to estimate open-water evaporation at each lake. The water temperature was assumed to be $1^{\circ} \mathrm{C}$ and the summer surface roughness was used. The lake moats are typically open from December through January, when relatively warm streamflow is delivered to the lakes (Chinn, 1993), therefore the hourly values from the latent heat model are summed for December and January only. The estimated annual evaporative loss for each lake showed little inter-annual variability, on the order of $\pm 1 \mathrm{~cm}$, and a mean annual rate was determined for each lake (Table 3.6). It is worth noting that the estimated summer evaporation rate for Lake Hoare $(0.22 \pm 0.03 \mathrm{~m})$ is less than the rate

of $\left.0.38 \mathrm{~m} \mathrm{(6.2} \mathrm{mm} \mathrm{day}{ }^{-1}\right)$ found based on pan evaporation experiments at Lake Hoare by Gooseff et al. (2003).

To my knowledge, the geometry of lake moats in Taylor Valley have not been rigorously described. Wharton et al. (1986) estimate the diffusive loss of $\mathrm{O}_{2}$ from the unfrozen moat at Lake Hoare based on a moat width of $5 \mathrm{~m}$. Assuming that the moat width is $5 \mathrm{~m}$ and that the lake perimeter does not vary significantly from the average perimeter, the moat areas at each lake were determined to be $\sim 2 \%$ of the total lake area. The moat area was multiplied by the estimated evaporation rate to calculate an annual evaporative loss from each lake. This evaporative loss is $\sim 2 \%$ of the mean annual loss due to lake ice sublimation for each lake, consistent with the relative area of the moats (Table 3.6). The magnitude of this loss is small enough to be considered within the uncertainty of the estimated lake budget and is ignored. 
Table 3.6 Estimated evaporation loss from lake moats. The estimated evaporation rate $(E)$ is applied to moat surface area $\left(A_{M}\right.$, based on the lake perimeter $\left.P_{L}\right)$. The ratio of moat area versus lake area $\left(A_{L}\right)$ and the ratio of the estimated annual losses due to evaporation $\left(L_{E}\right)$ versus sublimation $\left(L_{S}\right)$ are shown.

\begin{tabular}{ccccccc}
\hline & $\begin{array}{c}\mathrm{E}(\mathrm{SD}) \\
{\left[\mathrm{m} \mathrm{yr} \mathbf{r}^{-1}\right]}\end{array}$ & $\begin{array}{c}\mathbf{P}_{\mathrm{L}} \\
{[\mathrm{km}]}\end{array}$ & $\begin{array}{c}\mathbf{A}_{\mathrm{M}} \\
{\left[\times \mathbf{1 0}^{4} \mathbf{m}^{2}\right]}\end{array}$ & $\begin{array}{c}\mathbf{A}_{\mathrm{M}}: \mathbf{A}_{\mathrm{L}} \\
{[\%]}\end{array}$ & $\begin{array}{c}\mathrm{L}_{\mathrm{E}} \\
{\left[\times 10^{4} \mathbf{m}^{3} \mathbf{y r}^{-1}\right]}\end{array}$ & $\begin{array}{c}\mathrm{L}_{\mathrm{E}}: \mathrm{L}_{\mathrm{S}} \\
{[\%]}\end{array}$ \\
\hline Bonney & $0.30( \pm 0.03)$ & 16 & 8.0 & 1.8 & 2.4 & 1.5 \\
Hoare & $0.22( \pm 0.03)$ & 10 & 5.0 & 2.3 & 1.1 & 2.1 \\
Fryxell & $0.20( \pm 0.03)$ & 19 & 9.5 & 1.4 & 1.9 & 1.8 \\
\hline
\end{tabular}

\section{Simulated Taylor Valley water budget}

Lake-levels simulated with the M4 model, plus the inclusion of sub-aqueous melt (referred to as MM4), and the modified sublimation estimates results in predicted lakelevels that are close to observations (Figure 3.10). For all lakes, levels simulate the drop from 1995 to 2001 until the 2002 increase following the flood-year and subsequent rise. Starting in 2008 the simulated lake-level drops below observed levels.

Cumulative daily inflow and sublimation loss (Figure 3.11) show the modeled water balance in detail. Sharp increases in the cumulative curves indicate the short periods of summer melt inflow and increased sublimation. The high inter-annual variability of meltwater inflow, compared to sublimation loss, is visibly the primary control on lake-level variability. 


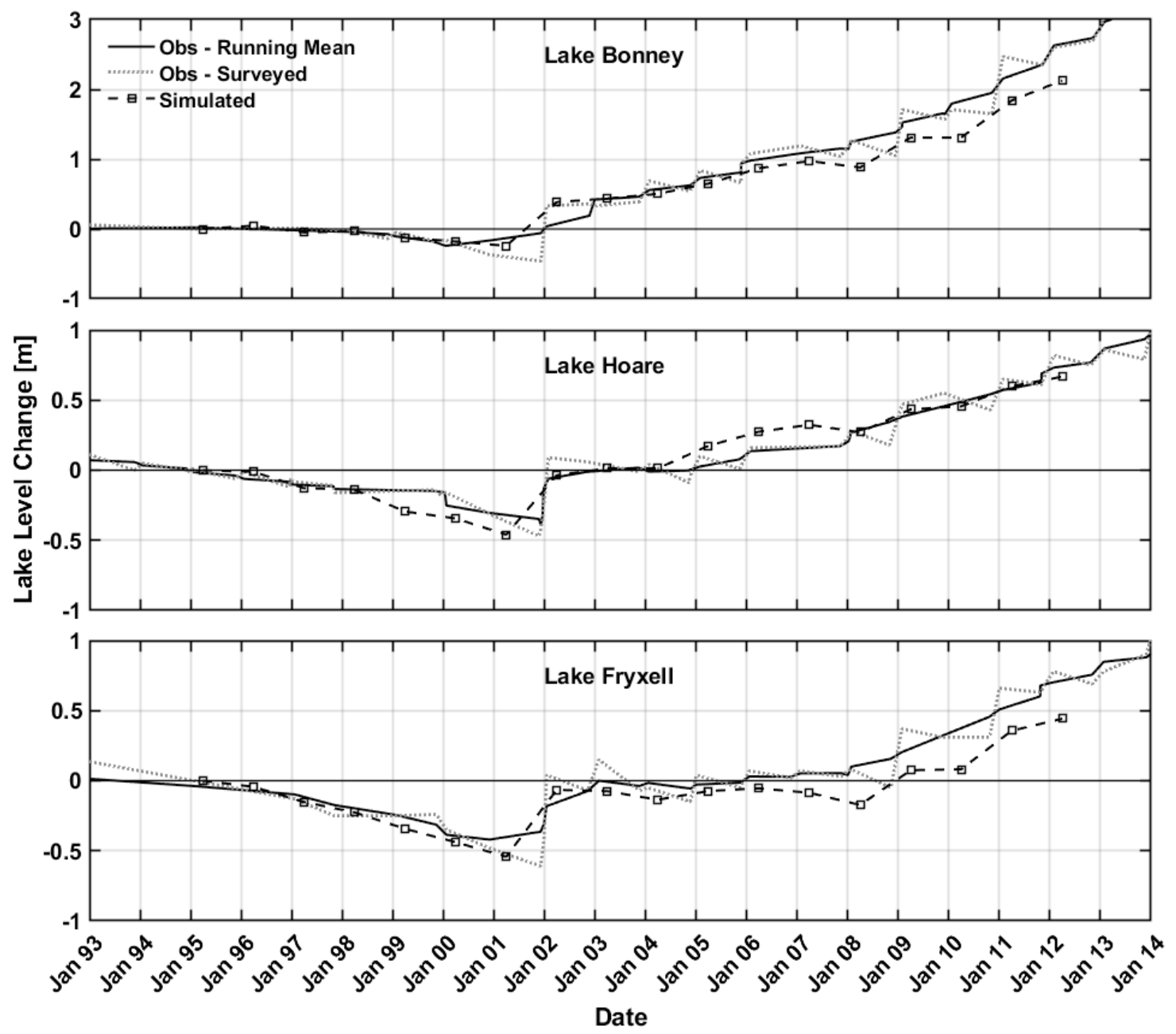

Figure 3.10 Lake-level simulated with modified inflows (MM4) and losses (dashed line with symbols). See Figure 3.8 caption.

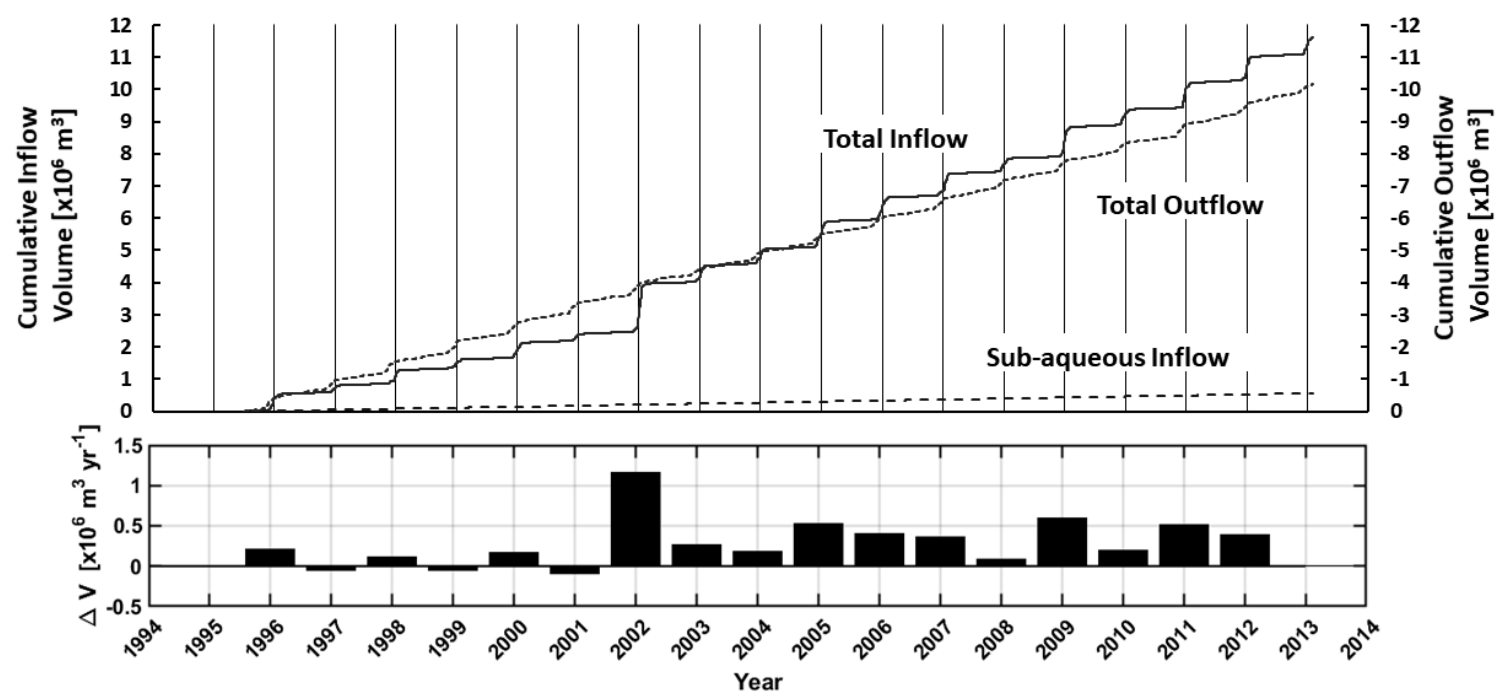

Figure 3.11 Cumulative daily inflow and sublimation loss (outflow) for Lake Hoare. 


\subsection{Analysis}

The water balance model can be used to describe the relative proportion of inflows to each lake. Based on MM4, streamflow through gauged streams makes up $31 \%$, $22 \%$ and $72 \%$ of total inflows to the lakes (Bonney, Hoare, and Fryxell). Sub-aqueous melt contributes $1 \%$ and $5 \%$ to Lakes Bonney and Hoare, respectively, while the remaining melt arrives to the lakes from contributing areas that drain directly to the lake or through ungauged streams (Table 3.7).

Table 3.7 Mean (1996-2013) annual inflow from various sources based on the simulated water budget for Taylor Valley lakes.

\begin{tabular}{|c|c|c|c|c|c|c|c|}
\hline & \multicolumn{4}{|c|}{$\begin{array}{l}\text { Mean Annual Volume } \\
{\left[\times 10^{5} \mathrm{~m}^{3} \mathrm{yr}^{-1}\right]}\end{array}$} & \multicolumn{3}{|c|}{$\begin{array}{c}\text { Proportion of Mean Annual Total } \\
{[\%]}\end{array}$} \\
\hline & Stream & Direct & $\begin{array}{c}\text { Sub- } \\
\text { aqueous }\end{array}$ & Total & Stream & Direct & $\begin{array}{c}\text { Sub- } \\
\text { aqueous }\end{array}$ \\
\hline Bonney & 6.92 & 15.29 & 0.32 & 22.21 & 30 & 69 & 1 \\
\hline Hoare & 1.39 & 4.55 & 0.32 & 6.25 & 22 & 73 & 5 \\
\hline Fryxell & 9.39 & 3.66 & 0.00 & 13.05 & 72 & 28 & 0 \\
\hline
\end{tabular}

The sensitivity of the lake-level response to basin geometry can be explored using model output. The 2002 flood-year marks a hydrological regime shift from a period of lower inflows and lake-level lowering, to higher inflows and lake-level rise, so this analysis is made for two periods, one before and one after 2002. The total volumetric input and loss for each lake was calculated for the period before 2002 and the period from 2002 onwards. To highlight the effect of hypsometry, the net-volume change over this period is divided by the 2001 lake area (the smallest area in the record). This value $(\Delta h)$ is equal to the expected lake-level change if the basin geometry were a 'well' with a constant area equal to the 2001 lake area. This theoretical level change is compared to the modeled level change given true basin hypsometry $(\Delta \mathrm{z}$; Table 
3.8). Values of the ratio $\Delta z: \Delta h$ closer to 1 suggest more vertical walls and a larger

'hypsometric effect'.

Table 3.8 Lake-level sensitivity to basin hypsometry. Inflow (I), losses (L) and net volume change $\left(\Delta V_{N E T}\right)$ are pre- and post-2002 total values. Lake area $\left(A_{L}\right)$ is from 2001 , the smallest lake area in the record. The mean annual inflow (I divided by the number of years) divided by the glacier contributing area to each lake $\left(A_{C}\right)$ gives the mean annual specific melt (M) for each lake catchment. The theoretical height change $\Delta h$ of the lakes, ignoring basin hypsometry is $\Delta V_{N E T}$ divided by the area. The ratio of the theoretical height change and the observed height change $\Delta z$ is the hypsometric effect (last column).

\begin{tabular}{|c|c|c|c|c|c|c|c|c|c|}
\hline & \multicolumn{9}{|c|}{ Pre-2002 } \\
\hline & 1 & $\mathbf{L}$ & $\Delta \mathbf{V}_{\mathrm{NET}}$ & \multirow{2}{*}{\multicolumn{2}{|c|}{$\begin{array}{c}A_{L} \quad A_{C} \\
{\left[\times 10^{6} \mathrm{~m}^{2}\right]}\end{array}$}} & $M$ & $\Delta h$ & $\Delta z$ & \multirow{2}{*}{$\begin{array}{c}\Delta z: \Delta h \\
{[-]}\end{array}$} \\
\hline & \multicolumn{3}{|c|}{$\left[\times 10^{6} \mathrm{~m}^{3}\right]$} & & & \multicolumn{3}{|c|}{$[\mathrm{m}]$} & \\
\hline Bonney & 8.78 & 9.85 & -1.07 & 4.38 & 52.69 & 0.028 & -0.245 & -0.237 & 0.965 \\
\hline Hoare & 2.32 & 3.32 & -1.00 & 2.10 & 5.19 & 0.075 & -0.476 & -0.417 & 0.875 \\
\hline \multirow[t]{4}{*}{ Fryxell } & 2.72 & 7.10 & -4.38 & 6.88 & 16.75 & 0.027 & -0.636 & -0.596 & 0.938 \\
\hline & \multicolumn{9}{|c|}{ Post-2002 } \\
\hline & 1 & $\mathbf{L}$ & $\Delta \mathbf{V}_{\mathrm{NET}}$ & $A_{L}$ & $A_{c}$ & $M$ & $\Delta \mathbf{h}$ & $\Delta z$ & $\Delta \mathrm{z}: \Delta \mathrm{h}$ \\
\hline & \multicolumn{3}{|c|}{$\left[\times 10^{6} \mathrm{~m}^{3}\right]$} & \multicolumn{2}{|c|}{$\left[\times 10^{6} \mathrm{~m}^{2}\right]$} & \multicolumn{3}{|c|}{ [m] } & {$[-]$} \\
\hline Bonney & 28.65 & 17.96 & 10.69 & 4.38 & 52.69 & 0.049 & 2.439 & 1.752 & 0.718 \\
\hline Hoare & 8.37 & 5.77 & 2.60 & 2.10 & 5.19 & 0.147 & 1.188 & 0.868 & 0.730 \\
\hline Fryxell & 22.31 & 11.62 & 10.70 & 6.88 & 16.75 & 0.121 & 1.529 & 0.745 & 0.487 \\
\hline
\end{tabular}

For the period after 2002, lake-level rise in the Bonney basin, followed closely by Hoare, shows the largest hypsometric effect. Both these basins are steeper than the Fryxell basin. The deepest part of Lake Hoare $(\sim 30 \mathrm{~m})$ is where the lake abuts Canada Glacier, creating a near vertical wall on this side. The large values of $\Delta z: \Delta h$ prior to 2002 , compared to the later period, are the result of very small lake-level changes over this period $(<0.5 \mathrm{~m})$.

Lake water budgets are primarily controlled by meltwater inflow (Figure 3.11), so the lake-level response can also be considered in terms of relative inflow to each lake. The mean annual inflow to each lake for both the pre- and post-2002 period is divided 
by the contributing area ( $A_{c}$; i.e. glacier ablation zones) to determine the mean annual specific melt (M) in each basin. The specific melt in the Bonney basin after 2002 is less than half of that for both Lakes Hoare and Fryxell, however, the total contributing area is much larger (an order of magnitude greater compared to Lake Hoare), making the overall inflow to Lake Bonney larger.

Finally, given post-flood year conditions, lake-level change can be projected through the end of the century. Estimates of future lake-level change are of importance to the MCM-LTER and USAP as key infrastructure, e.g. field camps and helicopter landing sites, to support USAP science operations are located only a few meters above current lake-levels. Estimates of future lake-levels could inform whether this infrastructure will need to be relocated away from rising lake-levels.

For each lake the mean annual inflow and sublimation loss rates were derived from the modeled period. Mean values were calculated for the entire 1996-2013 period as well as a pre-2002 (cool period) and post-2002 period (warm period). The lake-level model was run over the course of 90 years. If post- 2002 conditions were to persist the lakes would continue to rise through 2100, reaching $76 \mathrm{~m}$ asl (+14 m from 1995 datum) at Lake Bonney, $80 \mathrm{~m}$ asl $(+6 \mathrm{~m})$ at Lake Hoare, and $23 \mathrm{~m}$ asl $(+5 \mathrm{~m})$ at Lake Fryxell. The Hoare basin is separated from the Fryxell basin by a sill at $\sim 93 \mathrm{~m}$ asl along the piedmont lobe of Canada Glacier. Lake Hoare does not reach its spill-over point to Lake Fryxell by the end of the century under current conditions. Based on the pre-2002 conditions, lake-levels drop at all lakes through the end of the century. 


\section{Chapter 4. Discussion \& Conclusions}

Following Hoffman (2011), the ICEMELT model was used to predict meltwater runoff in Taylor Valley streams. The physical basis and hourly resolution of ICEMELT allow for efficient prediction of daily runoff dynamics when compared to previous meltwater modelling efforts in Taylor Valley (Dana et al. 2002; Ebnet et al. 2005). Furthermore, ICEMELT's skill in predicting daily runoff confirm the appropriateness of a simplified (same-day) routing scheme to the streams, a feature recognized by Hoffman (2011). Results show that predicted streamflow was generally better for streams in the Hoare and Bonney basins. Hoffman et al. (2016) attribute ICEMELT skill in predicting ablation on Canada and Taylor glaciers due to their proximity to calibration sites and the meteorological stations where albedo was used. These results show a more nuanced pattern in ICEMELT's ability to predict streamflow; predictive skill on Fryxell glaciers is varied from moderate skill on Howard and Commonwealth glaciers and poor skill on glaciers in the eastern Kukri Hills.

One deficiency of ICEMELT was the use of two point measurements of albedo rather than a spatially representative measure. I included a MODIS remotely-sensed albedo product into ICEMELT (M2), which improved daily and annual predictions of streamflow at nearly all streams from 2000 (first availability) to 2008, particularly during the 2002 flood-year. The spatial variability of albedo between glaciers was found to be high (Appendix A Figures A.4-6) and by accounting for this variability using MODIS albedo, $\mathrm{M} 2$ shows significant improvement. When compared to total annual observed streamflow, M2 predicted $7.71 \times 10^{5} \mathrm{~m}^{3}$ ( $2 \%$ of all gauged streamflow) less meltwater in 
all gauged streams $\left(5.14 \times 10^{4} \mathrm{~m}^{3}\right.$ less, or $40 \%$ of average total streamflow) over the course of the 1996-2013 modeling period, a larger fraction of this error resulting from under-prediction in the Fryxell basin. Further modifications to daily albedo values were made, including lowering albedo $-7 \%(\mathrm{M} 3)$, an adjustment within the instrumental uncertainty, and by $-30 \%$ after 2008 (M4).

Two primary deficiencies in the ICEMELT predicted streamflow (M1-M4) are immediately apparent. First, ICEMELT predicts essentially no meltwater discharge into Huey, Aiken, VonGuerard and Harnish streams all, the exception being during 2002, but the predicted melt this year is still significantly less than measured. Inflows from these streams account for $28 \%$ of the total measured stream inflows to Lake Fryxell. Considering the ungauged meltwater runoff from Commonwealth Glacier, this proportion is likely a bit lower, but still represents a significant amount in the lake water budget. Second, the high-melt water years of 2009 and 2011 are consistently underestimated across Taylor Valley. These years represent the second $\left(4.64 \times 10^{6} \mathrm{~m}^{3}\right)$ and third $\left(4.24 \times 10^{6} \mathrm{~m}^{3}\right)$ highest melt years after the 2002 flood-year $\left(5.53 \times 10^{6} \mathrm{~m}^{3}\right)$, respectively.

The cause for ICEMELT bias at Huey, Aiken, VonGuerard, and Harnish streams is unclear. Except for Huey Creek, which flows from a small ice and snow patch in a low saddle of the Asgard range, Aiken, VonGuerard and Harnish streams flow from small unnamed glaciers in the Kukri Hills. The similar behavior from the glacier feeding Huey Creek (south facing) and the Kukri Hills glaciers suggest that this issue is likely not due the north facing aspect of the Kukri Hills glaciers. Furthermore, both Delta and Crescent 
streams flow from the south-facing Kukri Hills, albeit from larger contributing areas, and do not show the same bias, making it less likely that this is an issue relating to the distribution of incoming shortwave radiation by MICROMET. To test whether this underprediction was the result of mapped contributing areas that were two small in the model, the smooth ice source area was doubled. This resulted in a negligible increase in melt, even during 2002.

These glaciers showed little sensitivity to ad hoc increases in albedo, surface roughness and net radiation, suggesting instead that ice temperatures at these locations were low enough to preclude melt, except for the warmest conditions found during the 2002 melt year.

While these sites are not situated at the same aspect they are all at similarly high elevations (relative to other glacier areas in the Fryxell basin). It is possible that the adiabatic lapse rate used by MICROMET is not applicable to this region. Perhaps if a lapse rate closer to the wet adiabatic rate was used in the Fryxell basin, due to its proximity to the moist coastal air, these higher elevation sites would experience warmer temperatures than are currently estimated.

The ICEMELT model markedly under-estimates 2009 and 2011 melt for all streams in Taylor Valley, suggesting environmental conditions during these years were poorly represented. Hoffman et al. (2016) recognized this bias in comparisons of modeled ablation to stake measurements. They hypothesized that fine, wind-blown sediments were incorporated into the subsurface (weathering crust) sometime between 2006 and 2007. Decreasing measured albedo by -0.08 (-5.5\% on average) to 
$-0.10(-6.8 \%)$ rectified the match between modeled and measured ablation. While this decrease to albedo allowed for prediction of ablation, this study shows that further decrease was required. A reduction of albedo by $-7 \%$ (-0.05 on average) prior to 2008 and $-30 \%$ after 2008 was required to remove model bias in predicting streamflow. Lowering albedo by $-30 \%$ is equivalent to a reduction in albedo of -0.16 and -0.21 for mean summer (DJF) MODIS and station albedo, respectively (Table 3.4). While these adjustments vary from each other based on the albedo measured any particular day, they show that an increase of net shortwave radiation those years can remove model bias.

In addition to a reduction in albedo by $-30 \%$ after 2008 , the aerodynamic surface roughness $\left(z_{0}\right)$ was increased in the Fryxell basin to $1 \mathrm{~mm}$. This increase is based on observations on Commonwealth and Howard glaciers of wind distributed sediment (A.G. Fountain, personal communication, July 2019) and algae (Sommers et al. 2019) increasing the surface roughness of flat glacier ice surfaces. Additionally, the reduction in albedo was not applied to cliffs or micro-topographic basins. Albedo adjustments for micro-topographic basins were parameterized by Hoffman (2016) and thus a further reduction was not appropriate. Furthermore, fine sediment would not accumulate on cliff walls and what does accumulate in basins would drain through the subsurface weathering crust to accumulate in $\sim 1 \mathrm{~m}$ deep pools at the base of the basins. Further work needs to be undertaken to study the albedo variation in Taylor Valley and its root causes. 
Another explanation for model under-prediction in 2009 and 2011 is an increase in net radiation these years due to low-level cloud cover. This effect, referred to as the 'radiation paradox' (Ambach 1974), has been described over high albedo ice areas in Greenland and elsewhere in Antarctica (Bintanja and van den Broeke 1996; van den Broeke et al. 2008). On days with low clouds over high albedo ice surfaces, the net SW cloud-effect is limited while the net LW cloud-effect increases net all-wave radiation. By counting the number of days with cloud-free values for the MODIS pixel co-located to each glacier meteorological station a rough estimate of the relative cloudiness of each season can be derived (Appendix E Figure E.3). No clear pattern of increased clouds during 2009 and 2011 can be made, but incoming long-wave radiation estimated by MICROMET is lower after 2008 than most years prior to 2008, perhaps suggesting these estimated values are too low. To explore this possibility net radiation was increased by $+20 \mathrm{~W} \mathrm{~m}^{-2}$, a value roughly equivalent to the difference in mean incoming longwave before and after 2008 (Appendix B Figure B.2). This increase had some effect on modelled meltwater, but didn't make up the 2009 and 2011 deficits. An improved cloud climatology of Taylor Valley is needed to explore the SW and LW cloud effect, particularly these years, to properly estimate their effect on net radiation and thus ablation. The GEE techniques described in Appendix A of this study could be adapted to build such a cloud climatology based on daily MODIS imagery.

The actual partitioning of summer ablation still remains unknown, but in lieu of direct measurement of the vapor flux over the lakes or a full, physically-based lake ice ablation model, this study is the first to make estimates of summer sublimation rates. 
The mean annual estimated sublimation at Lakes Bonney, Hoare, and Fryxell required to balance the water budgets were $0.37 \mathrm{~m} \mathrm{yr}^{-1}, 0.24 \mathrm{~m} \mathrm{yr}^{-1}$ and $0.16 \mathrm{~m} \mathrm{yr}^{-1}$, accounting for $74 \%, 28 \%$ and $24 \%$ of total ablation measured by Dugan et al. (2013), respectively (Table 3.6).

To consider sublimation more carefully, I examine the loss from Lake Hoare because meltwater inflows are best constrained and therefore loss is better constrained. Dugan et al. (2013) state that Lake Hoare had the highest rates of summer ablation, $0.89 \mathrm{~m} \mathrm{yr}^{-1}$ on average from 2001-10 (compared to $0.65 \mathrm{~m} \mathrm{yr}^{-1}$ at Lake Fryxell and $0.52 \mathrm{~m} \mathrm{yr}^{-1}$ at Lake Bonney), and that it is a result of sediment loading increasing surface roughness. Indeed, of the three Taylor Valley lakes, Lake Hoare has the highest aeolian flux of sediment (Šabacká et al. 2010). Our results agree qualitatively with Dugan et al. (2013). My estimated mean annual sublimation rate for Lake Hoare of $0.24 \mathrm{~m} \mathrm{yr}^{-1}$, is less than the $0.35 \mathrm{~m} \mathrm{yr}^{-1} \pm 6.3 \mathrm{~cm}$ estimated by Clow et al. (1988) for Lake Hoare in 1986. Dugan et al. (2013) noted that the 1986 winter was an outlier in terms of average wind speed $\left(\sim 3.3 \mathrm{~m} \mathrm{~s}^{-1}\right)$ compared to the 10 years of their study (median $\sim 2.6 \mathrm{~m} \mathrm{~s}^{-1}$ ) suggesting that my values is not out of line from that of Clow et al. (1988).

One important challenge to correctly simulating lake ice ablation is the effect of solar warming of the surface due to the lower albedo of wind-deposited sediment patches (Clow et al. 1988; Jepsen et al. 2010; Dugan et al. 2013). The sediment can raise surface temperatures to the melting point during periods when the otherwise cool air temperatures would keep them frozen, allowing evaporation to occur. A positive feedback also occurs between solar warming and sublimation as sediment patches 
deepen hollows into the lake ice surface (Figure 4.1), increasing the aerodynamic roughness and thereby increasing sublimation of the tips of the roughness features. While the effect of lower albedo of sediments on summer lake ice ablation is not explicitly modeled in this study, it's importance in driving losses due to evaposublimation are inferred through the required increase to summer surface roughness.

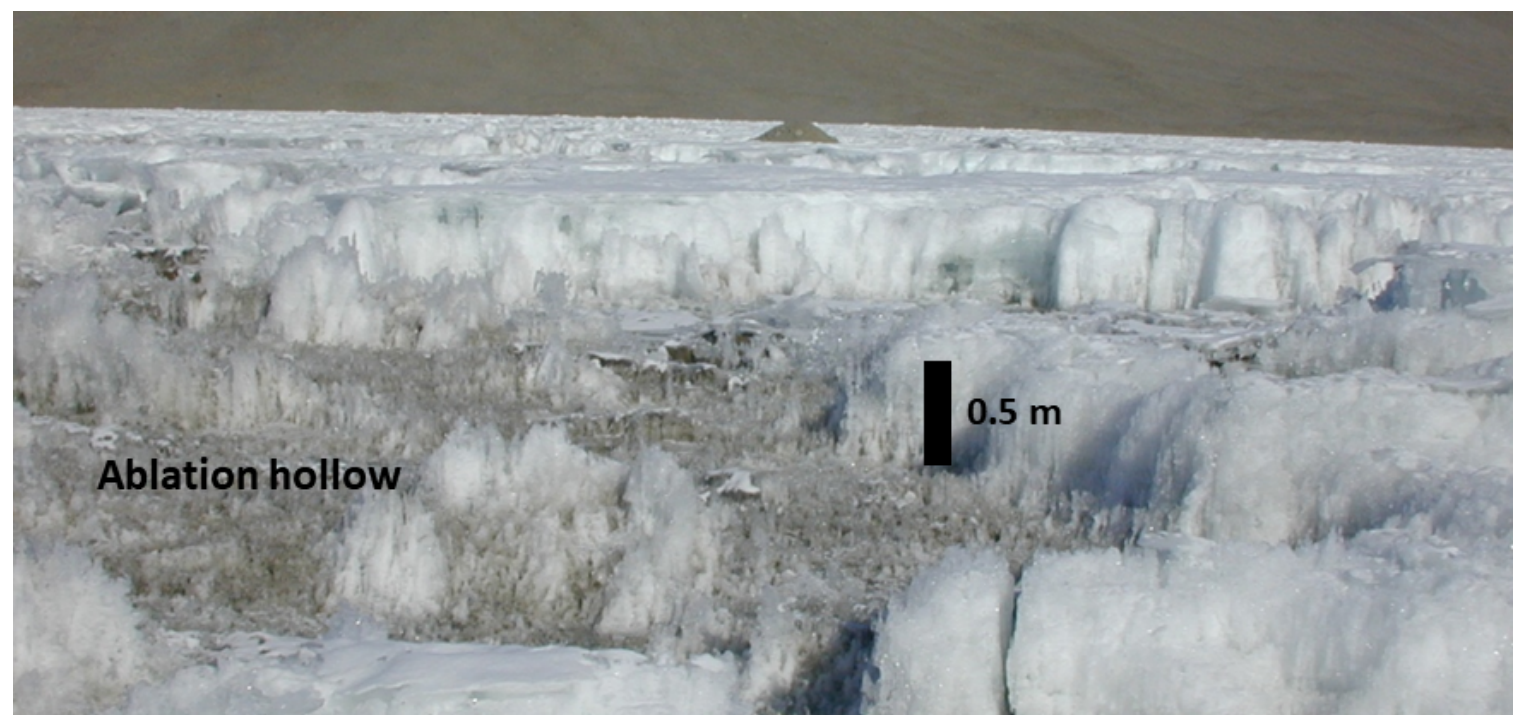

Figure 4.1 Example of a $0.5 \mathrm{~m}$ deep ablation hollow on the ice cover of Lake Hoare (photo courtesy of A.G. Fountain).

The summer surface roughness values required to close lake water budgets Lakes Bonney, Hoare and Fryxell were $4 \mathrm{~mm}, 12 \mathrm{~mm}$, and $0.4 \mathrm{~mm}$, respectively. In modelling the decay of lake ice in the Canadian Arctic, Heron and Woo (1994) report a $z_{0}$ value of $4.5 \pm 1.5 \mathrm{~mm}$, which is close to the value determined for Lake Bonney. The appropriateness of these $z_{0}$ values can also be considered relative to other published surface roughness values applied to model glacier surface energy balance. Brock et al. 2006 compiled published $z_{0}$ values derived through semi-direct means, e.g. wind profiles, eddy covariance, or micro topographic measurement techniques, or inferred as 
a residual in a closed energy balance. Values on the order of $1 \mathrm{~mm}$ are common for summer ice surfaces in Greenland while values on the order of $10 \mathrm{~mm}$ have been documented on rough ice on mid-latitude glaciers (Brock et al. 2006). Furthermore, field observations in Taylor Valley corroborate that summer lake ice surfaces are notably rougher than glacier surfaces.

Summer lake roughness values can also be examined relative to each other. Using 1 m LIDAR (Fountain et al. 2015), the standard deviation of elevation values within a 3by-3 cell moving window was calculated on a cell-by-cell basis (Appendix D Figure D.3). The mean roughness values (standard deviation of elevation) determined for each lake based on this method were $35 \mathrm{~mm}, 48 \mathrm{~mm}$, and $45 \mathrm{~mm}$ for Lakes Bonney, Hoare, and Fryxell, respectively. These values provide a proxy measure for the aerodynamic roughness $\left(z_{0}\right)$ and substantiate field observations that the ice surface at Lake Bonney is less rough than the other two lakes. It is interesting that the $z_{0}$ value required to close the water budget at Lake Fryxell is two orders of magnitude less than for Lake Hoare and out of line with the relative magnitude of roughness determined from the LIDAR, suggesting that the lower roughness value required here is the result of meltwater inflow deficit into Lake Fryxell.

The higher ratio of mean annual sublimation to total ablation at Lake Bonney is consistent with the documented climate gradients in Taylor Valley (Doran et al. 2002; Fountain et al. 2010; Nylen et al. 2004), with windier, drier and warmer conditions found further from the coast. Mean summer (December and January) sublimation accounted for $\sim 50 \%\left(0.20 \mathrm{~m} \mathrm{yr}^{-1}\right.$ and $\left.0.14 \mathrm{~m} \mathrm{yr}^{-1}\right)$ of estimated mean annual sublimation 
at Lakes Hoare and Bonney and $~ 30 \%\left(0.05 \mathrm{~m} \mathrm{yr}^{-1}\right)$ at Lake Fryxell, in-line with the finding by Clow et al. (1988), who found that the majority of sublimation occurs during the summer. The high proportion of summer sublimation at Lakes Hoare and Bonney, relative to Fryxell, is a function of the uncertainty in the Fryxell water budget, highlighted earlier, which required summer sublimation to be lowered by $-0.06 \mathrm{~m} \mathrm{yr}{ }^{-1}$. The implied mean annual inflow deficit, based on the average surface area of Lake Fryxell, is $\sim 4 \times 10^{4} \mathrm{~m} \mathrm{yr}^{-}{ }^{1}$, this value is close to the mean annual contribution from Aiken, VonGuerard and Harnish streams into Lake Fryxell $\left(2.6 \times 10^{4} \mathrm{~m} 3 \mathrm{yr}^{-1}\right)$.

Mean annual glacier ablation (both melt and sublimation), measured at the ablation stake nearest each lake, provide some constraint on lake ice sublimation. Assuming sublimation accounts for $30 \%$ of ablation (Hoffman et al. 2016), we find 0.23 $\pm 0.055 \mathrm{~m}$ w.e. $\mathrm{yr}^{-1}$ at Taylor Glacier, $0.16 \pm 0.080 \mathrm{~m}$ w.e. $\mathrm{yr}^{-1}$ on the west side of Canada Glacier near Lake Hoare and $0.11 \pm 0.073 \mathrm{~m}$ w.e. $\mathrm{yr}^{-1}$ at Commonwealth Glacier (A.G. Fountain, personal communication, July 2019). While these measured glacier sublimation values are close to those presented in this study, the discrepancy is likely due to the greater aerodynamic roughness and lower elevation of the lake ice compared to the glacier surface. Additionally, the estimated lake sublimation may be more than these glacier sublimation values due to the inclusion of loss from the lake model that occurs through evaporation, either from lake moats or wetted margins.

Northcott et al. (2009) show that lake wetted margins extend from $2 \mathrm{~m}$ (Lake Hoare) to 10 m (Lake Fryxell). These zones likely increase the area where evaporation can occur. Moat evaporation was estimated for a range of different widths to explore 
the effect of lake wetted margins in extending the effective zone of evaporation. Experimenting with widths from $1 \mathrm{~m}$ to $15 \mathrm{~m}$ resulted in estimated annual evaporative losses ranging from $\sim 0.3 \%$ to $7 \%$ of mean annual sublimation loss, respectively. The magnitude of these losses are small and within the uncertainty of the lake model.

Estimated lake water budgets provide insight into the relative inflow contributions from various sources. The volume of direct, ungauged inflows to the lakes are $69 \%, 73 \%$, and $28 \%$ for Lakes Bonney, Hoare and Fryxell, respectively. To my knowledge these figures are the first estimates of direct inflow and have importance for modelling biogeochemical fluxes to the lakes and ecosystem response (Gooseff et al. 2011; Spigel et al. 2018). It is also notable that at Lake Hoare, direct and sub-aqueous inflows together contribute over three quarters of the total inflow. At Lake Bonney, the combined direct and sub-aqueous melt inflows also made a significant contribution, about 70\%, slightly less than the $80-90 \%$ estimated by Spigel et al. (2018).

Furthermore, the annual sub-aqueous melt contribution at Lake Bonney was small (1\%) compared to an estimated $40-45 \%$ by Faucher et al. (2019) for the sub-aqueous inflow to Lake Untersee, East Antarctica, but this difference is likely proportional to the difference in contact area $\left(2.7 \times 10^{5} \mathrm{~m}^{2}\right.$ between Anuchin Glacier and the lake) and flow velocities $\left(8-9 \mathrm{~m} \mathrm{yr}^{-1}\right)$. As there is no direct surface melt from Anuchin Glacier to the lake, a large sub-glacial or groundwater flux $\left(2.78 \times 10^{6} \mathrm{~m}^{3} \mathrm{yr}^{-1}\right)$ sustaining lake volume was inferred at Lake Untersee (Faucher et al. 2019). On the other hand, sub-glacial and groundwater fluxes into Lake Bonney remain an area of uncertainty. Episodic sub-glacial melt discharged from Taylor Glacier into Lake Bonney at Blood Falls has been estimated 
from 2,000-6,000 $\mathrm{m}^{3} \mathrm{yr}^{-1}$ (Keys, 1978). These previous estimates of the sub-glacial inflow into Lake Bonney highlight that it is small compared to total annual inflows, less than one percent, and within the uncertainty of modeled inflow, making it impossible to infer much about this flux based on the methods in this study.

The modeled lake budgets presented in this study allow for analysis of the sensitivity the lakes to environmental conditions (inflow and loss rates) versus basin geometry. For the period prior to the flood year, Lakes Bonney and Hoare levels drop at a faster rate than Lake Fryxell due to the steeper valley walls in those basins. After the 2002 flood year, the rates of level change at each lake are in-line with valley geometry ( $\Delta z: \Delta h$ of $0.72,0.73$, and 0.48 for Bonney, Hoare and Fryxell). Additionally, the high inflow rate to Lake Bonney after 2002 is due to a much larger contributing area (an order of magnitude greater than that of Lake Hoare), rather than higher specific melt in this basin relative to the others. These results suggest that the elevated response in lake-level at Lake Bonney, compared to the other two lakes, is largely due to basin hypsometry and greater water input

Finally, given post-2002 conditions, lake-level change was simulated through the end of the century. Under present climate (post-2002), lake-levels would rise dramatically, with Lakes Bonney, Hoare and Fryxell reaching $76 \mathrm{~m}$ asl, $80 \mathrm{~m}$ asl and $23 \mathrm{~m}$ asl, displacing current camp locations. These projections need to be treated cautiously, however, as the mean conditions over this 2002-2013 period are not necessarily representative of the future conditions in Taylor Valley. 


\subsection{Conclusions}

The water budgets of three lakes in Taylor Valley were simulated from 1996 to 2013 based on estimated glacier meltwater inflow and lake ice sublimation loss. To my knowledge, the results presented in this thesis are the first attempt to simulate the full water balance of MDV lakes. Overall, predicted lake-levels matched measured levels for all three lakes prior to 2008. Results support previous assumptions that lake inflows are sourced entirely from glacier meltwater and that precipitation and shallow groundwater flux provide no significant input to the lakes. Poorly modeled glacier meltwater inflows limited lake-level predictions somewhat, particularly in the Fryxell basin, but measured streamflow was used to account for deficiencies in ICEMELT and allowed components of the water budget to be constrained.

Expanding on previous work by Hoffman (2011), predicted glacier meltwater volume was compared to valley-wide streamflow measurements. The use of MODIS remotely-sensed albedo measurements after 2000 improved model skill at all sites, resulting in a reduction in the cumulative under-prediction error of $5.2 \times 10^{6} \mathrm{~m}^{3}$ (nRMSE of 0.73 , compared to 0.91 ). Importantly, the model matched the 2002 flood-year. Furthermore, decreasing albedo by $-7 \%$, model results were improved further at most sites (cumulative error from $-23.6 \times 10^{7} \mathrm{~m}^{3}$ to $-17.6 \times 10^{7} \mathrm{~m}^{3}$ ). This decrease, which is within the instrumental uncertainty of the in-situ pyranometers and of MODIS, is equivalent to a mean reduction in albedo of around -0.04 . Overall, the model's skill in predicting daily and annual discharge from 1996 to 2008 was okay. 
Despite these improvements, modeled streamflow was insufficient for years after 2008 for all streams. A total reduction of albedo by $-30 \%(-0.18)$ after 2008 at all sites and an increase in surface roughness to $1 \mathrm{~mm}$ in the Fryxell basin were required to increase predicted streamflow during the 2009 and 2011 water years. These findings corroborate those of Hoffman et al. (2016) who determined a reduction to albedo of -0.09 was required to increase ablation to match measured ablation at Taylor, Canada, Commonwealth and Howard glaciers. Why the deficit in modeled streamflow was valley wide is unclear. Albedo decrease is one possibility, although not supported by station or MODIS measurements. Other factors may include increased incoming long-wave radiation due to cloud cover.

This study provides the means to partition the previously unknown inflows and sublimation loss rates to the water budget from various sources. Namely the first estimates of direct glacier inflow to the lakes are made, approximately $69 \%, 73 \%$ and 28\% for Lakes Bonney, Hoare and Fryxell, respectively. Sub-aqueous melt contributed only $1 \%$ and $5 \%$ at Lakes Bonney and Hoare. Losses from the lakes, required to balance the lake water budgets, suggest that summer sublimation accounts for about half the total annual sublimation loss from Lakes Bonney and Hoare (54\% and $57 \%$ ) but only one quarter from Lake Fryxell (24\%). The difference at Fryxell is due to summer sublimation needing to be lowered due to the inflow deficit from the Kukri Hills glaciers, from which streamflow was poorly modeled. Evaporation from the moats was small, about $2 \%$ from all lakes. Future work should involve detailed modeling of summer sublimation using a full lake ice ablation model, calibrated to vapor flux measurements over each lake. 
The relative sensitivity of lake response to basin geometry were examined. A simple comparison of modeled lake-level change to the theoretical lake-level change given a uniform geometry confirm that the elevated lake-level response from 2002-2013 at Lake Bonney was largely due to steeper basin geometry and more water input. Interestingly, the hypsometric effect on lake-level change at Lake Hoare is similar to that of Lake Bonney, despite a near identical lake-level change between Lakes Hoare and Fryxell. The meltwater inflow to Lakes Fryxell and Bonney are similar yet the lake-level rise is much greater at Lake Bonney due to differences in basin hypsometry. If the current climate (1996-2013) is unchanged the lakes would continue to rise, by as much as $10 \mathrm{~m}$ for Lake Bonney, through the end of the century. It is interesting to consider lake-level change for the intervening years since 2013 that were not modeled in this study.

Acknowledging the limitations of the estimated glacier meltwater inflows and lake ice sublimation outflows, the lake water balance model presented in this study provides the groundwork for exploring important questions about the formation of MDV lakes. The utility of the process-based water balance model described in this study is that it can be applied beyond the modern period to estimate the water balance required to fill and maintain large MDV paleo-lakes or make projections of future lake response to climate change. Future work should apply Monte Carlo methods to perturb the metrological data used to force the physically-based model to simulate lake response under a variety of future or paleo conditions. 


\section{References}

Ambach, W. 1974. The influence of cloudiness on the net radiation balance of a snow surface with high albedo. Journal of Glaciology 13 (67):73-84.

Bintanja, R., and M. R. Van Den Broeke. 1995. The Surface Energy Balance of Antarctic Snow and Blue Ice. Journal of Applied Meteorology 34 (4):902-926.

- - 1996. The influence of clouds on the radiation budget of ice and snow surfaces in Antarctica and Greenland in summer. International Journal of Climatology: A Journal of the Royal Meteorological Society 16 (11):1281-1296.

Bockheim, J. G., I. B. Campbell, and M. McLeod. 2007. Permafrost distribution and active-layer depths in the McMurdo Dry Valleys, Antarctica. Permafrost and Periglacial Processes 18 (3):217-227.

Bomblies, A., D. M. McKnight, and E. D. Andrews. 2001. Retrospective simulation of lake-level rise in Lake Bonney based on recent 21-year record: indication of recent climate change in the McMurdo Dry Valleys, Antarctica. Journal of Paleolimnology 25 (4):477-492.

Brandt, R. E., and S. G. Warren. 1993. Solar-heating rates and temperature profiles in Antarctic snow and ice. Journal of Glaciology 39 (131):99-110.

Brock, B. W., I. C. Willis, and M. J. Sharp. 2006. Measurement and parameterization of aerodynamic roughness length variations at Haut Glacier d'Arolla, Switzerland. Journal of Glaciology 52 (177):281-297.

Bull, C. 2009. Innocents in the Dry Valleys. University of Alaska Press.

Chinn, T. J. 1993. Physical hydrology of the dry valley lakes. Physical and biogeochemical processes in Antarctic lakes 59:1-51.

- - . 1981. Hydrology and climate in the Ross Sea area. Journal of the Royal Society of New Zealand 11 (4):373-386.

Clow, G. D., C. P. McKay, G. M. Simmons Jr, and R. A. Wharton Jr. 1988. Climatological observations and predicted sublimation rates at Lake Hoare, Antarctica. Journal of Climate 1 (7):715-728.

Conovitz, P. A., D. H. McKnight, L. H. Macdonald, A. G. Fountain, and H. R. House. 1998. Hydrologic Processes Influencing Streamflow Variation in Fryxell Basin, Antarctica. Ecosystem dynamics in a polar desert: The McMurdo dry valleys, Antarctica 72:93-108.

Cuffey, K. M., and W. S. B. Paterson. 2010. Chapter 5 Mass Balance Processes: 2. Surface Ablation and Energy Budget. In The Physics of Glaciers. Academic Press. 
Dana, G. L., R. E. Davis, A. G. Fountain, and R. A. Wharton. 2002. Satellite-derived indices of stream discharge in Taylor Valley, Antarctica. Hydrological processes $16(8): 1603-1616$.

Dana, G. L., R. A. Wharton, and R. A. Dubayah. 1998. Solar Radiation in the McMurdo Dry Valleys, Antarctica. Ecosystem dynamics in a polar desert: The McMurdo dry valleys, Antarctica 72:39-64.

Doran, P. T., G. L. Dana, J. T. Hastings, and R. A. Wharton Jr. 1996. McMurdo Dry Valleys Long-Term Ecological Research (LTER): LTER automatic weather network (LAWN). Antarctic Journal of the US (30):276-280.

Doran, P. T., and M. N. Gooseff. 2018. McMurdo Dry Valleys Lake-levels. https://www.mcmlter.org. [Dataset]

Doran, P. T., C. P. McKay, G. D. Clow, G. L. Dana, A. G. Fountain, T. Nylen, and W. B. Lyons. 2002. Valley floor climate observations from the McMurdo Dry Valleys, Antarctica, 1986-2000. Journal of Geophysical Research: Atmospheres 107 (D24):ACL-13.

Doran, P. T., C. P. McKay, A. G. Fountain, T. Nylen, D. M. McKnight, C. Jaros, and J. E. Barrett. 2008. Hydrologic response to extreme warm and cold summers in the McMurdo Dry Valleys, East Antarctica. Antarctic Science 20 (5):499-509.

Doran, P. T., J. C. Priscu, W. B. Lyons, J. E. Walsh, A. G. Fountain, D. M. McKnight, D. L. Moorhead, R. A. Virginia, D. H. Wall, and G. D. Clow. 2002. Antarctic climate cooling and terrestrial ecosystem response. Nature 415 (6871):517.

Dugan, H. A., M. K. Obryk, and P. T. Doran. 2013. Lake ice ablation rates from permanently ice-covered Antarctic lakes. Journal of Glaciology 59 (215):491-498.

Ebnet, A. F., A. G. Fountain, T. H. Nylen, D. M. McKnight, and C. L. Jaros. 2005. A temperature-index model of stream flow at below-freezing temperatures in Taylor Valley, Antarctica. Annals of Glaciology 40 (1):76-82.

Eveland, J. W., M. N. Gooseff, D. J. Lampkin, J. E. Barrett, and C. D. Takacs-Vesbach. 2013. Seasonal controls on snow distribution and aerial ablation at the snowpatch and landscape scales, McMurdo Dry Valleys, Antarctica. The Cryosphere 7 (3):917-931.

Faucher, B., D. Lacelle, D. A. Fisher, D. T. Andersen, and C. P. McKay. 2019. Energy and water mass balance of Lake Untersee and its perennial ice cover, East Antarctica. Antarctic Science:1-15.

Fountain, A. G., H. J. Basagic, and S. Niebuhr. 2016. Glaciers in equilibrium, McMurdo Dry Valleys, Antarctica. Journal of Glaciology 62 (235):976-989. 
Fountain, A. G., G. L. Dana, K. J. Lewis, B. H. Vaughn, and D. H. McKnight. 1998. Glaciers of the McMurdo dry valleys, southern Victoria Land, Antarctica. Ecosystem dynamics in a polar desert: The McMurdo dry valleys, Antarctica 72:65-75.

Fountain, A. G., W. B. Lyons, M. B. Burkins, G. L. Dana, P. T. Doran, K. J. Lewis, D. M. McKnight, D. L. Moorhead, A. N. Parsons, J. C. Priscu, D. H. Wall, R. A. Wharton, and R. A. Virginia. 1999. Physical Controls on the Taylor Valley Ecosystem, Antarctica. BioScience 49 (12):961-971.

Fountain, A. G., T. H. Nylen, K. L. MacClune, and G. L. Dana. 2006. Glacier mass balances (1993-2001), Taylor Valley, McMurdo Dry Valleys, Antarctica. Journal of Glaciology 52 (178):451-462.

Fountain, A. G., T. A. Neumann, P. L. Glenn, and T. Chinn. 2004. Can climate warming induce glacier advance in Taylor Valley, Antarctica? Journal of Glaciology 50 (171):556-564.

Fountain, A. G., T. H. Nylen, A. Monaghan, H. J. Basagic, and D. Bromwich. 2010. Snow in the McMurdo Dry Valleys, Antarctica. International Journal of Climatology 30 (5):633-642.

Gooseff, M. N., J. E. Barrett, B. J. Adams, P. T. Doran, A. G. Fountain, W. B. Lyons, D. M. McKnight, J. C. Priscu, E. R. Sokol, and C. Takacs-Vesbach. 2017. Decadal ecosystem response to an anomalous melt season in a polar desert in Antarctica. Nature ecology \& evolution 1 (9):1334.

Gooseff, M. N., J. E. Barrett, and J. S. Levy. 2013. Shallow groundwater systems in a polar desert, McMurdo Dry Valleys, Antarctica. Hydrogeology Journal 21 (1):171183.

Gooseff, M. N., D. M. McKnight, P. Doran, A. G. Fountain, and W. B. Lyons. 2011. Hydrological connectivity of the landscape of the McMurdo Dry Valleys, Antarctica. Geography Compass 5 (9):666-681.

Hall, B. L., G. H. Denton, and C. H. Hendy. 2000. Evidence from Taylor Valley for a Grounded Ice Sheet in the Ross Sea, Antarctica. Geografiska Annaler: Series A, Physical Geography 82 (2-3):275-303.

Henderson, R. A., W. M. Prebble, R. A. Hoare, K. B. Popplewell, D. A. House, and A. T. Wilson. 1966. An Ablation Rate for Lake Fryxell, Victoria Land, Antarctica. Journal of Glaciology 6 (43):129-133.

Heron, R., and M.-K. Woo. 1994. Decay of a High Arctic lake-ice cover: observations and modelling. Journal of Glaciology 40 (135):283-292. 
Hock, R. 2005. Glacier melt: a review of processes and their modelling. Progress in physical geography 29 (3):362-391.

Hoffman, M. J. 2011. Spatial and Temporal Variability of Glacier Melt in the McMurdo Dry Valleys, Antarctica.

Hoffman, M. J., A. G. Fountain, and G. E. Liston. 2008. Surface energy balance and melt thresholds over 11 years at Taylor Glacier, Antarctica. Journal of Geophysical Research 113.

- - . 2014. Near-surface internal melting: a substantial mass loss on Antarctic Dry Valley glaciers. Journal of Glaciology 60 (220):361-374.

- - . 2016. Distributed modeling of ablation (1996-2011) and climate sensitivity on the glaciers of Taylor Valley, Antarctica. Journal of Glaciology 62 (232):215-229.

Jepsen, S. M., E. E. Adams, and J. C. Priscu. 2010. Sediment melt-migration dynamics in perennial Antarctic lake ice. Arctic, Antarctic, and Alpine Research 42 (1):57-66.

Keys, J.R. 1979. Saline discharge at the terminus of Taylor Glacier. Antarctic Journal of the US, 14, 82-85

Levy, J. 2012. How big are the McMurdo Dry Valleys? Estimating ice-free area using Landsat image data. Antarctic Science 25 (1):119.

Levy, J. S., A. G. Fountain, M. N. Gooseff, K. A. Welch, and W. B. Lyons. 2011. Water tracks and permafrost in Taylor Valley, Antarctica: Extensive and shallow groundwater connectivity in a cold desert ecosystem. Bulletin 123 (11-12):22952311.

Lewis, K. J., A. G. Fountain, and G. L. Dana. 1998. Surface energy balance and meltwater production for a Dry Valley glacier, Taylor Valley, Antarctica. Annals of Glaciology 27 (1):603-609.

Liston, G. E., and K. Elder. 2006. A meteorological distribution system for highresolution terrestrial modeling (MicroMet). Journal of Hydrometeorology 7 (2):217-234.

Liston, G. E., J.-G. Winther, O. Bruland, H. Elvehøy, and K. Sand. 1999. Below-surface ice melt on the coastal Antarctic ice sheet. Journal of Glaciology 45 (150):273285.

McKnight, D., and M. Gooseff. 2016. McMurdo Dry Valleys Stream Gage Measurements. https://www.mcmlter.org. [Dataset] 
McKnight, D. M., D. K. Niyogi, A. S. Alger, A. Bomblies, P. A. Conovitz, and C. M. Tate. 1999. Dry Valley Streams in Antarctica: Ecosystems Waiting for Water. BioScience 49 (12):985-995.

Möller, R., M. Möller, H. Björnsson, S. Guđmundsson, F. Pálsson, B. Oddsson, P. A. Kukla, and C. Schneider. 2014. MODIS-derived albedo changes of Vatnajökull (Iceland) due to tephra deposition from the 2004 Grímsvötn eruption. International Journal of Applied Earth Observation and Geoinformation 26:256269.

Monaghan, A. J., D. H. Bromwich, J. G. Powers, and K. W. Manning. 2005. The climate of the McMurdo, Antarctica, region as represented by one year of forecasts from the Antarctic Mesoscale Prediction System. Journal of Climate 18 (8):1174-1189.

Nash, J. E., and J. V. Sutcliffe. 1970. River flow forecasting through conceptual models part I - A discussion of principles. Journal of Hydrology 10 (3):282-290.

Northcott, M. L., M. N. Gooseff, J. E. Barrett, L. H. Zeglin, C. D. Takacs-Vesbach, and J. Humphrey. 2009. Hydrologic characteristics of lake- and stream-side riparian wetted margins in the McMurdo Dry Valleys, Antarctica. Hydrological Processes 23 (9):1255-1267.

Nylen, T. H., A. G. Fountain, and P. T. Doran. 2004. Climatology of katabatic winds in the McMurdo dry valleys, southern Victoria Land, Antarctica. Journal of Geophysical Research: Atmospheres 109 (D3).

Obryk, M. K., P. T. Doran, E. D. Waddington, and C. P. Mckay. 2017. The influence of föhn winds on Glacial Lake Washburn and palaeotemperatures in the McMurdo Dry Valleys, Antarctica, during the Last Glacial Maximum. Antarctic Science:1-11.

Pettit, E. C., E. N. Whorton, E. D. Waddington, and R. S. Sletten. 2014. Influence of debris-rich basal ice on flow of a polar glacier. Journal of Glaciology 60 (223):989.

Priscu, J. 1995. McMurdo Dry Valleys Depths, Areas, Volumes Measured by Jeffrey Schmok. https://www.mcmlter.org. [Dataset]

Schaaf, C. B., F. Gao, A. H. Strahler, W. Lucht, X. Li, T. Tsang, N. C. Strugnell, X. Zhang, Y. Jin, J.-P. Muller, P. Lewis, M. Barnsley, P. Hobson, M. Disney, G. Roberts, M. Dunderdale, C. Doll, R. P. d'Entremont, B. Hu, S. Liang, J. L. Privette, and D. Roy. 2002. First operational BRDF, albedo nadir reflectance products from MODIS. Remote Sensing of Environment 83 (1):135-148.

Šabacká, M., J. C. Priscu, H. J. Basagic, A. G. Fountain, D. H. Wall, R. A. Virginia, and M. C. Greenwood. 2012. Aeolian flux of biotic and abiotic material in Taylor Valley, Antarctica. Geomorphology 155:102-111.

Schaaf, C., and Z. Wang. 2015. MCD43A3 MODIS Albedo Daily - 500m V006. [Dataset]. 
Scott, R. F. 1905. The voyage of the Discovery.

Sommers, P., J. L. Darcy, D. L. Porazinska, E. M. S. Gendron, A. G. Fountain, F. Zamora, K. Vincent, K. M. Cawley, A. J. Solon, L. Vimercati, J. Ryder, and S. K. Schmidt. 2019. Comparison of Microbial Communities in the Sediments and Water Columns of Frozen Cryoconite Holes in the McMurdo Dry Valleys, Antarctica. Frontiers in Microbiology 10.

Speirs, J. C., D. F. Steinhoff, H. A. McGowan, D. H. Bromwich, and A. J. Monaghan. 2010. Foehn winds in the McMurdo Dry Valleys, Antarctica: The origin of extreme warming events. Journal of Climate 23 (13):3577-3598.

Spigel, R. H., and J. C. Priscu. 1998. Physical Limnology of the McMurdo Dry Valleys Lakes. In Antarctic Research Series, ed. J. C. Priscu, 153-187. Washington, D. C.: American Geophysical Union

Spigel, R. H., J. C. Priscu, M. K. Obryk, W. Stone, and P. T. Doran. 2018. The physical limnology of a permanently ice-covered and chemically stratified Antarctic lake using high resolution spatial data from an autonomous underwater vehicle. Limnology and Oceanography 63 (3):1234-1252.

Street-Perrott, F. A. 1985. Lake-levels and climate reconstruction. Paleoclimate analysis and modelling: 291-340.

Stroeve, J., J. E. Box, Z. Wang, C. Schaaf, and A. Barrett. 2013. Re-evaluation of MODIS MCD43 Greenland albedo accuracy and trends. Remote Sensing of Environment 138:199-214.

Stroeve, J. C., J. E. Box, and T. Haran. 2006. Evaluation of the MODIS (MOD10A1) daily snow albedo product over the Greenland ice sheet. Remote Sensing of Environment 105 (2):155-171.

Taylor, K. E. 2001. Summarizing multiple aspects of model performance in a single diagram. Journal of Geophysical Research: Atmospheres 106 (D7):7183-7192.

Telling, J., C. Glennie, A. Fountain, and D. Finnegan. 2017. Analyzing glacier surface motion using LiDAR data. Remote Sensing 9 (3):283.

van den Broeke, M., P. Smeets, J. Ettema, and P. K. Munneke. 2008. Surface radiation balance in the ablation zone of the west Greenland ice sheet. Journal of geophysical research: Atmospheres 113 (D13).

Wharton, R. A., C. P. McKay, G. M. Simmons, and B. C. Parker. 1986. Oxygen budget of a perennially ice-covered Antarctic lake. Limnology and Oceanography 31 (2):437-443. 


\section{Appendix A: Incorporating Remotely-sensed MODIS Albedo}

\section{A1. Importance of Spatially-distributed Albedo}

Surface mass balance and melt are highly sensitive to solar radiation in Taylor Valley due to the relatively small energy contribution from the sensible heat flux and the importance of solar penetration and subsurface heating (Dana et al. 1998; Ebnet et al. 2005; Fountain et al. 1999). Using the ICEMELT model, Hoffman et al. (2016) demonstrate that lowering albedo by 0.01 resulted in an additional of $0.011 \mathrm{~m}$ w.e. of ablation and that a decrease of 0.02 was equivalent to increasing temperature by $1^{\circ} \mathrm{C} . \mathrm{A}$ known challenge to distributed melt modelling is the spatial and temporal variability of surface albedo (Hock 2005). In Taylor Valley, the spatio-temporal variability is due to snowfall, which increases albedo, and wind deposition of dust and sediment lowering the albedo. Furthermore, the distribution of snow and dust is uneven across glacier surfaces, complicating assessment.

Albedo and surface height change (snow and ablation) measurements are available at four glacier meteorological stations in Taylor Valley (Figure A.1). The Commonwealth Glacier (COHM) and Howard Glacier (HODM) meteorological stations are located relatively high on the glacier near the equilibrium line, so the measurements of albedo and snow accumulation made at these sites are biased towards more snow cover and higher albedo. For the COHM and Canada Glacier (CAAM) meteorological stations, located near the centerline of the glacier, a bias in the albedo values may exist towards the cleaner, relatively sediment-free ice relative to the margins. The opposite may be true at Taylor Glacier (TARM) or HODM stations. 


\section{A2. Previous Efforts to Account for Snow Cover}

Snow cover suppresses ice ablation by increasing the albedo of the ice surface and insulates the ice below. Indeed a thin snow cover on the ablation zone of glaciers in Taylor Valley can essentially terminate streamflow for days to weeks (Fountain et al. 1998). Hoffman et al. (2014) implemented a routine in ICEMELT to account for snow cover. By correlating albedo to snowfall events, an albedo threshold was determined to identify the presence of snow. This snow layer was removed when measured albedo dropped below the threshold (0.7). Alternatively if average daily wind speed exceeded $8.5 \mathrm{~m} \mathrm{~s}^{-1}$ the snow was considered eroded off the ice. Hoffman et al. (2016), found that this routine had a negligible impact on model efficiency and decide to ignore snow cover altogether. The SNOWMODEL and SNOWTRAN routines associated with MICROMET are not used to make distributed estimates of snow accumulation due to the complexities of snowfall and transport in Taylor Valley. Specifically, the redistribution of snow by strong winter foehn winds complicates the prediction of snow accumulation.

Hoffman (2011) explore the segmentation of Moderate Resolution Imaging Spectroradiometer (MODIS) imagery from November 21, 2001 using a ratio between MODIS Band 1 and Band 2. This technique was mostly successful in classifying snow cover, but Hoffman (2011) recognized the computational requirements of applying this analysis to all model days to extract daily snow cover and decided not to fully implement it. Expanding on the pilot study by Hoffman (2011) to supplement the 
available in-situ data, the utility of daily MODIS data is explored in this study to address the spatio-temporal variability of albedo rather than for delineating snow covered area.

\section{A3. MODIS Remotely-sensed Albedo}

The MCD43A3 Version 6 MODIS albedo product provides daily albedo measurements at a 500-m spatial resolution (Schaaf and Wang, 2015). The MODIS instrument, onboard both the Aqua and Terra satellites, images the same place on Earth every 1 to 2 days. These satellites have a sun-synchronous, near-polar orbit such that they acquire at least two images of Taylor Valley per day - at roughly 10:30 AM and 1:30 PM local time. The revisit time and spatial resolution of this MODIS albedo product allows for them to be used to supplement the spatially-limited, in-situ measurements.

The MCD43A3 product deploys a bi-directional reflectance distribution function (BRDF) to calculate broadband and spectral albedo at local solar noon using a centered, 16-day moving window, and the center day of the window given the highest weight. Albedo is available as 'black-sky' (direct component, abbreviated to BSA) and 'white-sky' (diffuse component, abbreviated to WSA) albedo for seven MODIS narrow and three broad bands (Table A.1).

The MCD43A3 albedo products have been shown to correspond well with in-situ measurements on the Greenland Ice Sheet (Stroeve et al. 2005; Stroeve et al. 2013; Moustafa et al. 2017). Stroeve et al. (2005) compared the MCD43A3 Version 4 broadband (0.3-0.5 $\mu \mathrm{m})$ albedo to in-situ radiometer measurements, finding an RMSE of 
\pm 0.07 , deemed to be within the instrumental uncertainty of the in-situ radiometers. The Version 5, broadband albedo was compared to in-situ radiometer measurements across the Greenland Ice Sheet, the resulting RMSE of 0.067 and overall mean bias of +0.022 , showed a slight improvement to the previous version (Stroeve et al. 2013). Using a multiple point-to-pixel comparison, Moustafa et al. (2017) find that the MCD43A Version 6 daily, broadband albedo was $\pm 7 \%$ of radiometer measurements sampled along a within-pixel transect. This methodology provides a robust validation of the MODIS albedo product by accounting for the within-pixel spatial heterogeneity (Moustafa et al. 2017).

Table A.1 MODIS spectral albedo bands and in-situ radiometer details. The LiCOR albedo values measured at CAAM were lowered by $8 \%$ to account for the narrow spectral sensitivity of this instrument (see page 25, Section 2.1). The MCD43A3 visible broadband, displayed below, would over-estimate albedo due to the higher reflectance of snow and ice in the visible portion of the spectrum. An uncertainty value for the MODIS product are derived from the RMSE when compared to the TARM station. The TARM station is located in a MODIS pixel with the lowest within-pixel heterogeneity of all the meteorological stations. The calculation of this value is explained in Section A.5 below.

\begin{tabular}{cccl}
\hline & $\begin{array}{c}\text { Spectral Sensitivity } \\
{[\mu \mathrm{m}]}\end{array}$ & $\begin{array}{c}\text { Uncertainty } \\
{[\%]}\end{array}$ & Notes \\
\hline MCD43A3 $\alpha_{\text {vis }}$ & $0.3-0.7$ & -- & \\
MCD43A3 $\alpha_{\text {sw }}$ & $0.3-5.0$ & \pm 7 & RMSE (this study) \\
LICOR LI200S $\alpha$ & $0.4-1.1$ & \pm 5 & Instrument used at CAAM; adjusted by 8\% \\
Eppley PSP $\alpha$ & $0.2-3.5$ & \pm 7 & Instrument used at TARM, HODM, COHM \\
\hline
\end{tabular}

\section{A4. Extracting MODIS Albedo}

Daily MCD43A3 shortwave broadband (0.3-5.0 $\mathrm{m})$ images were compiled in Google Earth Engine from 2000 to 2015. Google Earth Engine (GEE) is a cloud-based supercomputing platform available for public, non-commercial use. Specifically, GEE enables computationally intensive remote sensing analyses to be executed rapidly and 
programmatically via Java Script. Additionally, many publicly available satellite image collections are available. GEE allowed for rapid retrieval of 15 years of daily MODIS albedo values, drastically reducing the time to perform this retrieval.

Daily albedo time-series' of MCD43A3 broad-band visible and shortwave albedo were extracted for the pixel corresponding to each of the four glacier meteorological stations. Following Möller et al. (2014), a 'clear-sky' albedo was calculated using a linear combination of the BSA and WSA the components. These two components are essentially equal at approximately $50^{\circ}$, which corresponds to a typical solar noon zenith angle at the latitude of Taylor Valley (Stroeve et al. 2005). Comparison of the two components in the extracted time-series confirm the similarity of these two components in the study area (Figure A.2). When extracting MODIS albedo values for individual station pixels, data gaps due to cloud cover were present (Table A.2), to fill some of these gaps a 7-day running mean filter was applied to each of the MCD43A3 bands extracted.

\section{A5. Validating MODIS Albedo}

The MCD43A3 albedo product has been rigorously validated in a high-latitude setting, showing good correspondence to in-situ measured albedo (Stroeve et al. 2005; Stroeve et al. 2013; Moustafa et al. 2017). To our knowledge, this product has not been validated to blue-ice areas of Antarctica. Thus we make a preliminary validation of this product to ground measurements available in Taylor Valley. Using a point-to-pixel comparison, the MCD43A3 albedo bands are compared to radiometer measurements 
made at the four glacier stations. Figure A.1 shows the location of the four stations and corresponding pixels over a 15-m ASTER satellite image from November $29^{\text {th }}, 2000$, allowing for an assessment of the within-pixel variability of albedo. The HODM and COHM stations are clearly located in more spatially heterogeneous pixels, while TARM and CAAM are located in more spatially homogenous pixels. Resolving the within-pixel variability of albedo with a multiple point-to-pixel validation approach, like that used in Moustafa et al. (2017), is beyond the scope of this project and the availability of ground truth data.

The results of this comparison, displayed in Table A.2 and Figure A.2, show that the MCD43A3 product provides daily albedo values between \pm 0.06 to \pm 0.12 (based on RMSE) of values measured at four locations in Taylor Valley. The band with the best correspondence at all sites was the 'clear-sky' shortwave broadband albedo retrievals (Figure A.2). The Taylor Glacier station had the highest correspondence among all stations, with an RMSE of 0.06 for the raw and $0.04( \pm 7 \%)$ for the filtered albedo values. The Canada Glacier station also had an RMSE of 0.4 ( $\pm 7 \%)$ for the filtered albedo values, but the RMSE of 0.08 for raw values was higher than Taylor station. Howard Glacier station shows the worst correspondence using the raw values, likely due to its position close to the snowline (Figure A.1). The most cloud free retrievals on average were made at the Commonwealth station, this is notable considering its position at the mouth of the valley. Doran et al. (2002) found no correlation between incoming solar radiation fluxes and valley position. 
Table A.2 Annual RMSE of albedo measured in-situ and from MCD43A3I. The RMSE value is calculated using the raw (left) and 7-day running mean filter (right) albedo values. The number of days, displayed in parentheses, is the count of cloud-free images available in the raw MCD43A3 time-series for that pixel. The final row shows the RMSE across all days, the mean number of days (rather than the sum) with available data is displayed in parentheses. Year denotes the starting year of the austral summer (e.g. 2000 for the 2000-2001 austral summer).

\begin{tabular}{|c|c|c|c|c|c|c|c|c|c|c|c|c|}
\hline \multirow{3}{*}{$\begin{array}{l}\text { Year } \\
2000\end{array}$} & \multicolumn{12}{|c|}{$\begin{array}{c}\text { RMSE } \\
\text { [raw/filtered/n] }\end{array}$} \\
\hline & \multicolumn{3}{|c|}{$\alpha_{\text {TARM }}$ to $\alpha_{\text {MODIS }}$} & \multicolumn{3}{|c|}{$\alpha_{\text {CAAM }}$ to $\alpha_{\text {MODIS }}$} & \multicolumn{3}{|c|}{$\alpha_{\text {HODM }}$ to $\alpha_{\text {MODIS }}$} & \multicolumn{3}{|c|}{$\alpha_{\text {COHM }}$ to $\alpha_{\text {MODIS }}$} \\
\hline & 0.06 & 0.04 & (93) & 0.10 & 0.08 & (111) & 0.41 & -- & (34) & 0.10 & 0.08 & (114) \\
\hline 2001 & 0.07 & 0.04 & (103) & 0.11 & 0.08 & (111) & 0.24 & 0.25 & (85) & 0.08 & 0.07 & (114) \\
\hline 2002 & 0.07 & 0.05 & (90) & 0.12 & 0.11 & (85) & 0.18 & 0.06 & (64) & 0.12 & 0.12 & (116) \\
\hline 2003 & 0.04 & 0.03 & (102) & 0.10 & 0.06 & (96 & 0.15 & 0.12 & (87) & 0.07 & 0.05 & (111) \\
\hline 2004 & 0.07 & 0.03 & $(88)$ & 0.11 & 0.08 & $(85)$ & 0.17 & 0.09 & (67) & 0.10 & 0.09 & $(116)$ \\
\hline 2005 & 0.07 & 0.06 & (111) & 0.09 & 0.09 & (97) & 0.17 & 0.07 & (69) & 0.08 & 0.07 & (120) \\
\hline 2006 & 0.07 & 0.06 & (107) & 0.09 & 0.07 & (103) & 0.19 & 0.13 & (89) & 0.12 & 0.11 & (117) \\
\hline 2007 & 0.07 & 0.06 & (107) & 0.09 & 0.06 & $(87)$ & 0.25 & 0.18 & (49) & 0.10 & 0.08 & (117) \\
\hline 2008 & 0.06 & 0.06 & (113) & 0.10 & 0.06 & (104) & 0.17 & 0.12 & $(68)$ & 0.12 & 0.11 & $(104)$ \\
\hline 2009 & 0.06 & 0.06 & (103) & 0.11 & 0.09 & (92) & 0.19 & 0.07 & (81) & 0.08 & 0.06 & (114) \\
\hline 2010 & 0.07 & 0.04 & (104) & 0.14 & 0.04 & (91) & 0.23 & 0.07 & (79) & 0.07 & 0.06 & (107) \\
\hline 2011 & 0.08 & 0.06 & (112) & 0.12 & 0.11 & (108) & 0.30 & 0.28 & (95) & 0.09 & 0.08 & (120) \\
\hline 2012 & 0.08 & 0.06 & (85) & 0.15 & 0.13 & (73) & 0.40 & 0.32 & (78) & 0.12 & 0.12 & (110) \\
\hline 2013 & 0.08 & 0.06 & (115) & 0.08 & 0.06 & (105) & 0.25 & 0.25 & (87) & 0.12 & 0.12 & (120) \\
\hline 2014 & 0.09 & 0.07 & (112) & 0.11 & 0.09 & (101) & 0.32 & 0.31 & (71) & 0.19 & 0.19 & (119) \\
\hline All & 0.06 & 0.04 & (103) & 0.08 & 0.04 & (97) & 0.12 & 0.06 & (74) & 0.08 & 0.07 & (115) \\
\hline
\end{tabular}

\section{A6. Modifying ICEMELT}

Rather than incorporate fully-distributed (pixel-based) albedo into ICEMELT, a daily spatial average for each of the glacier domains is calculated. GEE was used to average MODIS images for all glacier pixels within twelve glacier zones (Figure A.1); ten of these zones correspond to a single glacier while a handful of small, unnamed glaciers are grouped together into the Borns and Wales glacier groups (see A.1). The spatial average removes some of the noise from mixed soil and ice pixels that result from the 
generalization of model glacier zones in the MODIS pixel, however, this effect is more the case for larger glaciers than the smaller ones. For small, named glaciers (ones that are not grouped together) where only a handful of MODIS pixels are sampled, the 'edge effects' are more important. These 'edge effects' are addressed in three ways: first, in the spatial-average, pixels are weighted in GEE based on their coverage by the masking feature (glacier zones), so partial pixels are weighted less. Second, a scale parameter can be set in GEE to resample the MODIS data to a finer resolution (50 meters), thereby decreasing generalization of the glacier zone features in the extraction step. Third, an inverse buffer of 100 meters was applied to the glacier zone features to reduce the influence of partial ground pixels at the edges.

The comparison of MCD43A3 retrievals and albedo measured at four glacier meteorological stations shows correspondence within the reported instrumental uncertainty of the pyranometers used for ground measurements and in agreement with the results of validation studies of the MCD43A3 albedo on the Greenland Ice Sheet, confirming that its suitability for application in the Taylor Valley meltwater model (Table A.1). Figures A.4-6 show the comparison of the spatially-average MODIS albedo for each of the 12 glacier groups compared to the nearest meteorological station. 

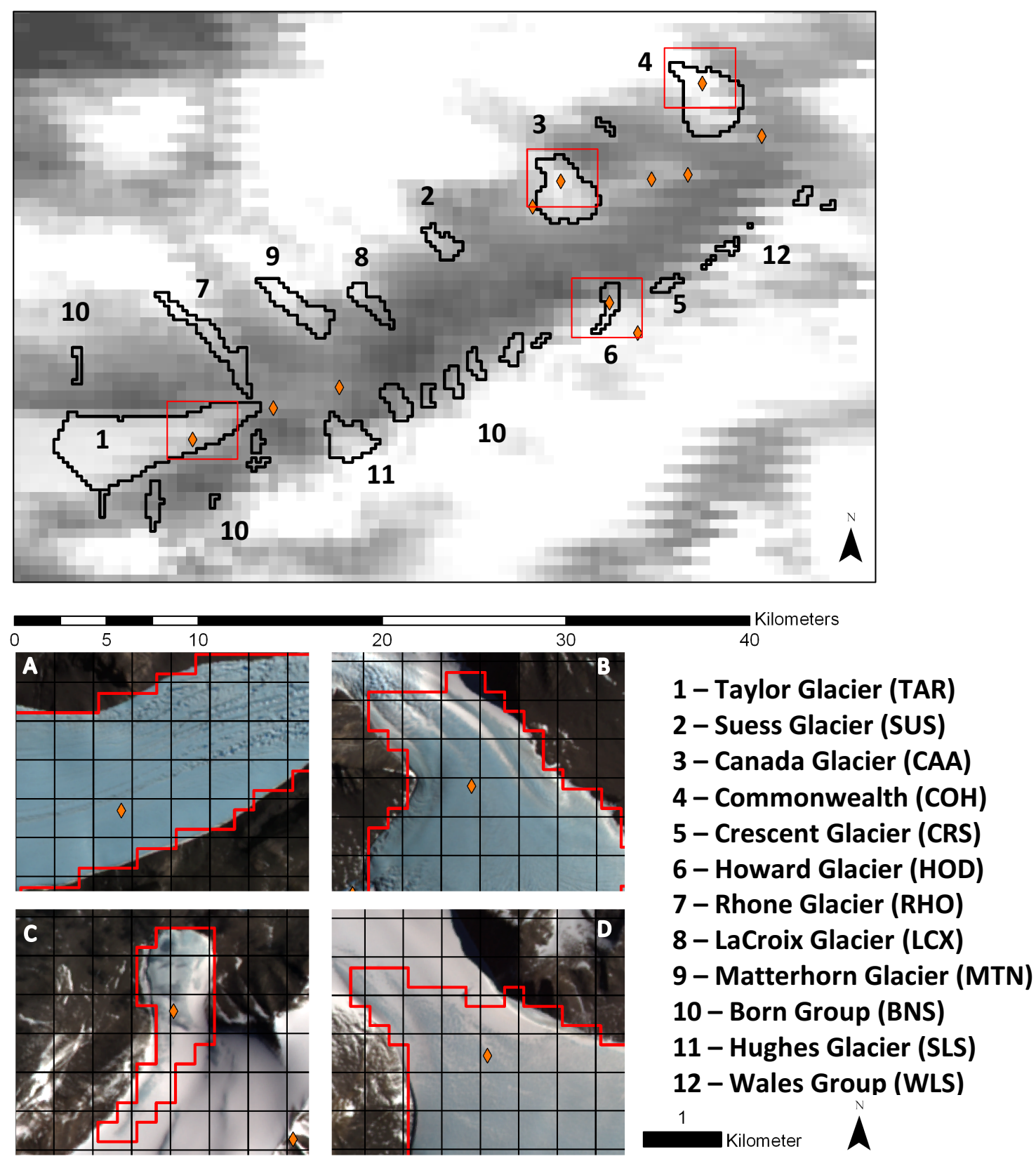

Figure A.1 A MODIS mean albedo image for the 2000-01 summer (top) with the general regions used to extract spatially-averaged glacier albedo shown (black outline). Maps showing the sub-pixel and general spatial variability of surface albedo at A) Taylor Glacier, B) Canada Glacier, C) Howard Glacier and D) Commonwealth Glacier. An ASTER satellite image (15-m) is displayed for lower panels as well as the MODIS pixel grid (black) and model glacier domain (red). Meteorological stations are shown with orange diamonds. Note the amount of dirt and rock in the non-buffered glacier zone. 

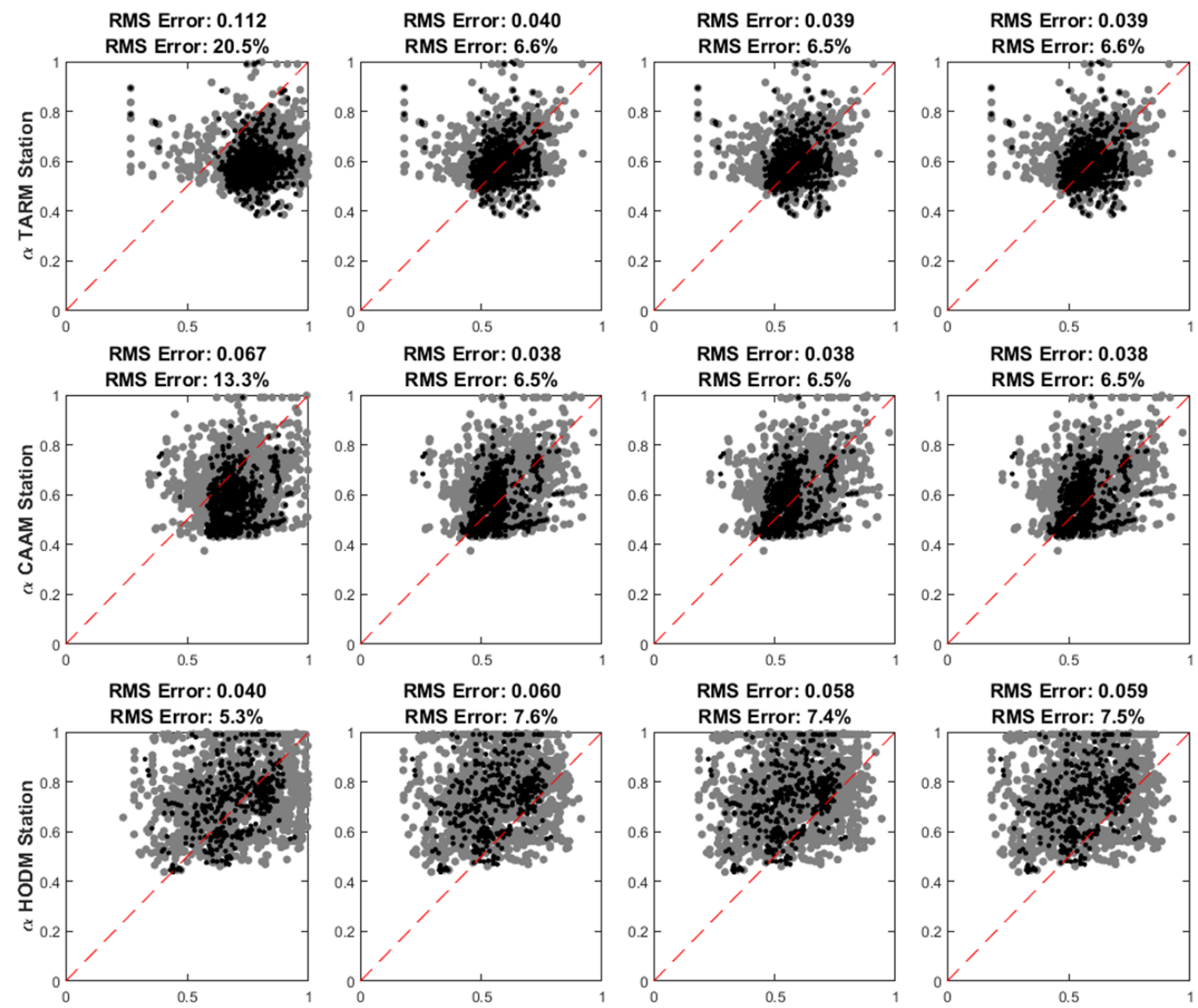

RMS Error: 0.060

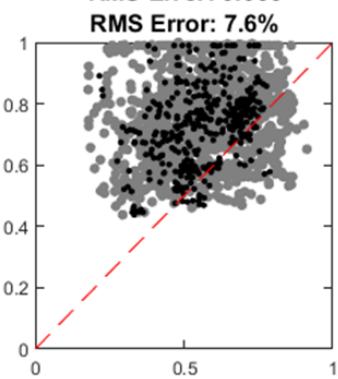

RMS Error: 0.058

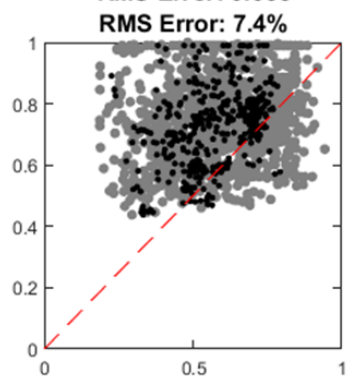

RMS Error: 0.059

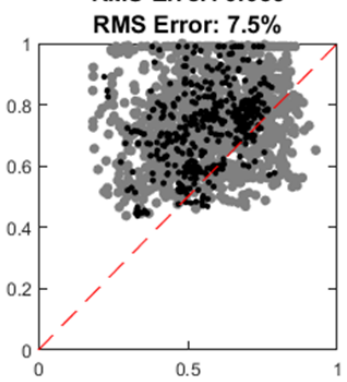

RMS Error: $\mathbf{0 . 0 8 0}$

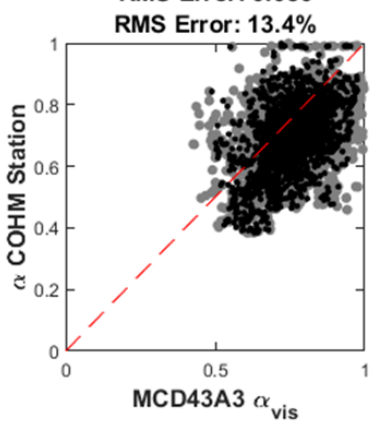

RMS Error: 0.070

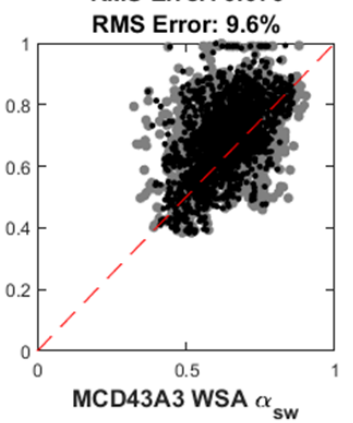

RMS Error: 0.067

RMS Error: $9.2 \%$

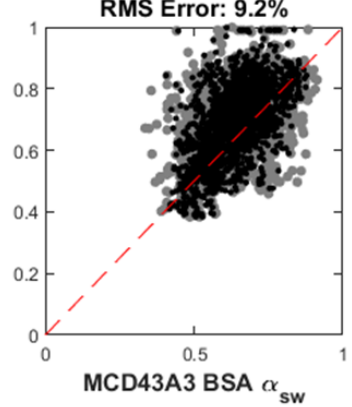

RMS Error: 0.068

RMS Error: $9.4 \%$

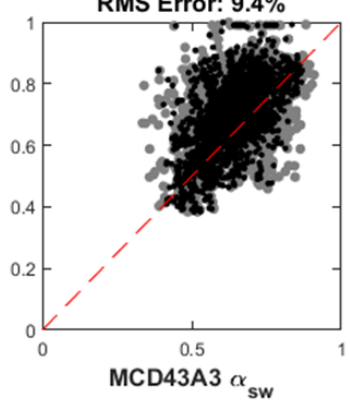

Figure A.2 Scatter plot of MCD43A3 remotely sensed albedo band'versus in-situ albedo measured at four Taylor Valley meteorological stations. Black points represent albedo values after a 7-day moving mean filter has been applied to reduce noise; grey points are the unfiltered values. Rows from top to bottom-Taylor (TARM), Canada (CAAM), Howard (HODM), and Commonwealth (COHM) meteorological stations. Columns from left to right-visible broadband, shortwave broadband 'white-sky, shortwave broadband 'black-sky' albedo and the shortwave broadband 'clear-sky' albedo. The RMSE and RMS percent error are displayed. 


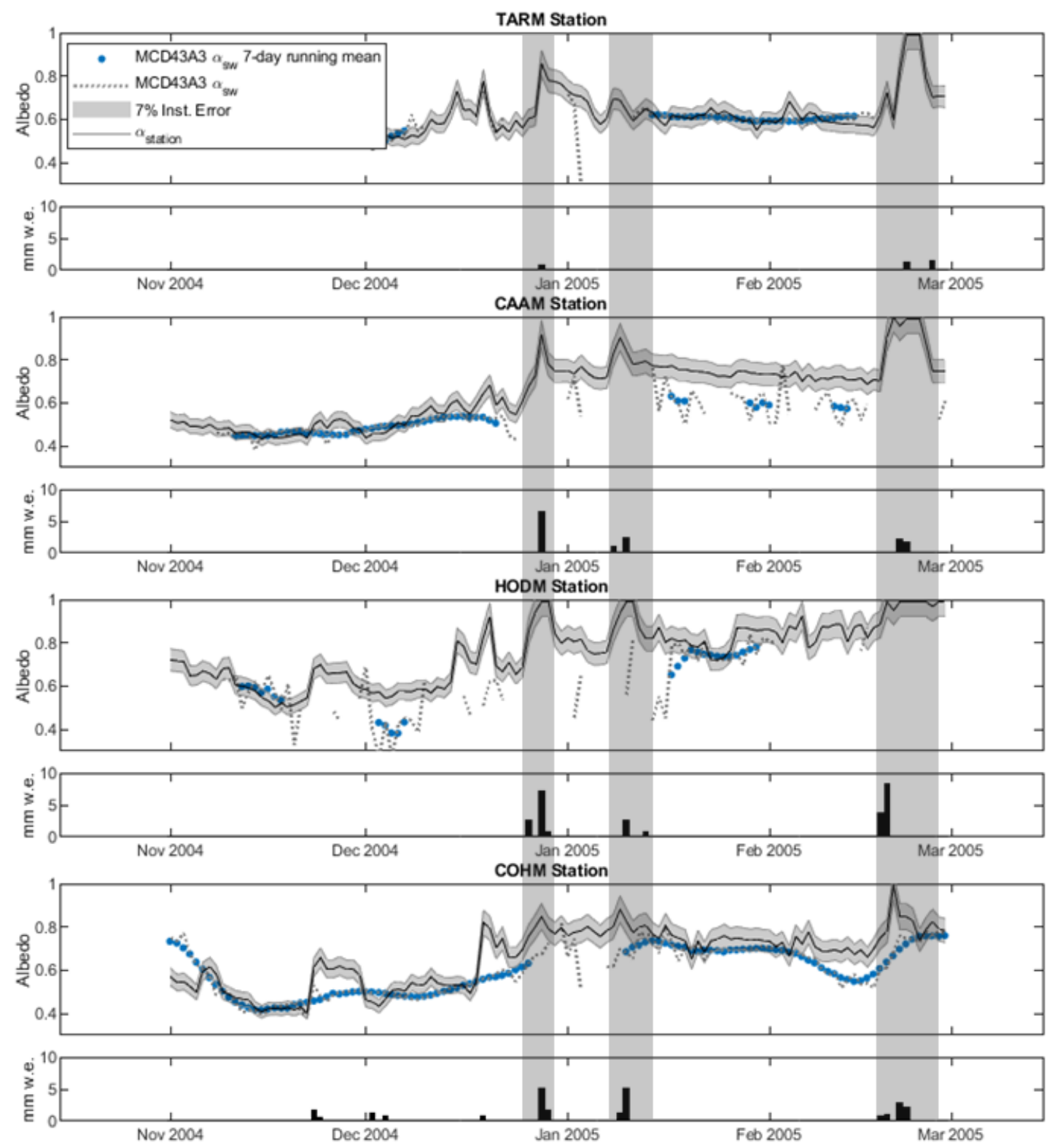

Figure A.3 Time-series of MCD43A3 shortwave broadband smoothed 'clear-sky' albedo (blue points), meteorological station albedo (black line) for the 2004-05 season; snowfall is plotted on lower panel of each plot. Rows from top to bottom-Taylor (TARM), Canada (CAAM), Howard (HODM), and Commonwealth (COHM) meteorological stations. The unfiltered, raw MODIS returns (grey points) are displayed as well. This plot shows the correlation of snowfall (vertical gray shading) to spikes in glacier albedo as well as gaps in MODIS data due to cloud cover. 

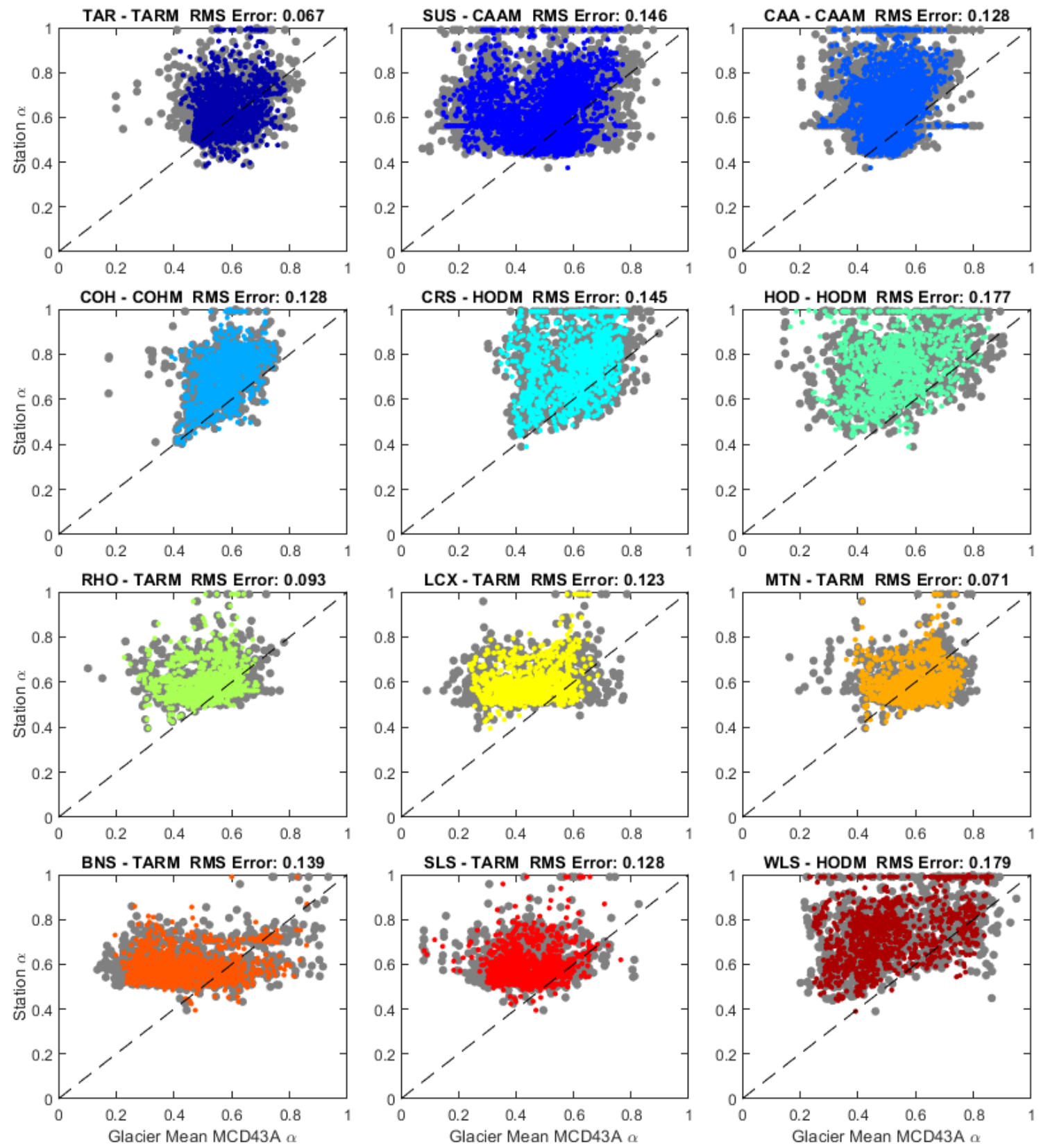

Figure A.4 Plots of MODIS spatially-averaged glacier and meteorological station albedo. Best RMS error for Taylor Glacier, likely due to the spatial homogeneity of albedo there, its location and size reducing the effects of snowfall and dust. The spatially-averaged glacier albedo consistently plots lower than the station albedo measured that day (points to the left of the 1:1 line). Abbreviations: Taylor Glacier (TAR), Suess Glacier (SUS), Canada Glacier (CAA), Commonwealth (COH), Crescent Glacier (CRS), Howard Glacier (HOD), Rhone Glacier (RHO), LaCroix Glacier (LCX), Matterhorn Glacier (MTN), Born Group (BNS), Hughes Glacier (SLS) and Wales Group (WLS). 

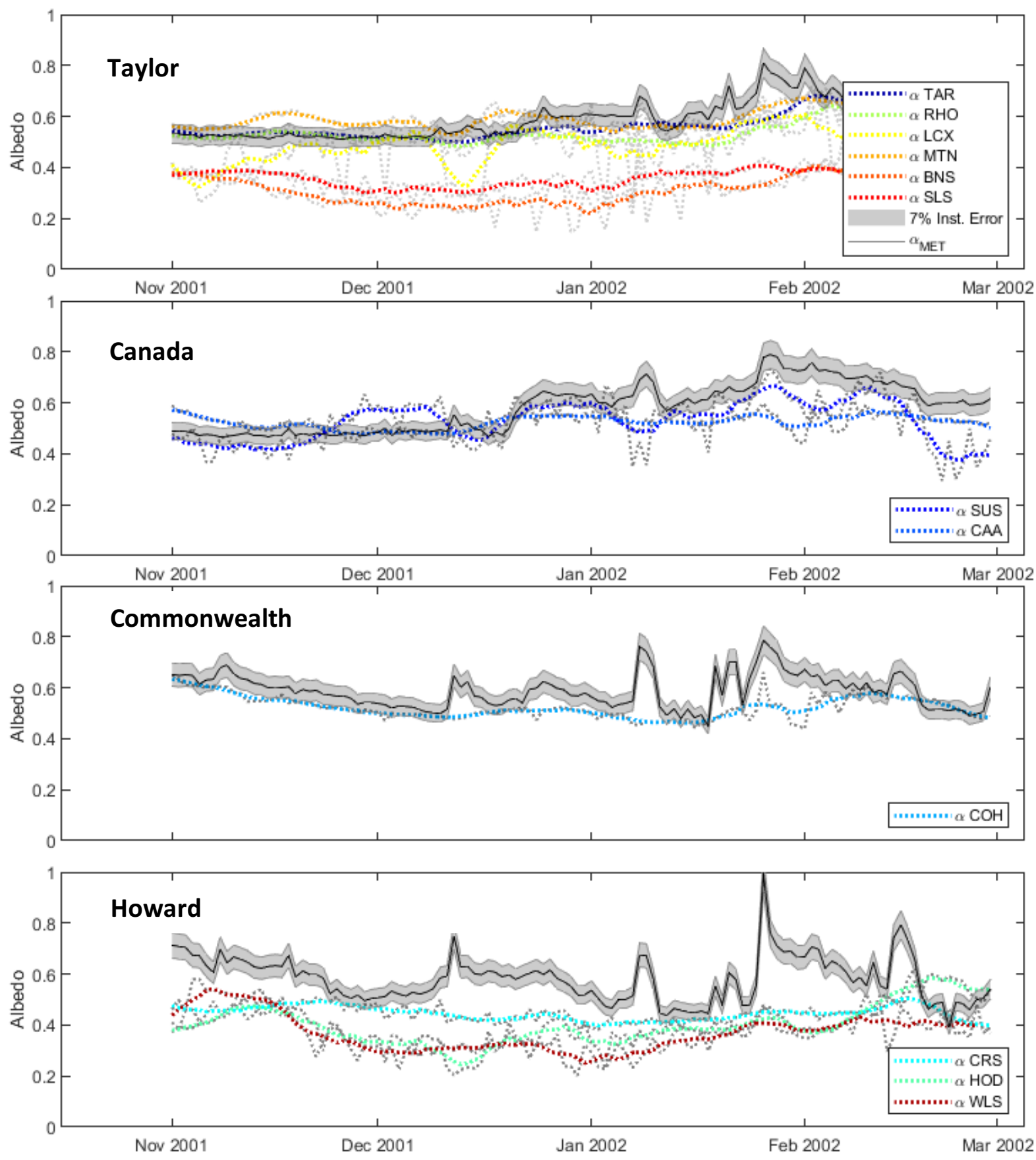

Figure A.5 Time-series of MODIS spatially-averaged glacier albedo (colored lines) and met station albedo (black line) for the 2001-2002 season. All glacier met stations measure lower albedo than the MODIS spatially-averaged albedo. 

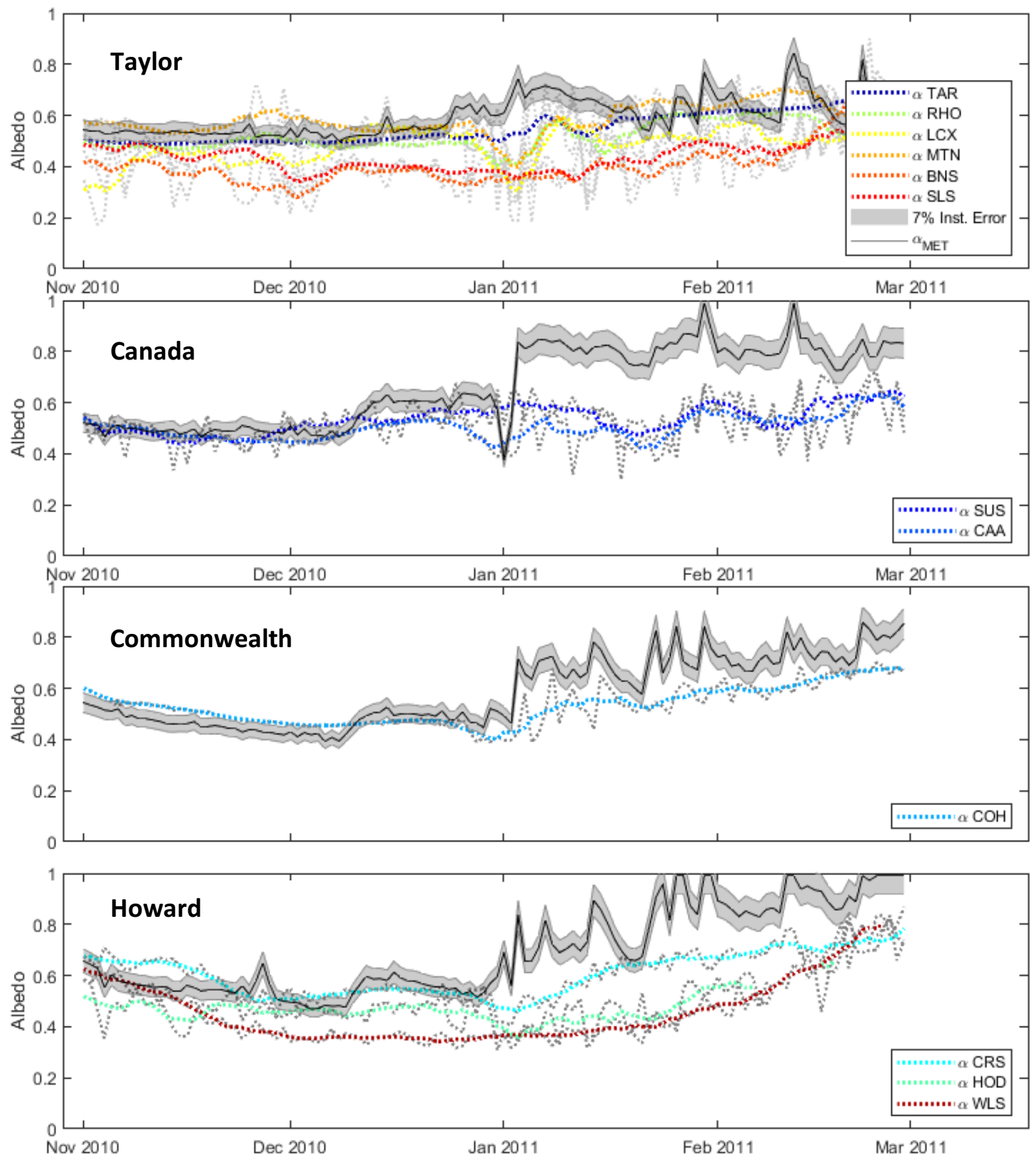

Figure A.6 Time-series of MODIS spatially-averaged glacier albedo (colored lines) and met station albedo (black line) for the 2010-2011 season. All glacier met stations measure lower albedo than the MODIS spatially-averaged albedo. 


\section{Appendix B: Meltwater Model Supplemental Information}

\section{B1. Over-prediction at Green Creek}

Under M2, Green Creek discharge is slightly over-estimated, but with this decrease of albedo by $7 \%$, over-prediction at Green Creek is significantly higher, likely due to the relative distribution of basin micro-topography in this catchment. Hoffman (2011) estimated that Green Creek receives 60-90\% of annual runoff from microtopographic basins, which comprise only about $35 \%$ of the catchment area. To account for the darker ice generally found in these basins, the model lowers albedo in the basin wall and floor sub-domains by 0.17 and 0.065 , respectively. Hoffman (2011) point out that the effect of mapped basin area on meltwater production by the model might cause over-prediction of melt in Green Creek, a finding that is supported by streamflow results at Green Creek in this study (CE of $1.75 \times 10^{6} \mathrm{~m}^{3}$ more modeled than measured runoff on days with observed melt). For that reason, the reduction of albedo by $7 \%$ was only applied to the smooth ice sub-domain.

\section{B2. Adjustment to Commonwealth Stream Drainage Area}

The drainage divide between the contributing area to Commonwealth Stream and the adjacent drainage area was updated based on a DEM and aerial imagery, resulting in a reallocation of $437,500 \mathrm{~m}^{2}$ (seven grid cells) to Commonwealth Stream. Re-inspection of the catchment boundary was motivated by the difference in model results between Lost Seal and Commonwealth streams. Lost Seal had better results, compared to Commonwealth, despite conditions at these sites likely being similar, suggesting the issue was instead due to the mapped size of the contributing areas. 
Table B.1 Results from model runs M1 and M2. The Nash-Sutcliffe Efficiency (E), coefficient of determination $\left(r^{2}\right)$, normalized root-mean-squared error (nRMSE) and cumulative error (CE in $10^{6} \mathrm{~m}^{3}$ ) are shown for each gauged stream. Error was calculated as the difference between observed and simulated discharge (obs. - sim.) on days with observed discharge. The numbers in the left-most column correspond to the map in Figure 2.1. The final row shows results from all streams in aggregate.

\begin{tabular}{rccccccccc}
\hline & & \multicolumn{4}{c}{ Model w/ station albedo (M1) } & \multicolumn{3}{c}{ Model w/ MODIS albedo (M2) } \\
\cline { 3 - 9 } & Stream & $\mathbf{E}$ & $\mathbf{r}^{2}$ & nRMSE & $\mathbf{C E}$ & $\mathbf{E}$ & $\mathbf{r}^{\mathbf{2}}$ & nRMSE & CE \\
\hline 1 & Santa Fe & -0.15 & 0.33 & 1.07 & 2.82 & -0.15 & 0.33 & 1.07 & 2.82 \\
2 & Priscu & 0.02 & 0.78 & 0.99 & 1.53 & 0.49 & 0.75 & 0.71 & 1.04 \\
3 & Lawson & -0.16 & 0.88 & 1.08 & 2.01 & 0.14 & 0.88 & 0.93 & 1.75 \\
4 & House & 0.19 & 0.82 & 0.90 & 0.30 & 0.42 & 0.77 & 0.76 & 0.25 \\
5 & Andersen & -0.14 & 0.83 & 1.07 & 1.62 & 0.28 & 0.81 & 0.85 & 1.31 \\
6 & Green & 0.69 & 0.94 & 0.56 & 1.13 & 0.96 & 0.97 & 0.19 & -0.05 \\
7 & Canada & -0.24 & 0.88 & 1.12 & 3.32 & 0.19 & 0.89 & 0.90 & 2.76 \\
8 & Delta & -0.39 & 0.74 & 1.18 & 1.49 & 0.77 & 0.86 & 0.48 & 0.60 \\
9 & Crescent & -0.51 & 0.73 & 1.23 & 0.76 & 0.11 & 0.59 & 0.94 & 0.60 \\
10 & Huey & -0.32 & 0.46 & 1.15 & 0.40 & -0.30 & 0.63 & 1.14 & 0.40 \\
11 & Aiken & -0.48 & 0.76 & 1.22 & 3.12 & -0.41 & 0.71 & 1.19 & 3.05 \\
12 & Von Guerard & -0.60 & 0.74 & 1.27 & 1.05 & -0.56 & 0.62 & 1.25 & 1.04 \\
13 & Harnish & -0.46 & 0.64 & 1.21 & 0.47 & -0.40 & 0.62 & 1.18 & 0.46 \\
14 & Lost Seal & -0.31 & 0.66 & 1.14 & 3.61 & 0.14 & 0.74 & 0.93 & 2.92 \\
15 & Commonwealth & -0.85 & 0.66 & 1.36 & 5.17 & -0.41 & 0.76 & 1.19 & 4.61 \\
\hline & All & $\mathbf{0 . 1 8}$ & $\mathbf{0 . 5 8}$ & $\mathbf{0 . 9 1}$ & $\mathbf{2 8 . 8 0}$ & $\mathbf{0 . 4 7}$ & $\mathbf{0 . 7 1}$ & $\mathbf{0 . 7 3}$ & $\mathbf{2 3 . 5 7}$ \\
\hline
\end{tabular}

Table B.2 Results from model runs M3 and M4. See caption Figure B.1 above for details.

\begin{tabular}{rccccccccc}
\hline & & \multicolumn{3}{c}{ Model albedo -7\% (M3) } & \multicolumn{3}{c}{ Model adjusted (M4) } \\
\cline { 3 - 9 } & Stream & $\mathbf{E}$ & $\mathbf{r}^{\mathbf{2}}$ & nRMSE & CE & E & $\mathbf{r}^{2}$ & nRMSE & CE \\
\hline 1 & Santa Fe & -0.07 & 0.35 & 1.03 & 2.61 & -0.07 & 0.35 & 1.03 & 2.62 \\
2 & Priscu & 0.67 & 0.77 & 0.58 & 0.73 & 0.72 & 0.77 & 0.53 & 0.66 \\
3 & Lawson & 0.47 & 0.90 & 0.72 & 1.37 & 0.54 & 0.89 & 0.68 & 1.31 \\
4 & House & 0.60 & 0.76 & 0.63 & 0.19 & 0.74 & 0.80 & 0.51 & 0.15 \\
5 & Andersen & 0.61 & 0.85 & 0.63 & 0.94 & 0.82 & 0.86 & 0.42 & 0.61 \\
6 & Green & 0.20 & 0.95 & 0.89 & -2.12 & 0.30 & 0.95 & 0.84 & -1.75 \\
7 & Canada & 0.55 & 0.93 & 0.67 & 2.06 & 0.85 & 0.93 & 0.39 & 1.41 \\
8 & Delta & 0.84 & 0.88 & 0.40 & 0.32 & 0.47 & 0.87 & 0.72 & -0.18 \\
9 & Crescent & 0.22 & 0.60 & 0.88 & 0.55 & 0.37 & 0.56 & 0.79 & 0.46 \\
10 & Huey & -0.27 & 0.74 & 1.13 & 0.40 & -0.03 & 0.83 & 1.01 & 0.37 \\
11 & Aiken & -0.39 & 0.75 & 1.18 & 3.03 & -0.35 & 0.81 & 1.16 & 3.01 \\
12 & Von Guerard & -0.54 & 0.64 & 1.24 & 1.04 & -0.54 & 0.64 & 1.24 & 1.04 \\
13 & Harnish & -0.37 & 0.65 & 1.17 & 0.45 & -0.36 & 0.63 & 1.17 & 0.45 \\
14 & Lost Seal & 0.37 & 0.76 & 0.79 & 2.42 & 0.73 & 0.76 & 0.52 & 1.38 \\
15 & Commonwealth & 0.17 & 0.77 & 0.91 & 3.61 & 0.52 & 0.78 & 0.69 & $\mathbf{2} .91$ \\
\hline & All & $\mathbf{0 . 6 3}$ & $\mathbf{0 . 7 7}$ & $\mathbf{0 . 6 0}$ & $\mathbf{1 7 . 6 2}$ & $\mathbf{0 . 7 9}$ & $\mathbf{0 . 8 4}$ & $\mathbf{0 . 4 5}$ & $\mathbf{1 2 . 7 1}$ \\
\hline
\end{tabular}




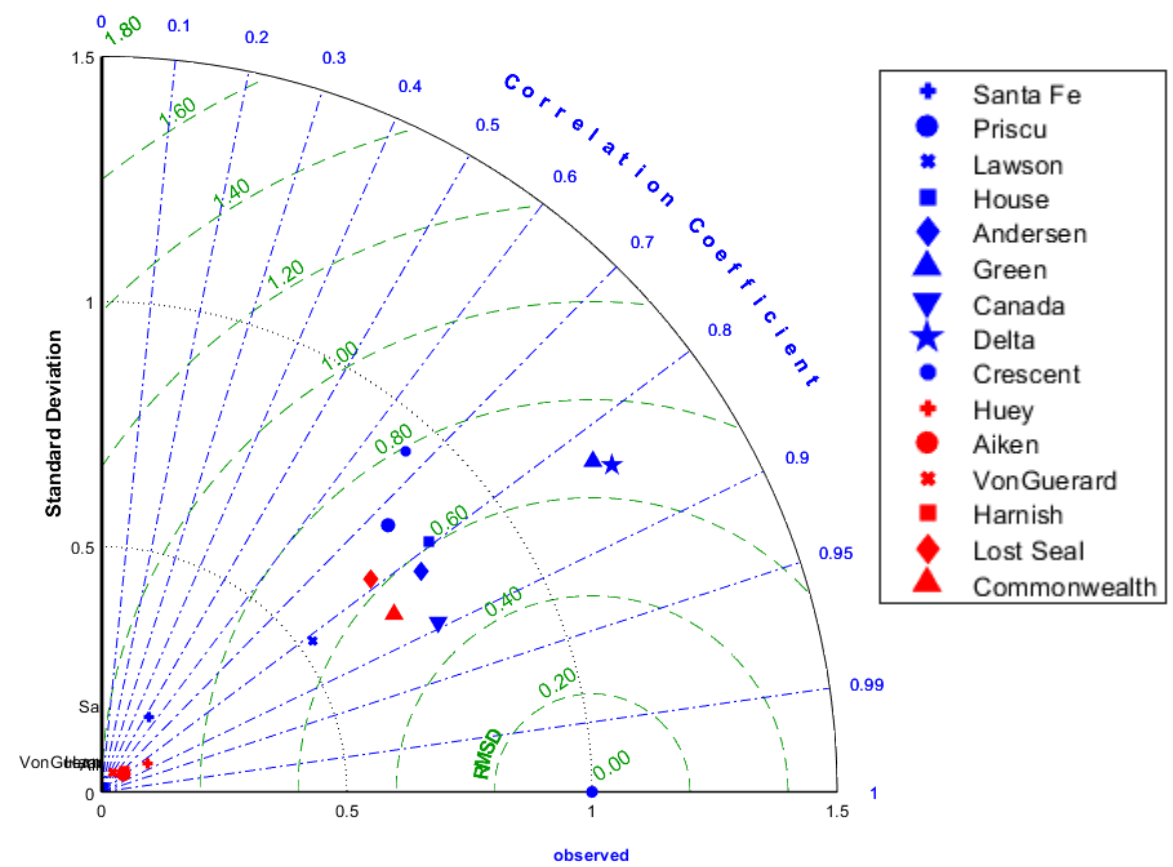

Figure B.1 Taylor diagram (Taylor, 2001) summarizing model (M4) performance, showing centered RMS difference, correlation coefficient and standard deviations compared with measurements. The location of the blue point indicates perfect agreement with observations.

Table B.3 Summary mean summer (DJF) albedo based on -7\% and -30\% reductions.

\begin{tabular}{rlllllllllll}
\hline & \multicolumn{2}{c}{ Commonwealth } & \multicolumn{2}{c}{ Howard } & \multicolumn{2}{c}{ Canada } & \multicolumn{2}{c}{ Taylor } & \multicolumn{2}{c}{ All } \\
& $\boldsymbol{\alpha}_{\text {MOD }}$ & $\boldsymbol{\alpha}_{\text {STA }}$ & $\boldsymbol{\alpha}_{\text {MOD }}$ & $\boldsymbol{\alpha}_{\text {STA }}$ & $\boldsymbol{\alpha}_{\text {MOD }}$ & $\boldsymbol{\alpha}_{\text {STA }}$ & $\boldsymbol{\alpha}_{\text {MOD }}$ & $\boldsymbol{\alpha}_{\text {STA }}$ & $\boldsymbol{\alpha}_{\text {MOD }}$ & $\boldsymbol{\alpha}_{\text {STA }}$ \\
\hline Mean & 0.57 & 0.71 & 0.51 & 0.76 & 0.53 & 0.65 & 0.55 & 0.61 & 0.54 & 0.68 \\
$\mathbf{- 7 \%}$ & 0.53 & 0.66 & 0.47 & 0.71 & 0.49 & 0.60 & 0.51 & 0.57 & 0.50 & 0.63 \\
Diff. & -0.04 & -0.05 & -0.04 & -0.05 & -0.04 & -0.05 & -0.04 & -0.04 & -0.04 & -0.05 \\
$-\mathbf{- 3 0 \%}$ & 0.40 & 0.50 & 0.35 & 0.53 & 0.37 & 0.45 & 0.39 & 0.43 & 0.38 & 0.48 \\
Diff. & 0.17 & 0.21 & 0.15 & 0.23 & 0.16 & 0.19 & 0.17 & 0.18 & 0.16 & 0.20 \\
\hline
\end{tabular}



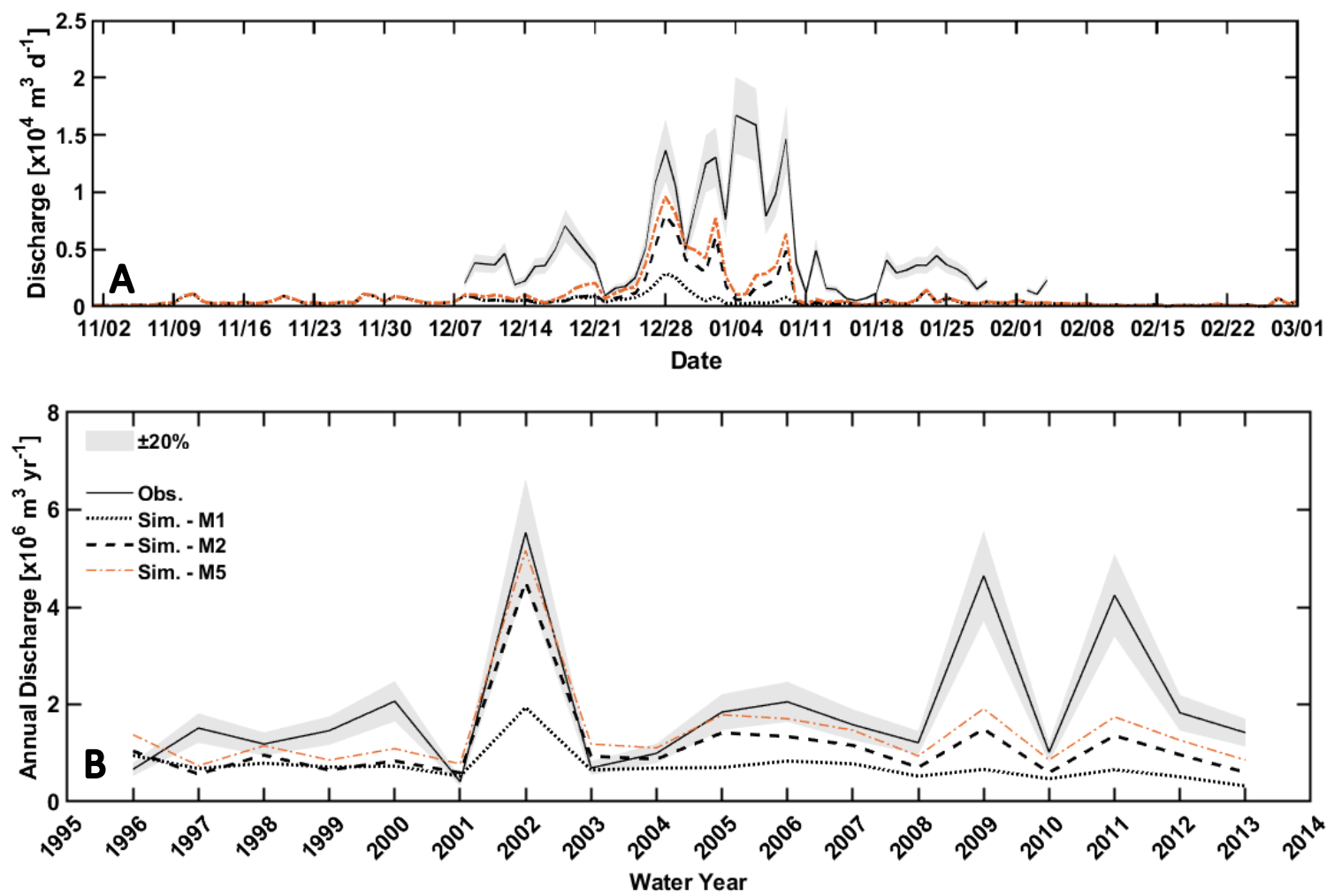

Figure B.2 Results showing the addition of $+20 \mathrm{~W} \mathrm{~m}^{2}$ to net radiation (M5) at Priscu Stream during the 2009 water year (A) and across Taylor Valley (B). 
Appendix C: Streamflow Data Quality

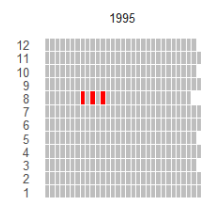

2001

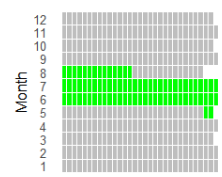

2007

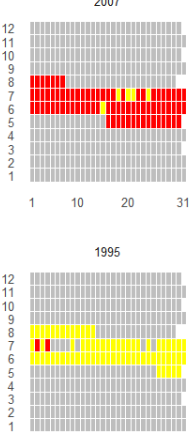

2001

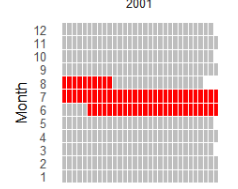

2007

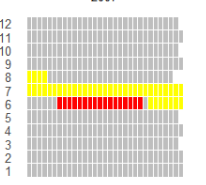

1995

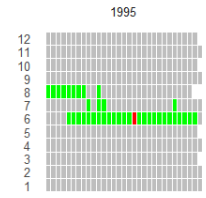

2001

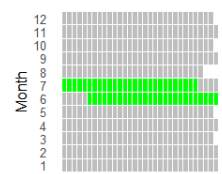

2007
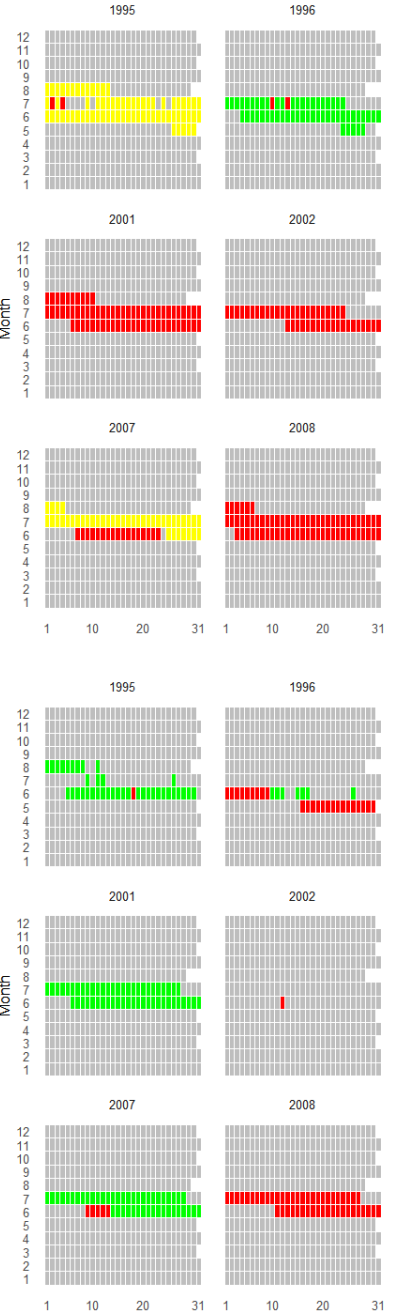

2002

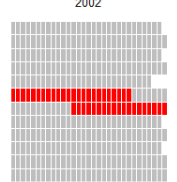

2008

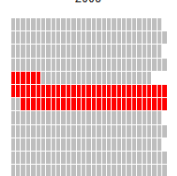

1996

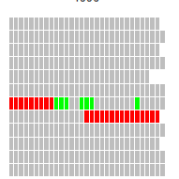

2002

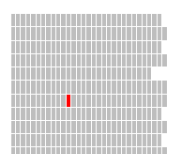

(IIIIII
1997

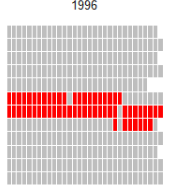

2002

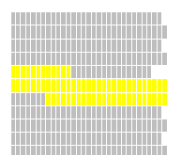

2008

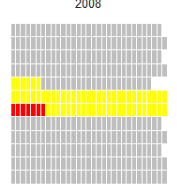

Day

Data Quality good fair $\square$ poor no data
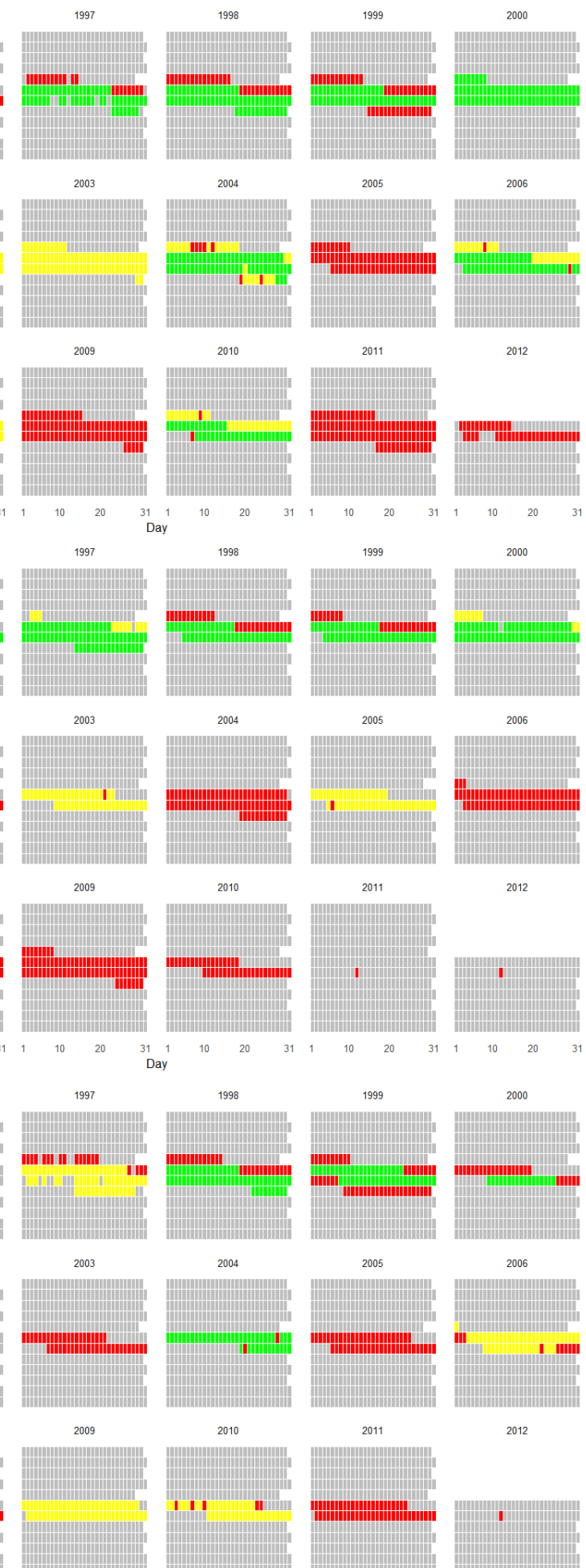

2005
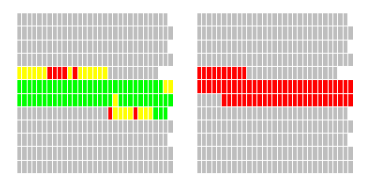

2006

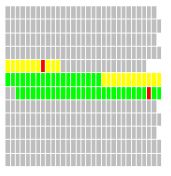

2011
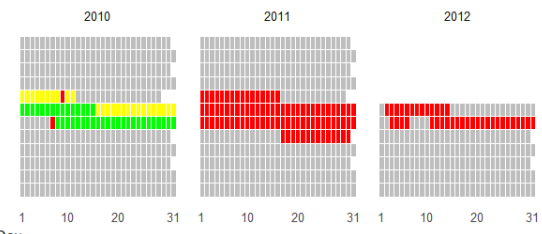

1999
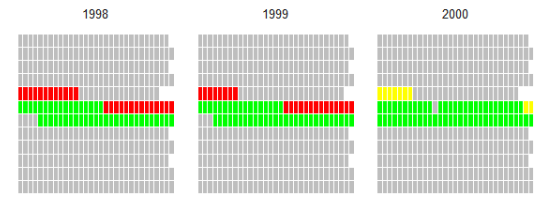

Priscu

2005

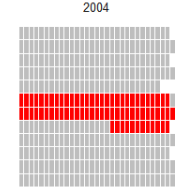

2010
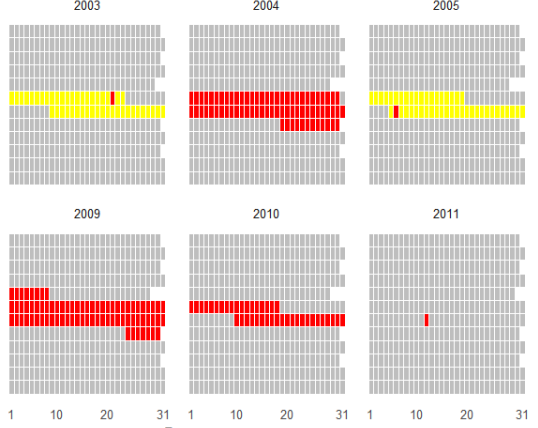

2011
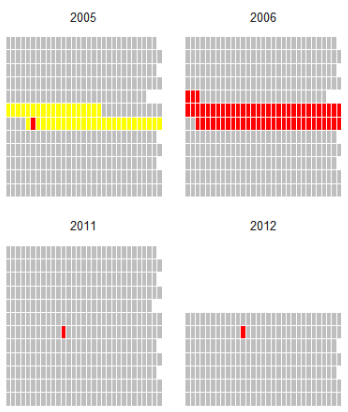

2012

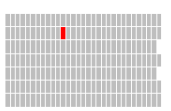

1999
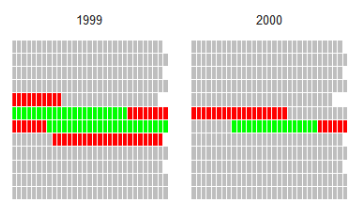

2005

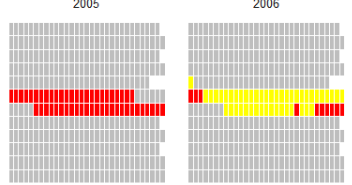

2012

2011

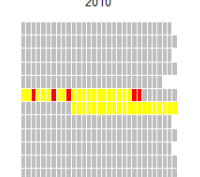

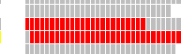
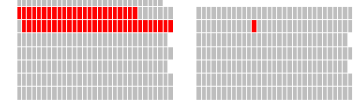

House

Lawson

\section{Priscu}



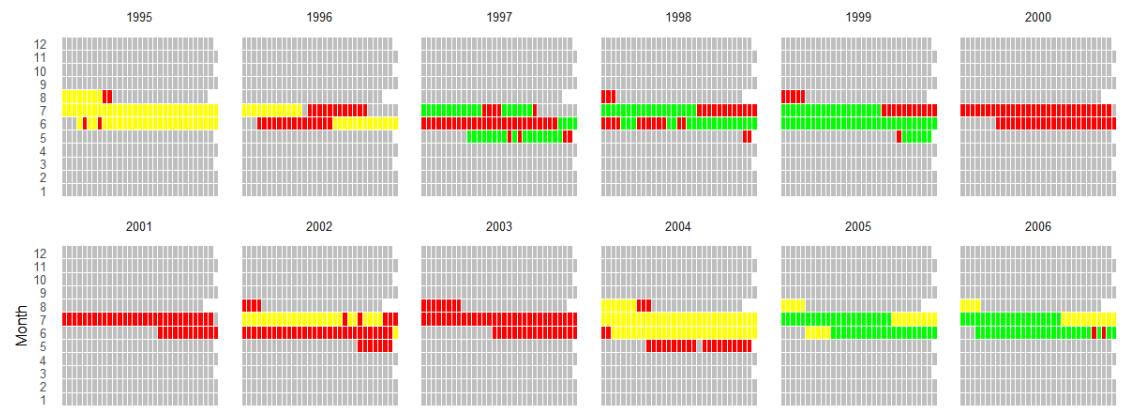

2007
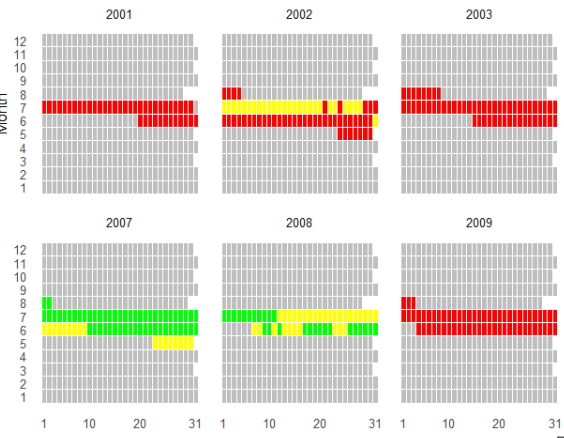

2009

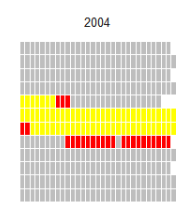

2010
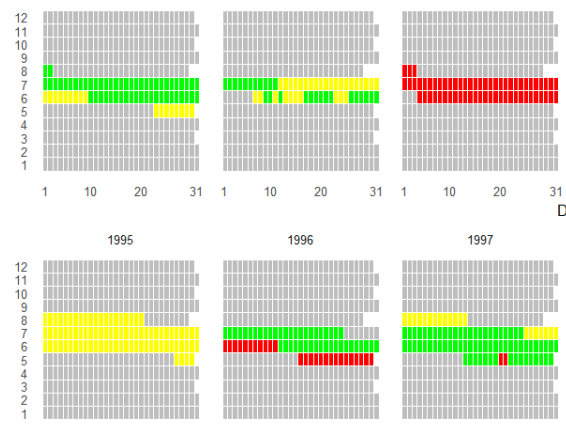

2001

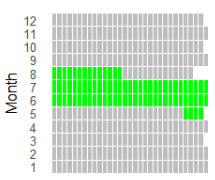

2007

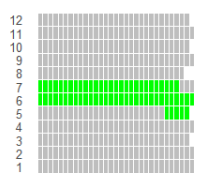

1996

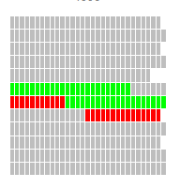

2002

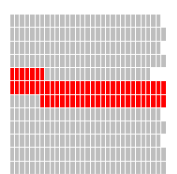

2008

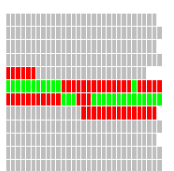

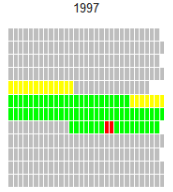

2003

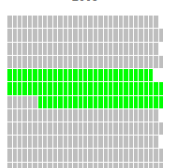

2009

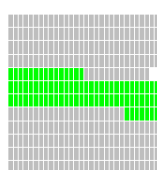

2005

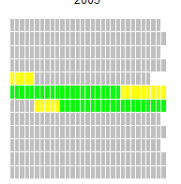

2011

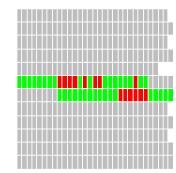

1998

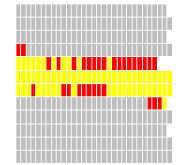

2004

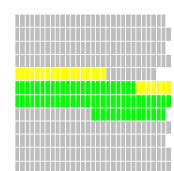

2010
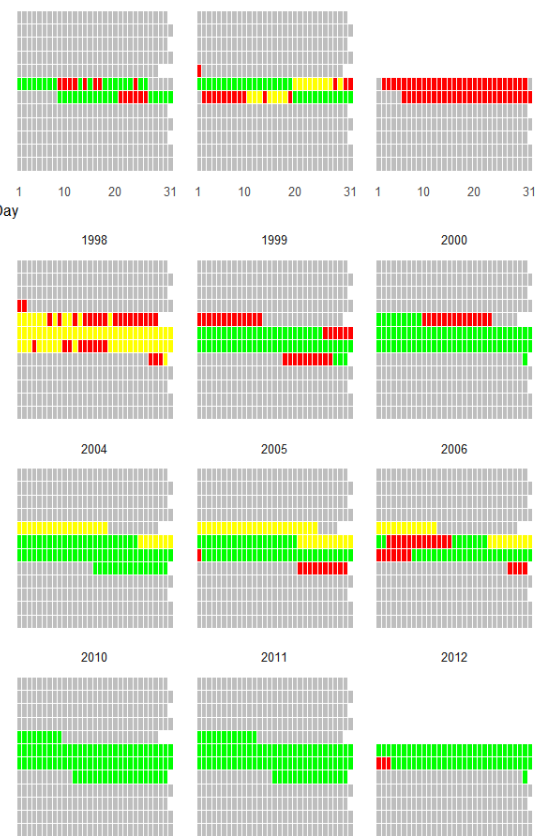

1999

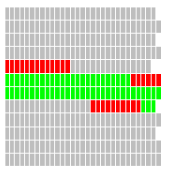

2005

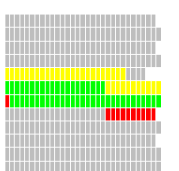

2011

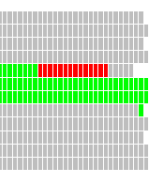

2006

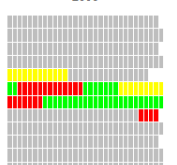

2012
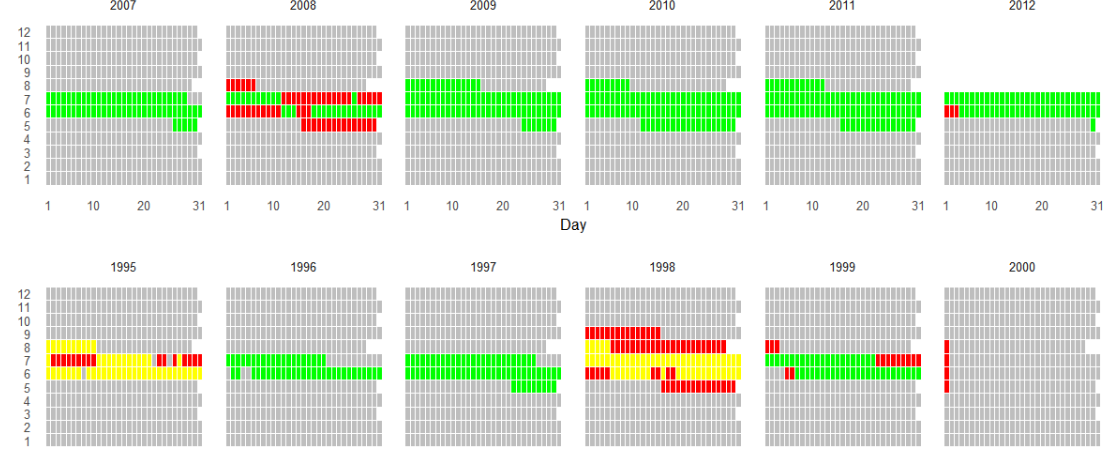

2001

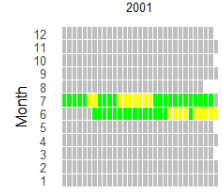

2007

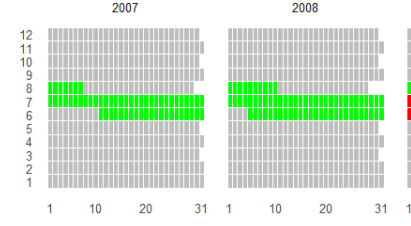

1997

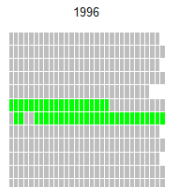

2002

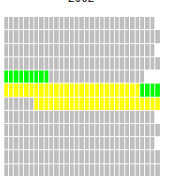

2008

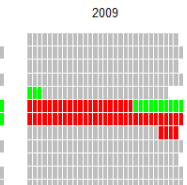

1998

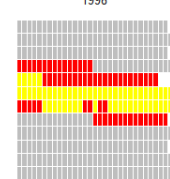

2004

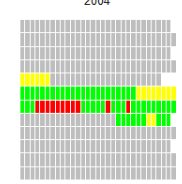

2010

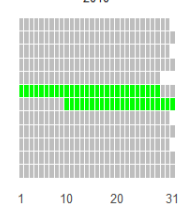

Day
1999

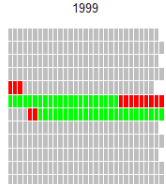

2005

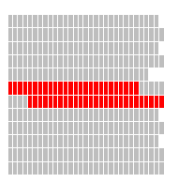

2011

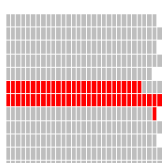

\section{Andersen}

\section{Canada}

.



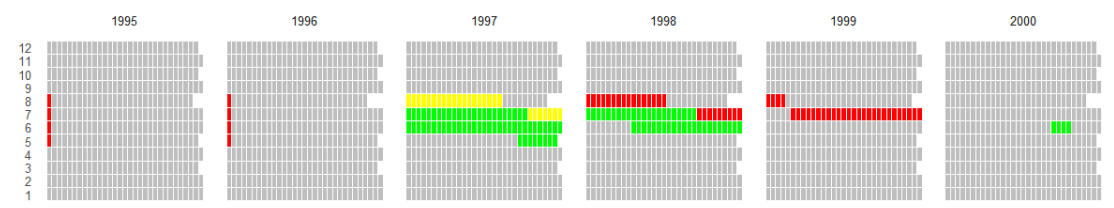

Delta

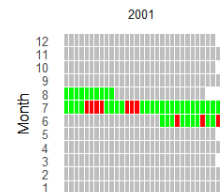

2007
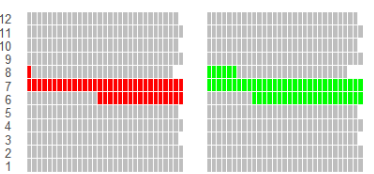

1995

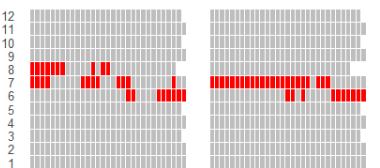

2001

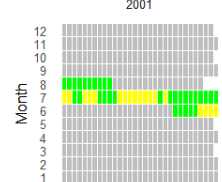

2007

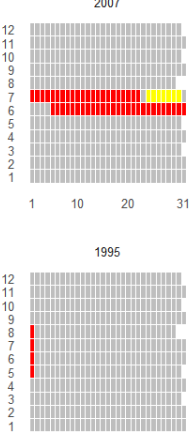

2001

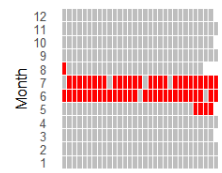

2007

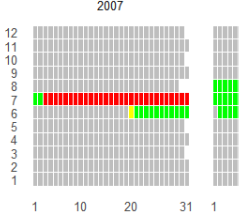

2002

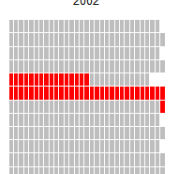

2008

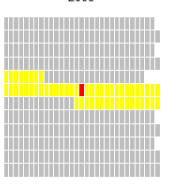

1996

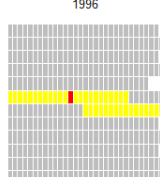

2002

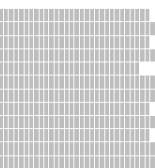

2008

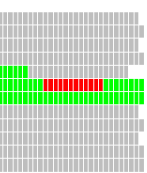

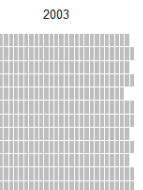

2009
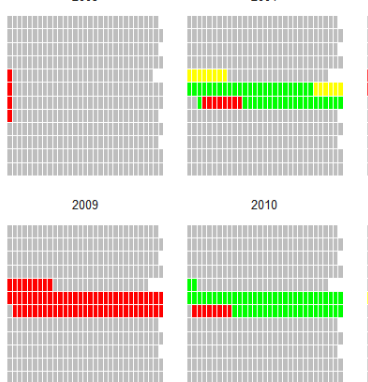

2010

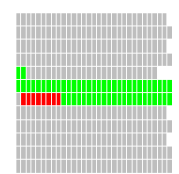

2005

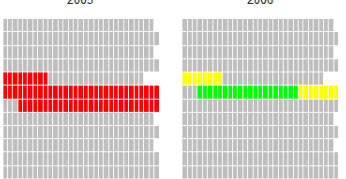

2011

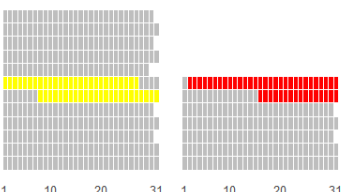

1999

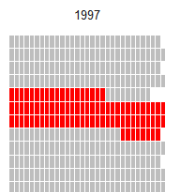

2003

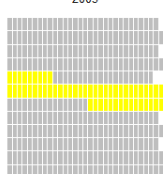

2009

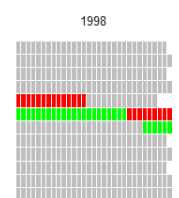

2004

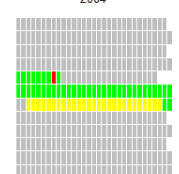

2010
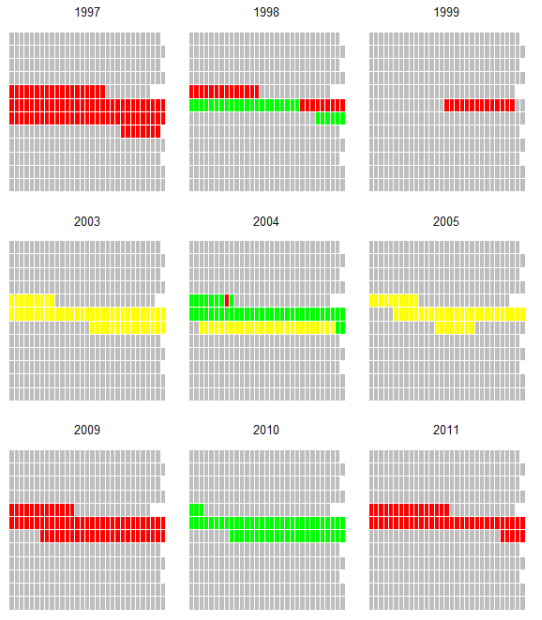

2000

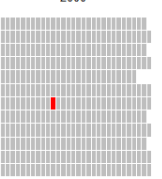

2005

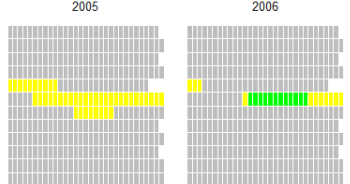

2011

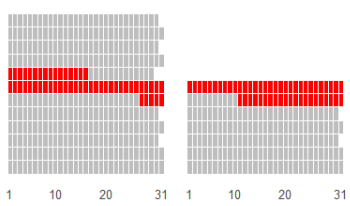

1999

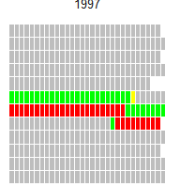

2003
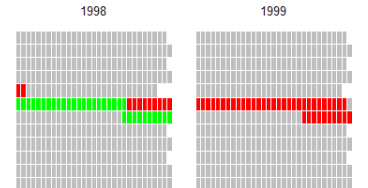

2005

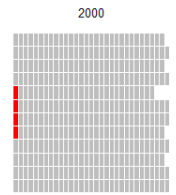

2006

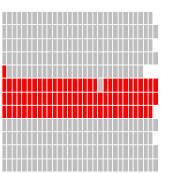

2010

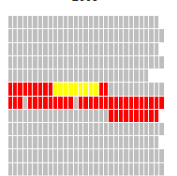

2011

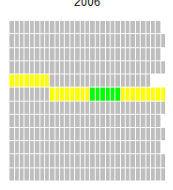

2012

2009
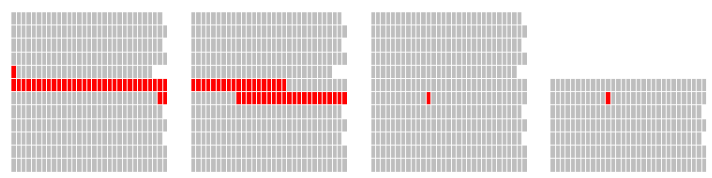

Data Quality good fair poor no data

\section{Crescent}

\section{Huey}




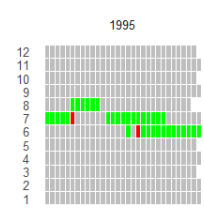

2001

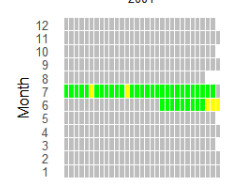

2007
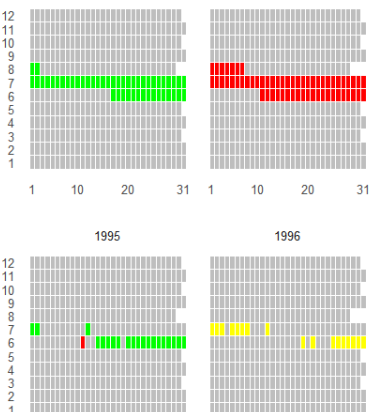

2002

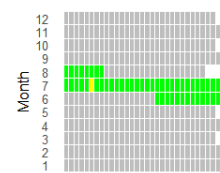

2007
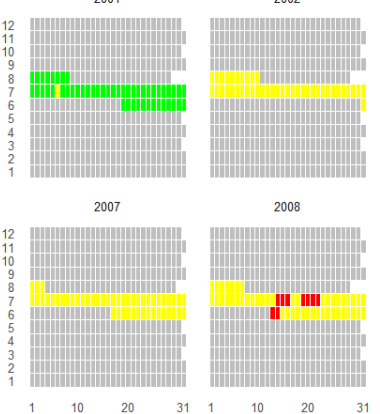

2008
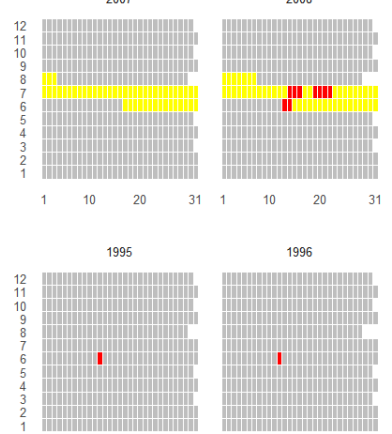

2001

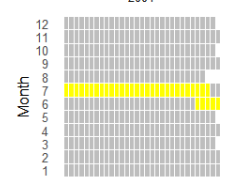

2007

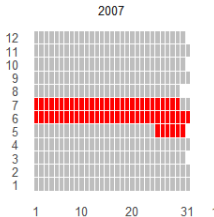

1996

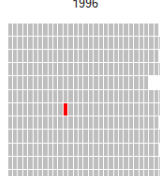

2002

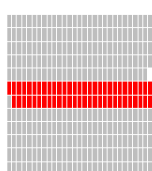

2008

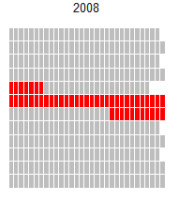

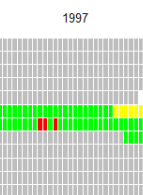

2003

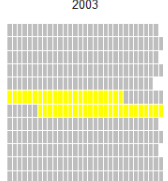

2009

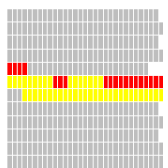

1997

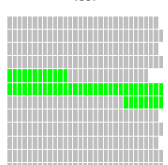

2003

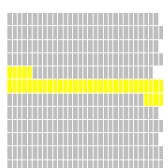

2009

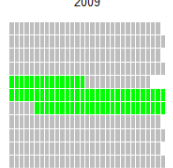

$20 \quad 31$
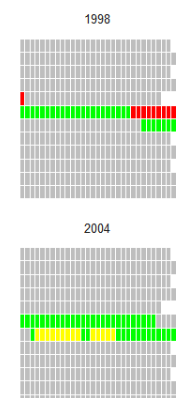

2010
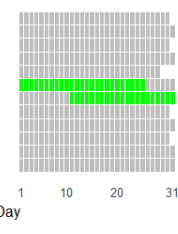

1998

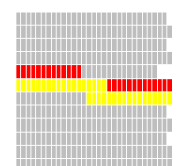

2004

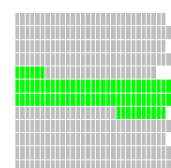

2010

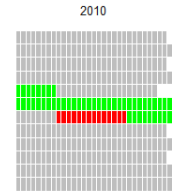
Day

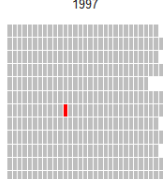

2003

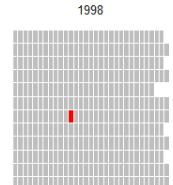

2004

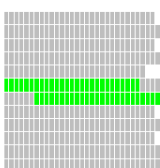

2010

2009

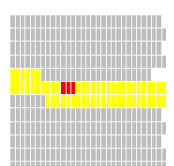

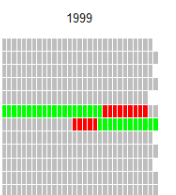

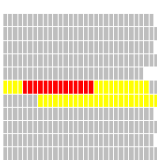

2011
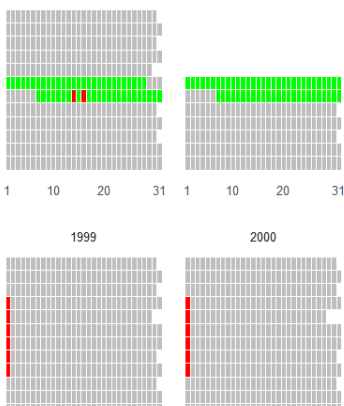

2005

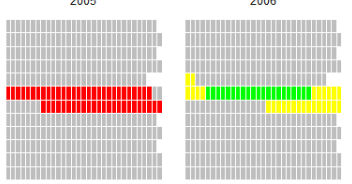

201
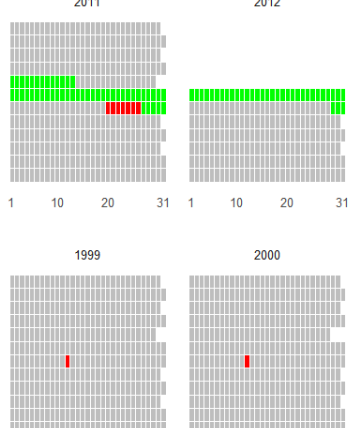

2005

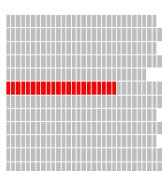

2011

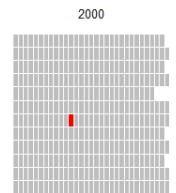

2006

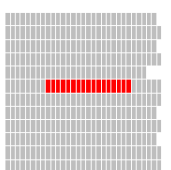

2012

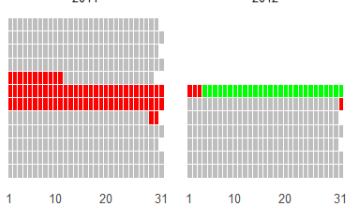

Data Quality \good fair $\square$ poor no data
Aiken

VonGuerard

Harnish 


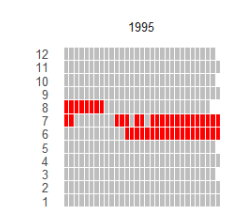

2001

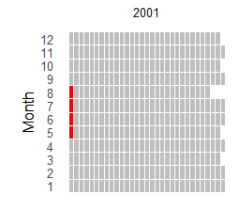

2007

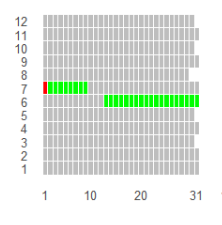

1995

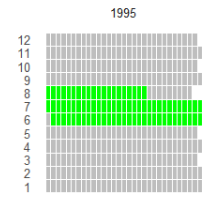

2001

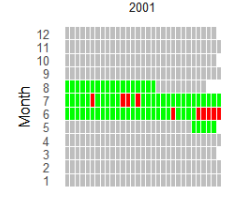

2007

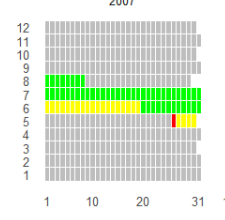

1996

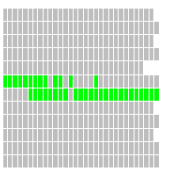

2002

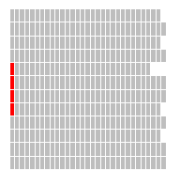

2008

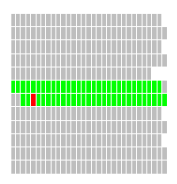

1996

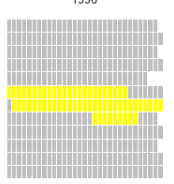

2002

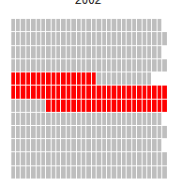

2008

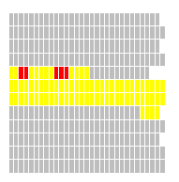

1997

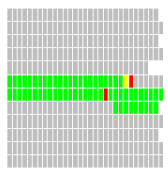

2003

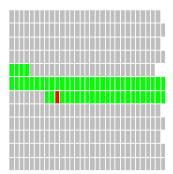

2009

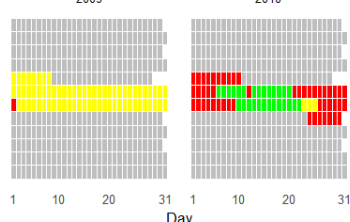

1997

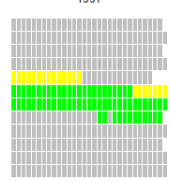

2003

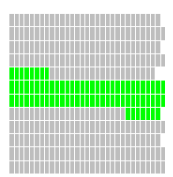

2009

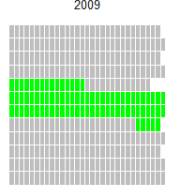

1998

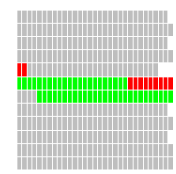

2004

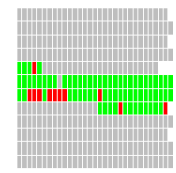

2010

1998

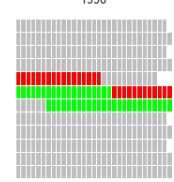

2004

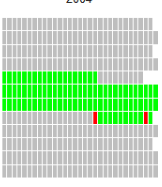

2010

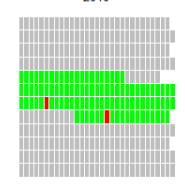

1999

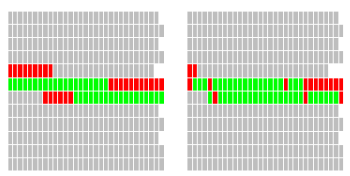

2005

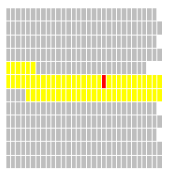

2011

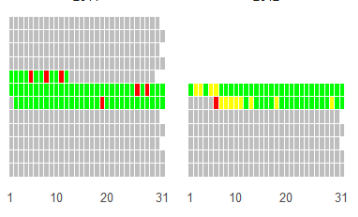

1999

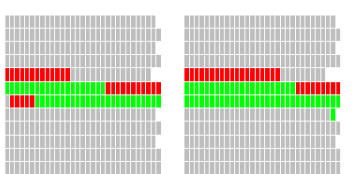

2005

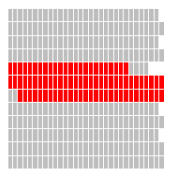

2011

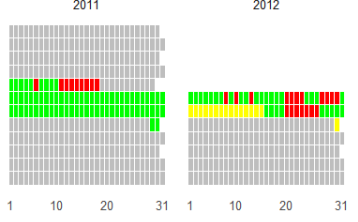

2006

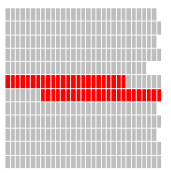

2012

2006

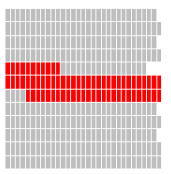

2012

\section{Lost Seal}

Data Quality good fair $\square$ poor no data

\section{Commonwealth}

Figure C.1 Streamflow data quality codes for gauged Taylor Valley streams. A rating of 'good' indicates most data are within 10\%, a rating of 'fair' indicates most data are accurate within 25\%, a rating of 'poor' indicates that significant amounts of data may be $>25 \%$ off. Periods of missing data are shown in grey. Stream gauges are not active outside of the summer season (November to March). Months are labelled 1 to 12 based on water year June to July. 


\section{Appendix D: Lake Model Supplemental Information}
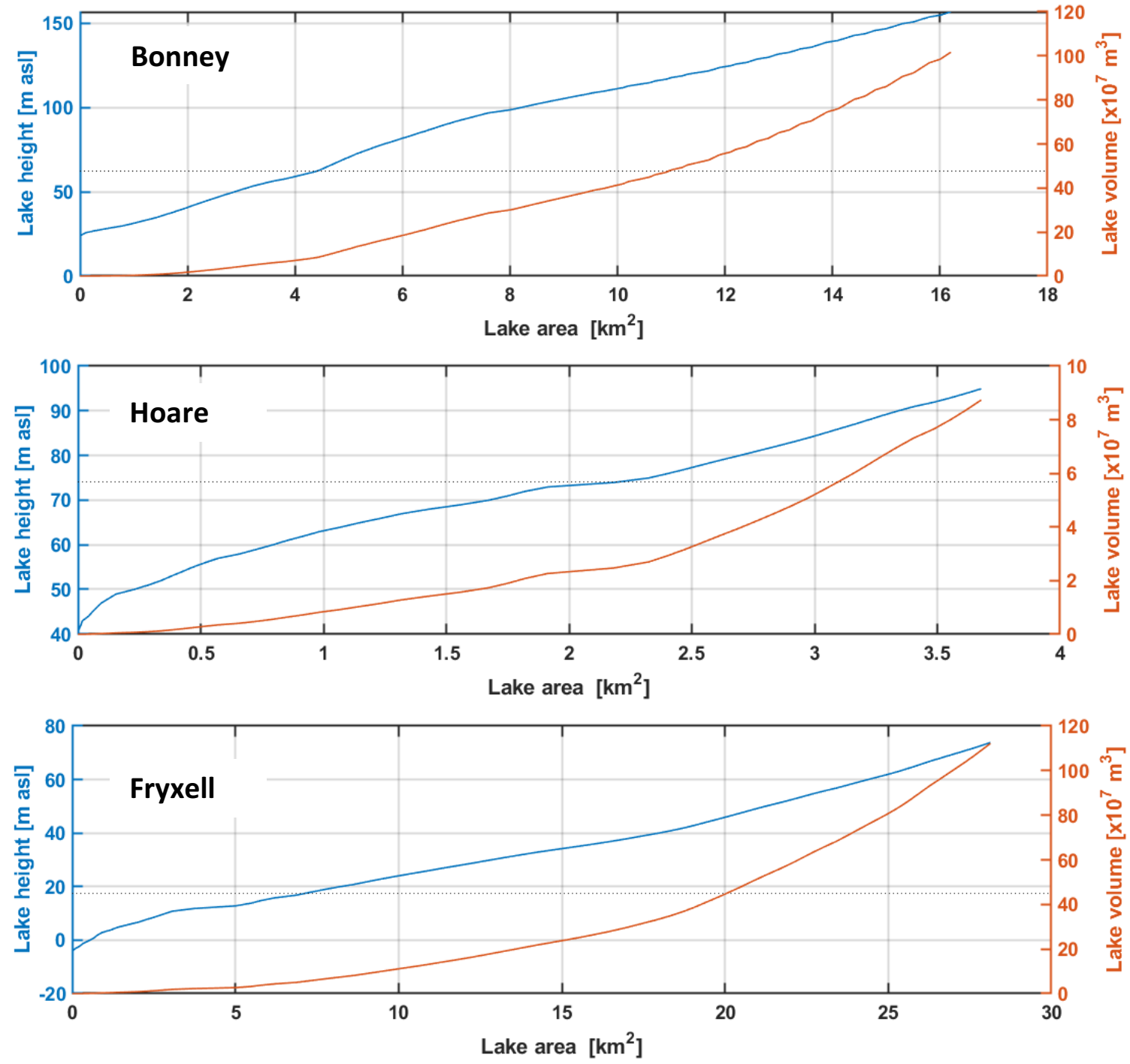

Figure D.1 Lake height-area and volume-area relationship plots. Thin black dotted line shows the approximate lake surface elevations (based on 1995 survey).

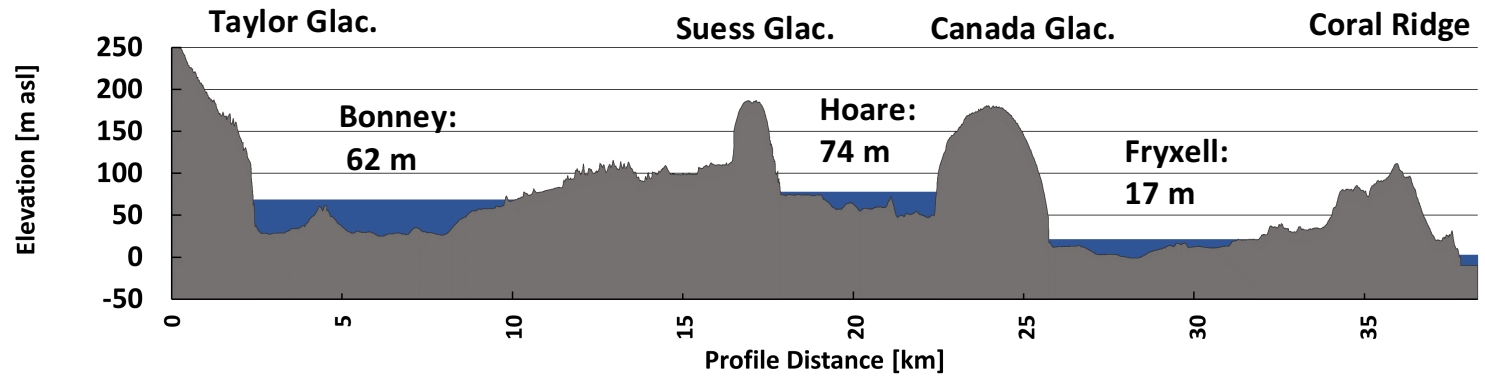

Figure D.2 Longitudinal profile of Taylor Valley. Approximate lake surface elevations (based on 1995 survey) are shown. 

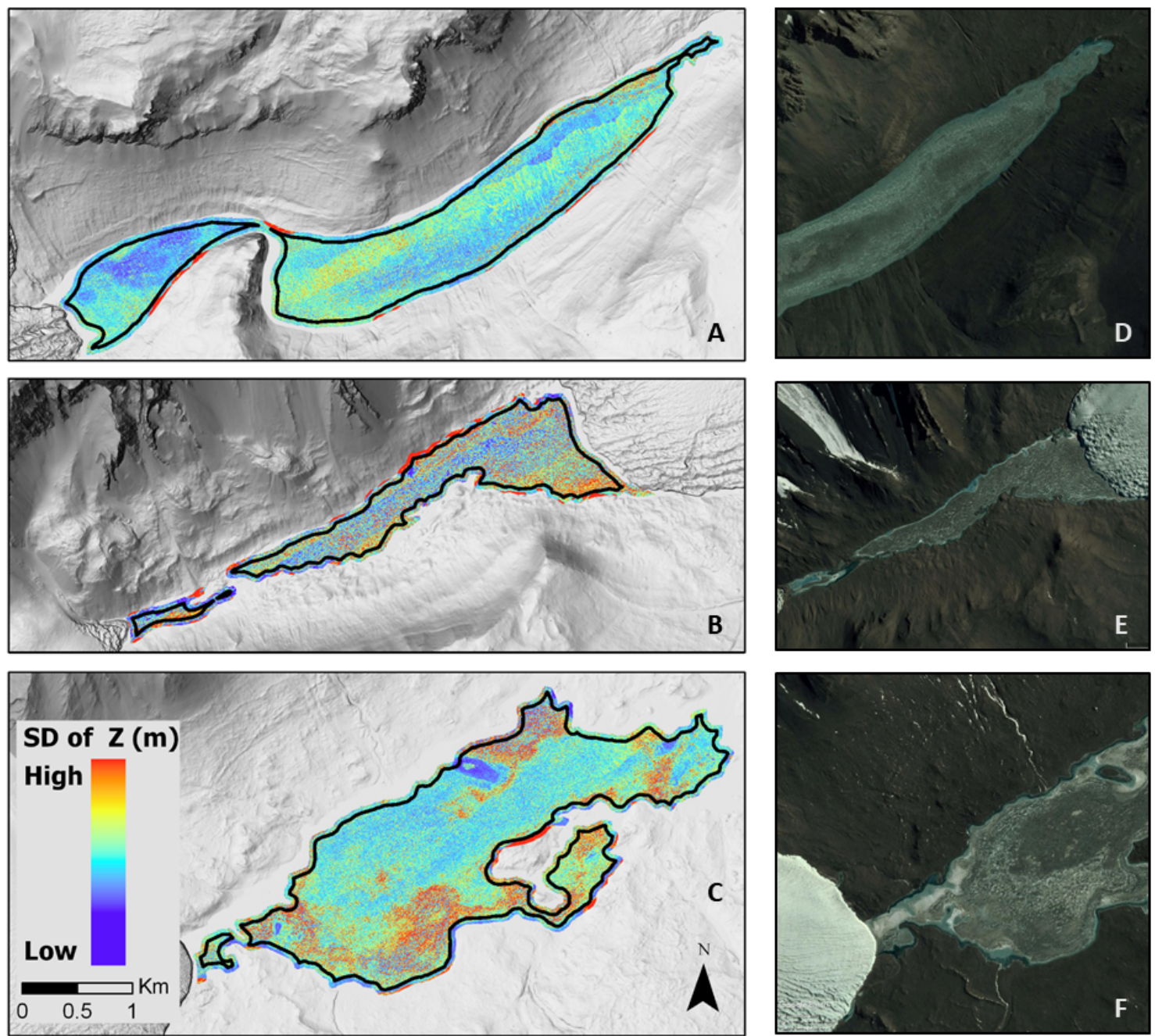

Figure D.3 Maps showing the standard deviation of LIDAR (collected austral summer 2014-15) elevations for each lake (A-C) and satellite imagery (Sentinel) of each lake surface from November 15, 2008. Black outline marks zone used to calculate a mean surface roughness value for each lake. 


\section{Appendix E: Climate Summary}
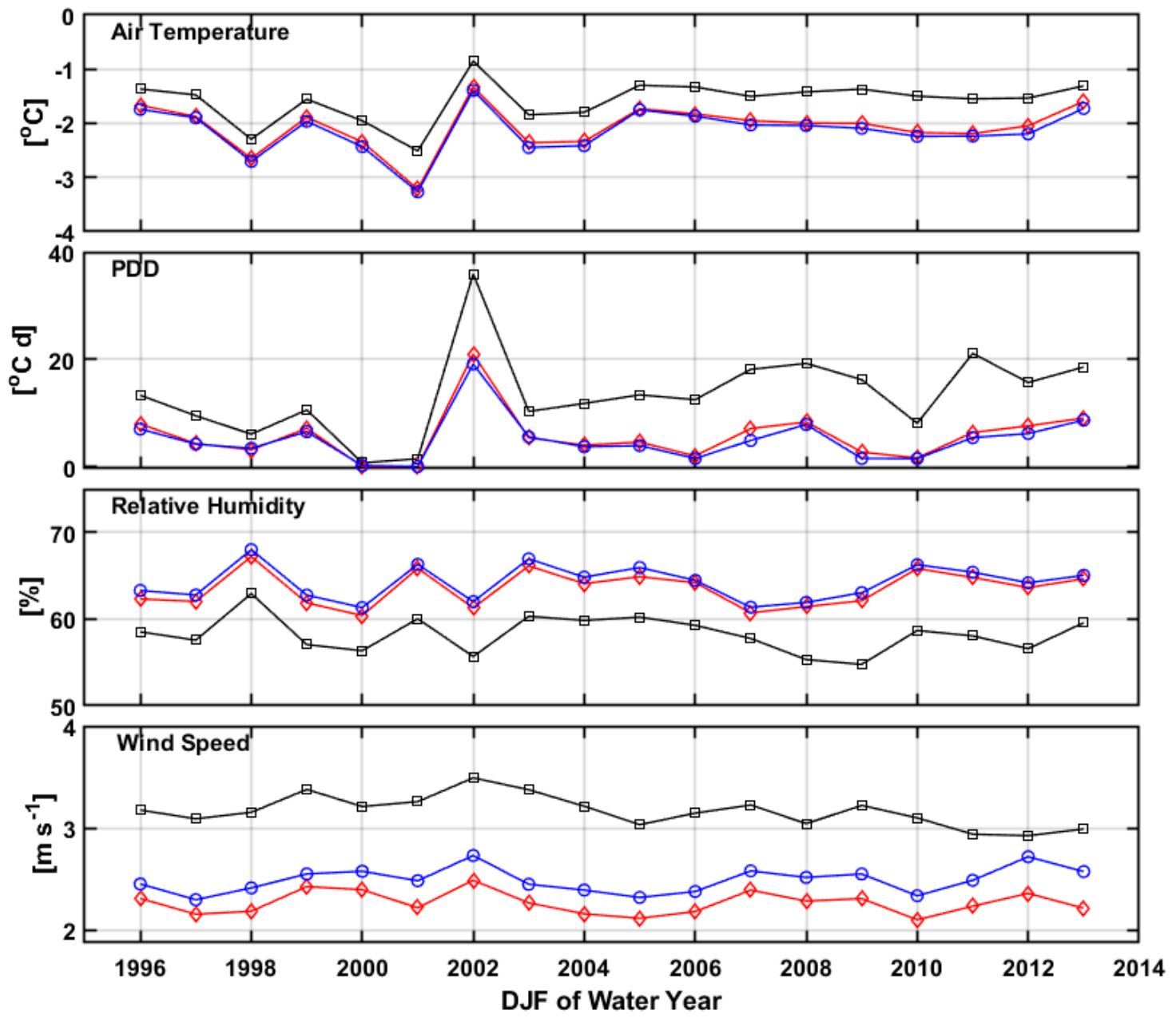

Figure E.1 Summary of mean summer (DJF) climate for Bonney (black), Hoare (red), Fryxell (blue) lake meteorological stations. Meteorological variables based on MICROMET. 

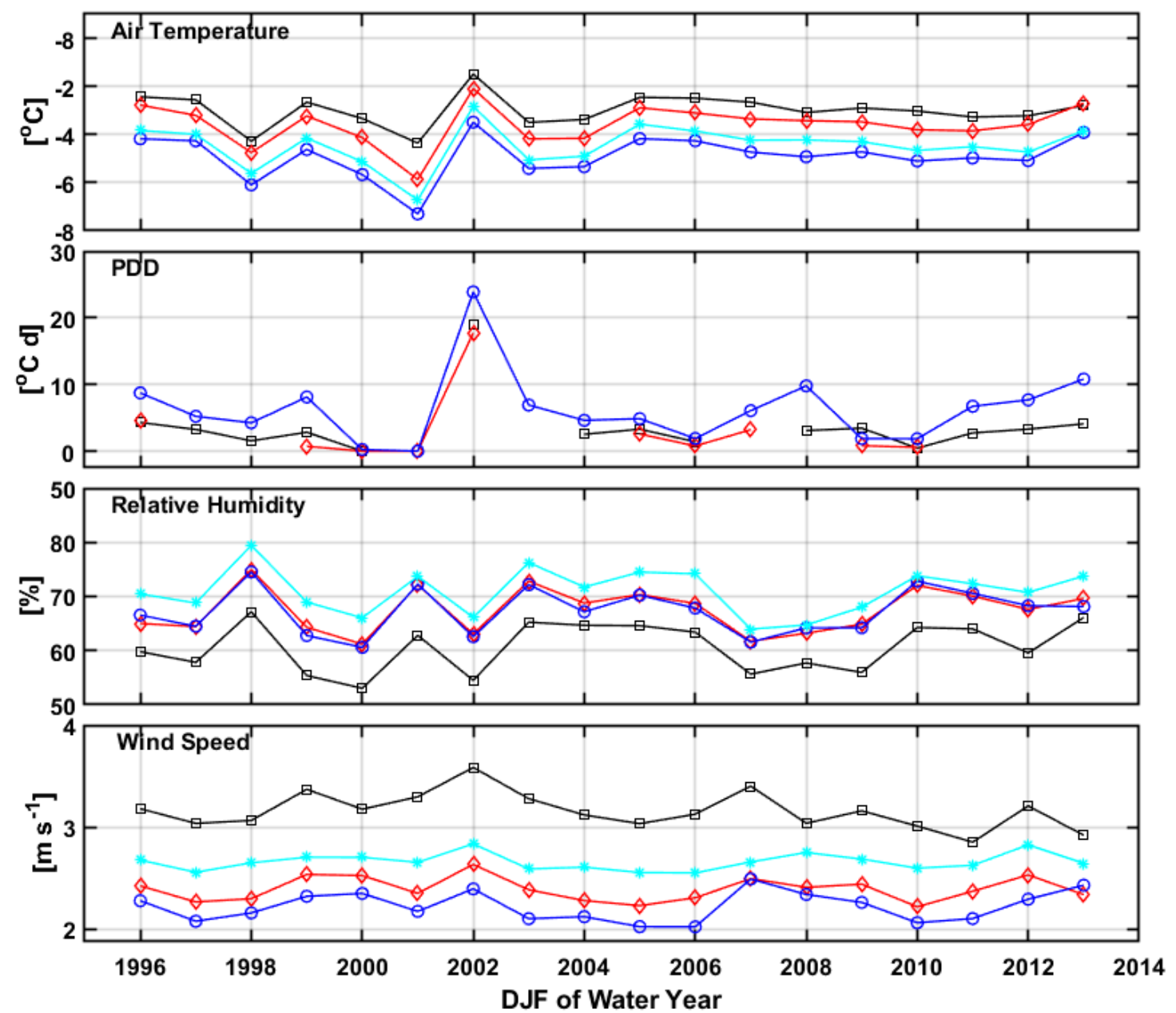

Figure E.2 Summary of mean summer (DJF) climate for Taylor (black), Canada (red), Commonwealth (blue), and Howard (cyan) glacier meteorological stations. Meteorological variables based on MICROMET. 

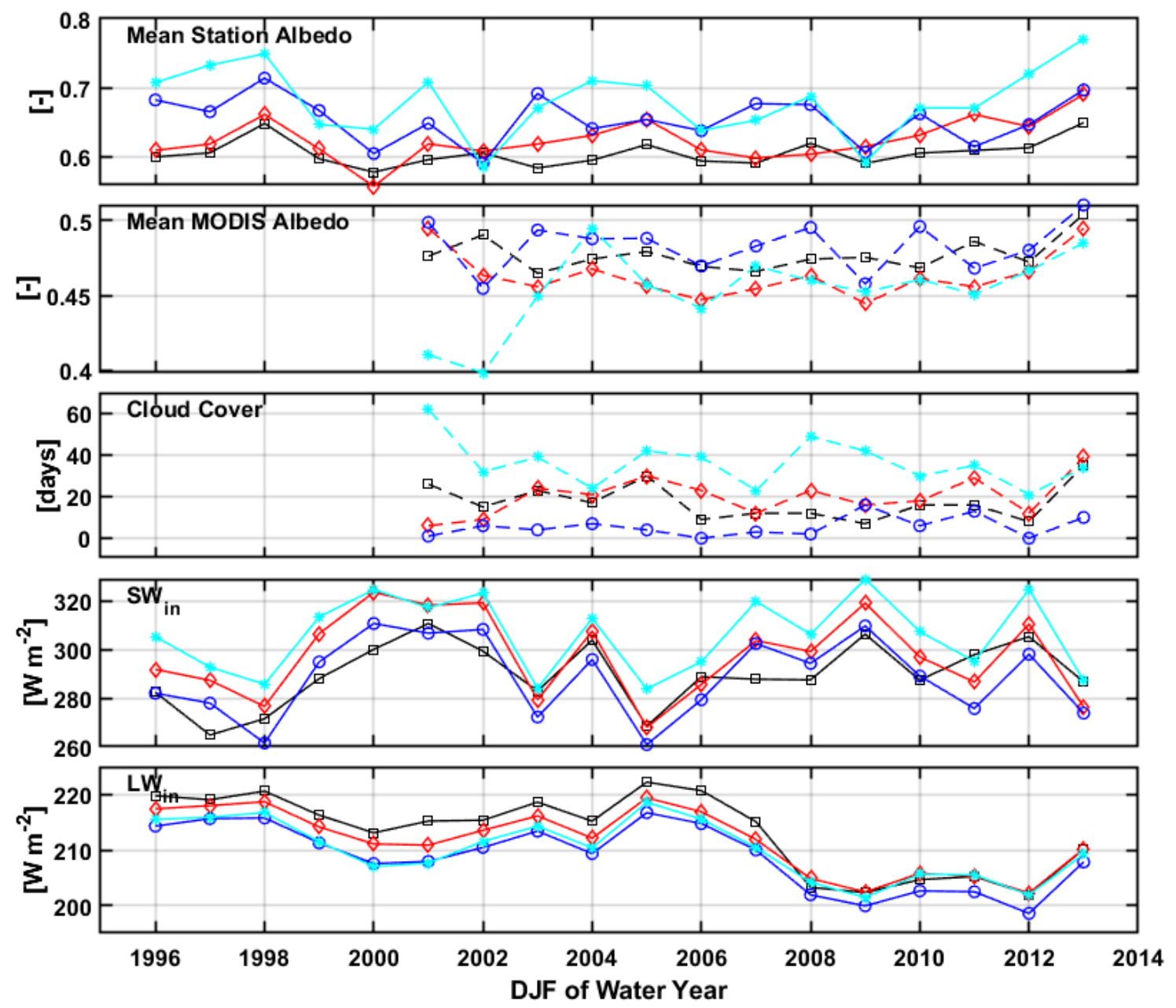

Figure E.3 Summary of mean summer (DJF) station albedo, MODIS albedo, cloud cover (based on MODIS), MICROMET incoming short-and long-wave radiation for Taylor (black), Canada (red), Commonwealth (blue), and Howard (cyan) glacier meteorological stations. 